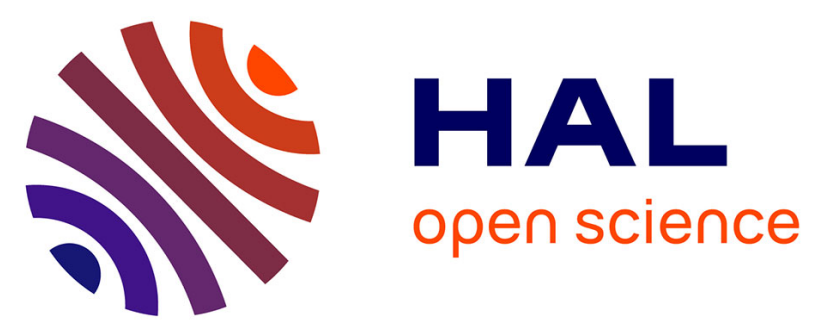

\title{
Conception and use of an individual-based model of residential choice in a planning decision process. Feedback from an experimental trial in the city of Besançon, France
}

Cécile Tannier, Joanne Hirtzel, Richard Stephenson, Armelle Couillet, Gilles Vuidel, Samy Youssoufi

\section{To cite this version:}

Cécile Tannier, Joanne Hirtzel, Richard Stephenson, Armelle Couillet, Gilles Vuidel, et al.. Conception and use of an individual-based model of residential choice in a planning decision process. Feedback from an experimental trial in the city of Besançon, France. Progress in Planning, 2016, 108, pp.1-38. 10.1016/j.progress.2015.04.001 . hal-01167928

\section{HAL Id: hal-01167928 \\ https://hal.science/hal-01167928}

Submitted on 14 Jun 2021

HAL is a multi-disciplinary open access archive for the deposit and dissemination of scientific research documents, whether they are published or not. The documents may come from teaching and research institutions in France or abroad, or from public or private research centers.
L'archive ouverte pluridisciplinaire HAL, est destinée au dépôt et à la diffusion de documents scientifiques de niveau recherche, publiés ou non, émanant des établissements d'enseignement et de recherche français ou étrangers, des laboratoires publics ou privés. 
TANNIER C., HIRTZEL J., STEPHENSON R., COUILLET A., VUIDEL G., YOUSSOUFI S. (2016), Conception and use of an individual-based model of residential choice in a planning decision process. Feedback from an experimental trial in the city of Besançon, France, Progress in Planning, vol. 108, pp. 1-38.

\title{
Conception and use of an individual-based model of residential choice in a planning decision process. Feedback from an experimental trial in the city of Besançon, France
}

\begin{abstract}
In this paper, we present an experiment involving the use of a complex spatial simulation platform to support a planning decision process in the city of Besançon (eastern France). In medium-sized towns across France, middle-income households with children are leaving to settle in periurban areas, and Besançon is no exception. Under those circumstances, the political objective of the Besançon City authority is to keep middle- and high-income households with children within the city. The simulation platform MobiSim was used in this context to explore the possible outcomes of spatial planning policies, set by both the Greater Besançon authority (Besançon and the surrounding periurban communities) and the city of Besançon, on residential migrations over a 20 year period.
\end{abstract}

The experiment began in October 2012. It involved two successive stages. The first being the collective definition and simulation of a baseline position simply extending existing trends from 2010 to 2030: the 'Business as usual' scenario. The second stage was a collective reflection on possible modifications to some of the variables and parameters of this scenario in order to simulate a pro-active policy of housing construction in the medium term.

The simulation platform chosen for the planning experiment is a Land-Use and Transport Interaction platform, which integrates several models representing demographic, social, economic, and spatial processes. Modelled entities are individuals and dwellings. Rules determine how individuals form households. Other rules locate dwellings in buildings.

Under the conditions represented in the model, the 'Pro-active housing construction' scenario in Besançon allows an overall reduction of migration flows from Besançon to the surrounding periurban areas. More single parent families choose to reside in Besançon during the whole simulation time. Couples with children, however, choose preferentially to reside in Besançon until 2022 only. At this date, the controlled housing developments become less numerous.

This experiment gave the researchers and the planning actors involved in it the occasion to exchange their scientific knowledge and their empirical knowledge. The simulation of the 'Business as usual' scenario was, as it were, a means to thoroughly explore one possible future. The experiment then led the group to discuss possible planning actions designed to reduce migration flows of households with children out of Besançon into periurban areas.

The experiment also shows some limitations: it highlights that this kind of PSS makes the planning actors heavily dependent on the expertise of the researchers for every stage of the process.

\section{Keywords}

Planning scenarios; housing policy; residential mobility; computer simulation. 


\section{Introduction}

In a global context of urban sprawl and increasing housing costs, policies for residential mobility and residential development are an important aspect of urban and regional planning. There are two major planning concerns: firstly, to ensure that housing supply meets housing demand both quantitatively and qualitatively, and secondly to reduce the negative environmental impacts that may result from residential development, especially an increase of the length and the number of trips by car and the fragmentation of natural and agricultural areas. This paper explores one attempt to use a complex simulation platform to find ways to address these major concerns for the city of Besançon in France.

In medium-sized towns across France, middle-income households with children are leaving to settle in periurban areas. Classical explanations for this are the household preferences for detached housing in a green residential environment where housing costs (land prices and taxes) are lower, although transportation costs in these periurban areas are higher. Considering this, the political objective of the Besançon's city authority, located in eastern France, is to keep middle- and high-income households with children within the city. Setting this objective raises the question of the possible effects of applying existing policies set in the official planning documents for the urban region of Besançon (i.e. the strategic land use plan and the local housing plan) on residential mobility of middle- and high-income households with children in the city, notably centre-to-periphery migration flows, with a view to retaining this population within the city boundaries.

This question has been addressed in the frame of an experimental trial involving two researchers in geography and planning from the University of Franche-Comté (Besançon, France) and two planning practitioners working in Besançon city council's planning service: the Department of Planning, Projects and Forward Planning (la Direction 'Urbanisme, Projets et Planification'). To answer this question, this group of researchers and planners has conceived and piloted the use of a very detailed individual-based model of residential choice that represents the current known behaviours of households and that takes into account a range of recommendations set by scholars to ensure the usefulness of simulation models to support planning decision processes.

Many models have been developed since the 50s to explain and/or forecast residential choices and residential dynamics. Most of them are based on micro-economic assumptions. They often use the multinomial logit model (Weisbrod et al., 1980; Wegener, 1985; Prashker et al., 2008) or the nested logit model (Quigley, 1985; Ben Akiva and de Palma, 1986; Ettema et al., 2007; Kim et al., 2005; Vega and Reynolds-Feighan, 2009). As an alternative, multi-agent simulation models are also sometimes used (Benenson, 1998; Filatova et al., 2009; Ettema et al., 2011). All these models allow a better understanding of variables and processes involved in residential choices and residential migration. However, they contribute little to defining planning policies or to supporting planning decisions. The large number of variables involved in residential decisions and the existence of non-linear relationships between them explain the difficulty of forecasting future configurations of both residential locations (who will live where in the future) and residential satisfaction (who will be more or less satisfied and where). Because of this complexity, a simple linear extrapolation of trends offers no real help in making planning choices. Yet identifying possible bifurcation points, as suggested for instance by Wilson (2010), is difficult. Despite this difficulty, the group of researchers and planners in Besançon has chosen to build a model that represents the complexity of residential location dynamics and to pilot its use. The planning practioners were interested in dealing 
with this complexity because they are constantly confronted by it in their daily work. They hoped the researchers could help them to manage it. As for the researchers, it was important to build a model that represents complex processes involved in residential location dynamics.

According to Batty et al. (2013), the role of models in the planning and design of city systems has radically changed during the last decades. "Fifty years ago there was a sense in which both model builders and stakeholders regarded models as providing predictions which could be used with some confidence to help figure out the impact of their plans in rather definite ways with a high degree of certainty. This confidence is now widely regarded as having been misplaced and the role of most models is now to inform, steer, and focus dialogue (Epstein, 2008), notwithstanding the continuing practical plea for some measures of certainty about the future. Interaction between model builders and stakeholders has thus become the name of the game (...)" Following the same idea, Failing et al. (2007) argued that the integration of science and local know-how during decision making becomes an unavoidable task, in Europe as well as in North America. Indeed, many publications dedidated to the analysis of the use of planning support systems (PSS) insist on the necessity for planners and system developers to share knowledge and demands, and to adopt a cooperative development process (Vonk et al., 2007; Te Brömmelstroet and Schrijnen, 2010; Van Delden, 2009). This requirement holds especially when both the targeted planning task and the PSS used for achieving it are complex. In the process of the pilot test presented in this paper, the group of researchers and planners has tried to follow this recommendation.

Another point raised by Silva and Te Brömmelstroet (2014) is that the effective use of PSS is currently suffering from a 'rigour-relevance dilemma', with developers mainly concerned with rigour while users are mainly concerned with relevance. Ever more complex PSS are developed by researchers as a pursuit of scientific rigour and this seems to increase the gap between supply (scientists) and demand (planning practioners). In the frame of the pilot described here, one objective was to test the possibility to develop a complex simulation model that is not a black box and that can be used as a discussion medium between planners and researchers.

The paper is organized as follows. We first briefly describe the context of the pilot and how its guidelines have been defined jointly by the researchers and the planning practitioners involved in it. Then we describe the model, whose variables and rules have been set by both the researchers and the planning practitioners. After this, we describe the way this model has been used to determine the possible outcomes of the planning policies contained in the official planning documents (local housing plan and strategic land use plan) on the migration flows of households from the centre city to its surrounding periurban areas. Finally, we expose how the researchers and the planning practitioners have imagined an alternative planning policy that is the application of a pro-active housing construction by the city of Besançon, and how the model has allowed them to explore the possible outcomes of this policy on the residential locations of households. 


\section{The trial: context, objectives and guiding principles}

\subsection{The context for the experimental trial}

The study area is the urban region of Besançon known as le Grand Besançon, in eastern France: Le Grand Besançon is an intercommunal authority responsible for a range of policy areas including planning and transport. We will refer to this area as Greater Besançon. This urban region includes a core city (117,000 inhabitants) managed by one local authority (la Ville de Besançon, which we will refer to as Besançon City Council) and periurban residential areas with low population densities spread across 58 smaller local authorities. The experimental trial with the simulation model involves two researchers in geography and planning, and two urban planners from the core city's planning service (la Direction 'Urbanisme, Projets et Planification' of Besançon). Note: although not all the authors of this paper participated in the trial they all contributed to the development of the model and/or the presentation and interpretation of its results (see Appendix 1).

Besançon's centre city is lossing population. Nevertheless, the number of inhabitants and the number of households is increasing in the whole urban region. Because employment is mostly concentrated in the centre city, car-based commuting is increasing, both in terms of frequency and distances travelled. As a consequence, urban road congestion is also rising. To counter this phenomenon, a tramway line has been constructed. This new transportation infrastructure, combined with the creation of park and ride close to the edge of the urban area, aims to reduce car use in the city. Its construction has been financed by all the local authorities of the urban region.

Not only does Besançon's centre city contain most of the urban region's employment it is also home to most of its low-income households. More than $90 \%$ of the urban region's social housing is located within the city and a large proportion of the city's residents have incomes below the threshold for income tax (a key indicator of low income).

This situation has informed the planning policies contained in the official planning document for the urban region, the Schéma de cohérence territorial (Territorial coherence framework) or SCoT (2011) which states that $60 \%$ of the dwellings constructed have to be built within the centre city (40\% in the periurban municipalities). It is worth noting at this point that the city of Besançon still has a number of sites left for new residential developments, many of them being located near to tram stops. Besides this, the SCoT and the PLH (Local Housing Plan, 2010) encourage each periurban municipality to include a minimum proportion of social dwellings in its targeted residential growth. The SRU (Solidarité et renouvellement urbain) law of 2000 imposes a minimum share of $20 \%$ social dwellings in middle-sized urban agglomerations. Greater Besançon already fulfils this requirement thus its objective is only to achieve a more homogeneous distribution of the social dwellings among all the communities of the urban region.

Under those circumstances, the political objective of the Besançon City authority (i.e. the mayor of the city and other political representatives) is to keep middle- and high-income households with children within the city. The arguments for this are to minimise car-based commuting and to benefit from the economic resources of these households (they pay taxes, and have relatively high household consumption levels). Besançon City council's aim is not to push poor households away (Watson 2009), but to attract and/or retain better off households, 
thus increasing the city council's tax base and its ability to finance its progressive social policies.

The department responsible for achieving this policy objective is Besançon city council's planning service: the Department of Planning, Projects and Forward Planning (la Direction 'Urbanisme, Projets et Planification'). Planners working in this department want to know if the policies of the SCoT (strategic land use plan) and the PLH (housing plan) as well as rising fuel prices and the new tramline will lead to more middle- and high-income households with children choosing to settle in the city of Besançon. If not, what additional planning policies could reduce the centre-to-periphery migration flows?

A number of other questions flow from those posed above. For example, what are the crucial decision criteria for households wishing to buy their own property? Are size and cost most important, or is housing type (flat or detached house) or even the quality of the residential environment (landscape, services, public transport) equally significant? Will the attractiveness of public transport increase as fuel prices increase? As the population ages, will the elderly remain in their current housing if they are living in large houses in the urban periphery?

\subsection{Origins, objectives and stages of the experimental trial}

Initially, the planners in the city's Department of Planning, Projects and Forward Planning envisaged carrying out a survey of household residential preferences to answer these and other questions. To this end, they contacted specialists in the university research centre 'Theories and Models for Planning' (TheMA) in June 2012. In a series of face to face and email exchanges between June and September 2012, the planners laid out the political objectives of Besançon's city council, while the researchers presented their knowledge of residential migration processes.

The conclusion was that a survey would simply generate facts that were already well known. Not only did many comparable surveys already exist in other French or European cities (e.g. Hur, Nasar, and Chun 2010; Ellis, Lee, and Kweon 2006; Bonaiuto, Fornara, and Bonnes, 2003), but a similar survey had already been undertaken recently in the periurban areas of Besançon as part of a doctoral study (Youssoufi and Foltete, 2013).

The researchers then proposed an alternative approach using computer simulation to explore the possible outcomes of spatial planning policies on residential location dynamics by developing a simulation model incorporating the planners' and researchers' knowledge of people's residential choices. The model would be used to explore the possible effects of different development scenarios on residential migration over a 20 year period but not to forecast the future. The planners accepted the proposition and the trial began in October 2012.

The trial involved two successive stages. The first being the collective definition and simulation of a baseline position simply extending existing trends from 2010 to 2030: the 'Business as usual' (BAU) scenario. The second stage was a collective reflection on possible modifications to some of the variables and parameters of the 'Business as usual' scenario in order to simulate a pro-active policy of housing construction in the medium term.

The motivation of the planning actors for participating in this experimental trial was to clear up some of their concerns about the feasibility of achieving the objectives set by the political actors. The motivation of the researchers was to see if the simulation model they were 
working on could be useful for planning policy development. It is important to note that although the collaboration started following an initiative taken by Besançon City Council, the local authority did not fund the trial with the simulation platform. This helped to ensure that the researchers involved were able to express their opinions freely. Indeed, exploring some of the implications of the research findings underpinning the simulation model was an objective of the researchers, and sharing these with the planners was a part of ensuring that the simulation results were understood and seen as useful.

\section{Choice of an appropriate simulation model}

Various forms of computerised tools already exist, which aim to assist spatial decisionmaking. Some of them allow the identification of optimal locations for retailing or other facilities (Thomas 2002). Other tools take into account a series of criteria to identify areas worth urbanizing or worth protecting (e.g. Malczewski, 2004; Arentze et al., 2006; Li and Liu, 2008; Janssen et al., 2008; Ligmann-Zielinska et al., 2008; Roberts et al., 2011). Despite the number of existing tools, few publications show the applications of such SDSS (spatial decision support systems) or PSS (planning support systems) in 'real' situations. Te Brömmelstroet (2009) proposes three explanations for this: 1) the gap between the modelling and planning communities is too large; 2) PSS are technology oriented rather than planning oriented; 3) these instruments do not fit the complex dynamics of real-world planning contexts.

Multi-agents systems specifically developed for assisting participatory processes have, however, proven to be useful (Becu, Neef, Schreinemachers, Sangkapitux 2008; Castella, Tran Ngoc Trung, Boissau 2005; Bousquet et al. 2002). These simulation models efficiently support collective decision-making where different stakeholders have conflicted objectives. Nevertheless, in the case presented in this paper, the purpose was not to achieve a consensus between conflicting objectives: the objective of Besançon City Council was clearly set: to retain more middle- and high-income households within the city boundary. The question related to the effectiveness of the planning rules set by the SCoT and the PLH to reach this objective as well as the possibility of using additional planning levers to better achieve it.

Other multi-agents systems are capable of generating urbanization schemes in the context of urban planning processes (Saarloos et al., 2005; Ma et al., 2006), but in the case of the experimental trial described here, the central question is not where to locate new residential developments: the allocation rules are already defined in the SCoT and the PLH.

Other types of simulation models can be used in the context of prospective approaches. In particular, cellular automata models allow the simulation of land use changes considering different prospective scenarios (White et al., 1997; Antoni, 2006; Li and Liu, 2008). Cellular automata simulations reveal which spatial configurations of urban growth emerge according to a given set of spatial interaction rules and spatial constraints. They do not really address, however, the questions asked by Besançon's planners where the spatial configuration of urban growth is an input not an output.

In the specific case of residential migration dynamics, two interrelated urban spatial systems have to be considered jointly: the urban development system (construction of new residential buildings and new places of activity) and the daily mobility system (where each individual carries out his or her activities). This led us to choose a Land-Use and Transport Interaction 
(LUTI) simulation platform (Wegener, 2004) to support the experimental trial. A LUTI simulation platform focuses on the interactions between transport planning and land-use planning. For this, it integrates several models representing demographic, social, economic, and spatial processes.

We assume that the success of the trial involving both researchers and planning actors requires a simulation model that represents the complexity of phenomena involved, it should not be too reductive but, nevertheless, easy to understand. The model is not there to provide solutions but to support discussions and collective reflection. The following section details the guiding principles adopted for building the model used in the trial.

\subsection{A model for testing planning scenarios}

The model is descriptive and exploratory, but not predictive because of the complexity of the phenomena involved. It is also not prescriptive: its aim is to explore and not to provide solutions or to identify the best solution among a small set of options. It is a structured examination of the complex dynamics at work in a city with a view to offering computerised assistance for human reasoning, rather than a replacement for it.

For the model to be an effective medium for discussion, both the researchers and the planners have to trust it. It is necessary to reach an agreement concerning the assumptions and the rules contained in the model (Van Delden, 2009). Hence the model should not be a black box. Following the idea of a "comprehensive model", all the factors, which seem important for the group, have to be introduced into the model. How these factors are related together has also to be explicitly set. The model should integrate both the scientific knowledge of researchers and the empirical knowledge of planning actors.

To support creativity, the model has to be strictly formalized: only if the framework is sufficiently constrained, will it help to identify what can change more or less easily, and what cannot. The model has to be constrained enough but not too much otherwise it might be too difficult to set the behaviour rules of households. Some flexibility is required to represent phenomena and rules imperfectly known but that are supposed to play a role in residential dynamics. To achieve enough flexibility, it is possible to introduce imprecision when defining evaluation rules (when distinguishing between push and pull factors, or those that are important or unimportant). It is also possible to introduce uncertainty when defining choice rules.

Variables influencing daily and residential mobility patterns must be easy to modify in order to simulate numerous prospective scenarios. Scenarios consist of changes in spatial variables (to represent a change in spatial planning rules) and changes in context variables.

In any modelling approach, exogenous variables are required when they cannot be predicted by the model, above all those that can be regulated by planning controls (Wilson, 2010). In the case of the trial, interesting exogenous variables are demographic parameters specifying long-term demographic trends (average age of the first child...), in- and out-migration, and fuel price changes over the course of time. Other variables related to housing construction can be levers for planning in the French case (Kamps, 2013): number of residential buildings constructed each year, types of constructed buildings (houses or flats), dwelling sizes, and 
planning zones. For testing scenarios, it may also be interesting to introduce an exogenous parameter to represent spatial differences in taxes, which influence housing costs.

The aim of the model is to simulate the effect of planning policies on mobility patterns and behaviours but not to simulate the economic effects of planning policies. As a consequence, it is not useful to model explicitly the housing market (supply and demand mechanisms) as do for instance Filatova et al. (2009) or Ettema et al. (2011). More generally, the modelled processes must not necessarily refer to market equilibrium (being static or dynamic) or to a set system of preferences. Without economic mechanisms, the endogenous residential dynamics results mainly from intra-urban spatial differentiations -site (landscape) and situation (accessibility to employment and amenities) - combined with the individual characteristics of the households (income, life style, age...).

Although economic mechanisms, in particular price formation, and economic concepts such as bid rent or hedonic prices are not modelled, the model does not deny micro-economic theories. Economic variables (household income, dwelling cost, transportation cost) are taken into account. Macro-economic phenomena (e.g. economic or financial crises) can also be taken into account throughout an exogenous change of housing costs and household incomes.

The model calibration allows the quantitative transcription of stylized facts representing the current context and the current behaviours, which will be modified later to create scenarios. The quantification of stylized facts is not based on the statistical estimation of a system of stated or revealed preferences. However, statistical (or survey) data are used to set realistic value ranges for parameters as well as to give a rough estimate of changes in variables. One objective is to determine how much it is possible to quantitatively change things in the model while obtaining plausible simulation results. The path of possible trajectories is not, however, infinite. For instance, simulating a change which reduces Besançon to a population of only 10,000 residents or a town with a purely periurban population is beyond the realms of possibility.

\subsection{A model of complex processes}

Building a model implies necessarily a simplification (the model does not describe the entire world). The crucial question is: which interactions are essential and which are not.

Household mobility within urban regions, unlike long-distance mobility, is almost exclusively determined by housing considerations, i.e. changing housing needs during the life cycle (Wegener, 1985). Consequently, demographic parameters specifying long-term demographic trends (birth and death rates, average age of the first child, etc.) have to be taken into account. Wilson (2010) also argues that a dynamic model of location behaviour has to integrate several types of conceptual models: theories of demography at the aggregate level, theories of economy, a theory of spatial structure, and a theory of spatial interaction. Building a general model consists in assembling best-practice sub models (in particular, a residential mobility model and a daily mobility model), and linking them.

This led us to choose a Land-Use and Transport Interaction (LUTI) simulation platform (Wegener, 2004) to support the experiment. A LUTI simulation platform focuses on the interactions between transport planning and land-use planning. For this, it integrates several models representing demographic, social, economic, and spatial processes. 
In the specific case of residential migration dynamics, two interrelated urban spatial systems have to be considered jointly: the urban development system (construction of new residential buildings and new places of activity) and the daily mobility system (where each individual carries out his or her activities).

Non-linear dynamics characterizing residential migration processes result not only from the interactions between residential mobility and daily mobility, but also from push-pull interactions that occur in residential location decisions. All residential migration models classically distinguish "push" factors (propensity to move) from "pull” factors (choice factors) (Ben-Akiva and de Palma 1986; Andersson et al., 2002; Pellegrini and Fotheringham, 2002). Most often, a household is not content with its residential situation, and envisages moving (push factors). Thus, a household takes a decision and looks for a dwelling that corresponds to its expectations (pull factors). These models, generally called "two stages" (decision to move and choice of dwelling) or "three stages" (decision, search, and choice) consider the push-pull factors in a consecutive and independent fashion (Raju et al., 1998; Fernandez et al., 2005; Brown and Robinson 2006; Jordan et al., 2011). Models that consider push pull factor interactions, most commonly through the idea of economic utility, are rarer (Benenson, 2004; Ettema et al., 2007). The model constructed for this experimental trial models the decision to move as a single process composed of two interacting elements: the decision to leave a current dwelling, and the choice of a new location. The idea of a single process means that a single model represents the spatial decision.

\subsection{A simple to understand model, lending itself to discussion}

The model is designed to be simple to understand and to lend itself to discussion. In order to respect this guiding principle we chose to build an individual-based model in which behaviours are explicitly modelled (Benenson 1998; Benenson, Omer, Hatna 2002). The fact that entities represent "real" agents seems more intuitive and evocative for planning actors having no modelling skills.

Modelled entities are individuals and dwellings. Rules determine how individuals form households. Other rules locate dwellings in buildings. Modelling at the scale of individuals allows a coherent simulation of demographic changes taking into account lifecycle events (determining residential mobility), and a good characterization of individual modal choices and household residential choices. Spatial disaggregation (at the scale of dwellings and buildings) is an appropriate solution to simulate pedestrian mobility in short distance trips (from building to building), to analyse household residential preferences considering the dwellings in their local environment, and to simulate distinct scenarios of residential development based on various planning and design rules.

Stylized facts represent household residential behaviour and individual mobility behaviour. Behaviour changes result from changes in the characteristics of households and individuals (births, unions, ageing, deaths...) as well as changes in their environment. Available places to live change as a consequence of dwelling construction. Places where individuals undertake their activities (shops, places of employment, etc.) do not change endogenously, except green and natural areas. At an aggregated analysis level, daily and residential mobility patterns result from the behaviours of households and individuals. 
Our aim is to formalize the residential choice process in a realistic manner, which explains that our model contains numerous variables. Nevertheless behaviours are represented by simple stylized facts. Abstract formulations and concepts are avoided. For instance, the concepts of utility and rent calculated in market equilibrium, which seem too abstract and difficult to understand when working with planning actors, are not used.

\subsection{The simulation platform: MobiSim}

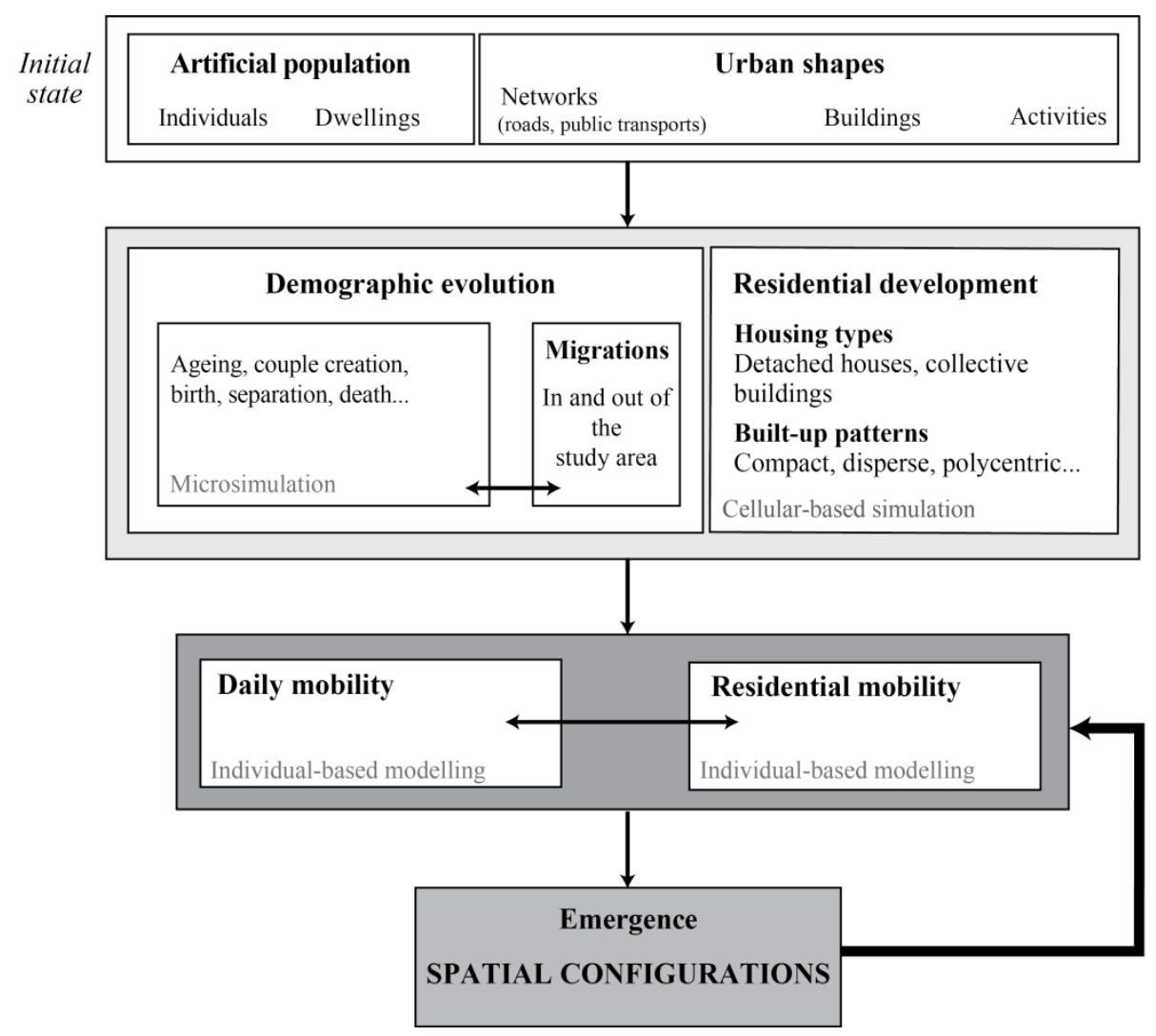

Figure 1. Architecture of the simulation platform MobiSim

The simulation platform chosen for the experimental trial under consideration is called MobiSim. It combines several models operating in interaction with one another (Figure 1). The individuals in MobiSim come from an artificial population, reconstituted from population census data from INSEE (Antoni et al., 2011). This is necessary in France because of the absence of disaggregated demographic data. This artificial population changes through a microsimulation module of demographic change. This is essential for the modelling of residential mobility which depends principally on the position of individuals in their lifecycle (Ioannides, 1987; Dieleman and Mulder, 2002). Annual migrations in and out of the urban region are also taken into account in the demographic model. The development of the space occurs through the residential development simulation model. The two models (demographic change and residential development) influence directly the simulation model of residential mobility, without the latter influencing the former in return.

The models of daily and residential mobility allow the representation of agent behaviours in interaction with their environment. From these behaviours emerge the spatial configurations that influence in turn the different components of the platform at the next iteration. These two 
models interact directly through traffic congestion (depending on the residential location of agents, traffic flows will rise or fall), and through the integration of accessibility costs in the simulation of residential mobility.

The MobiSim platform endogenously calculates at each simulation step: the location of newly constructed buildings; daily mobility patterns (at the individual level including modal choice); individual transitions (birth, ageing, death); household transitions (couple creation, separation, child leaving); intra-urban migrations (at the household level).

Exogenous variables have been chosen in order to make it possible to create spatial planning scenarios (e.g. modification of the public transport system) or context change scenarios (e.g. strong fuel price increases in the course of time). A series of exogenous variables (also nonpredictable with the model but interesting for testing different scenarios) define the shape and intensity of residential development: number of dwellings constructed each year, types of buildings (houses or blocks of flats), dwelling sizes, and local built density.

The following section concentrates on the presentation of the model for simulating residential migrations based on the MobiSim platform.

\subsection{General description of the residential mobility model}

Decisions to move are taken by households. A household is considered as an entity within which decisions are taken in a collegial way. It is assumed that the head of the household takes decisions taking into account the opinions of the other members of the household.

Each dwelling is characterised by intrinsic characteristics and those of its environment. A distinction is made between the local residential environment, also known as the neighbourhood, and the overall residential environment (Timmermans et al., 1992; Dieleman and Mulder, 2002; Benenson, 2004; Prashker et al., 2008; Devisch et al., 2009). Working on these three levels of analysis - dwelling, neighbourhood environment and overall residential environment - makes the link between residential and daily household mobility simpler.

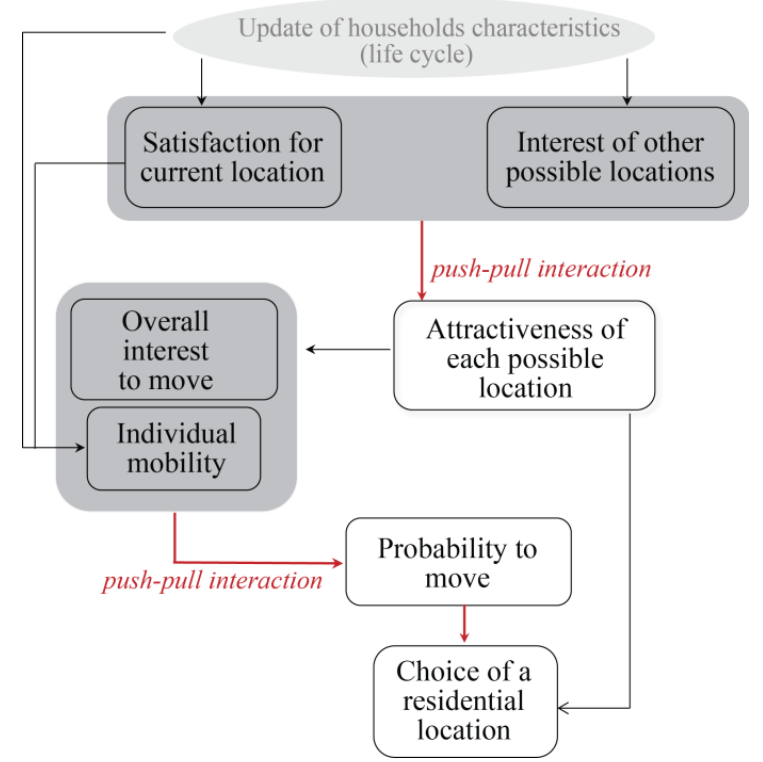

Figure 2. Architecture of the residential mobility model 
The model is based, on the one hand, on the appreciation of each household of the attributes of the dwelling they currently occupy and, on the other hand, the attributes of dwellings they could occupy (possible future residential locations) and their respective residential environments (Figure 2). The dwellings that the household could occupy are the dwellings currently vacant.

Residential satisfaction (push factors) is characterised by:

- the variables characterising the dwelling: measuring the match between dwelling characteristics and household socio-economic characteristics;

- the local residential: to measure the quality of life of a household in a given dwelling; the overall residential environment: simply the distance from the city centre (no account is taken of accessibility to employment).

The choice factors (pull factors) involve an evaluation of what a household could obtain, what it might experience in another location. Other locations are considered as imperfectly known, unlived in and unfamiliar. The majority of the variables representing choice factors are the same as those pushing households to move (i.e. residential satisfaction factors) however their role is often different (cf. section 3.2). The literature on individual choice factors (pull factors) is abundant, but the weighting between factors is poorly understood. Following an in-depth reading of the literature in the field, however, sufficient elements have been identified to develop hypotheses and to quantify this aspect of the model. The attributes characterising local accessibility (shops and services, green space and public transport) have relatively little importance compared to the attributes of the general environment and, above all, the attributes of the dwelling. The attributes characterising local accessibility are more representative of residential satisfaction (push) than choice factors ( $p u l l$ ). It should be noted, however, that high income households show more interest in their residential environment (visible landscape, similar neighbours) than other types of households when choosing a dwelling (Fernandez et al., 2005).

When comparing possible residential locations, a household does not assess all the possibilities in a city. Households have limited knowledge of the opportunities that exist. Accordingly, the number of residential locations evaluated by households in the model is limited (Ettema et al., 2011).

Purely economic variables (housing cost, transportation cost and income) are taken into account at the same time as other variables characterising the lifestyle and stage in the lifecycle of households. Economic variables are prominent factors but they do not fully determine individual decisions: a number of studies have shown that preferences and residential choices are only partially statistically correlated to the socio-economic and demographic characteristics of households, with the exception of their point in the lifecycle (Fernandez et al., 2005). They are thus fuzzy constraints, which might be overcome in some cases.

At the moment of dwelling choice, the constraint of income comes into play in the same way as other fundamental factors, and necessitates a compromise. Household income is, in addition, a proxy for measuring the household's social group and how well it corresponds to its social environment. The resulting socio-spatial segregation forces those with the lowest incomes to stay close to employment areas, while also benefiting from good accessibility based on public transport. Higher social classes prefer centrality, urbaneness, and proximity to 
cultural and landscape heritage. Life cycles play a part in their segregation, introducing a spatial and temporal dynamic (Charlot et al., 2009).

In accordance with Gärling and Friman (2002), Francescato (2002), and Ge and Hokao (2006), we also adopted the hypothesis that household lifestyles are independent of income and socio-demographic characteristics.

The model then allows the calculation of the probability of each household moving and, for those that do move, the determination of their dwelling choice. For these aspects of the model, the formalisation was inspired by sociodynamic probabilistic models (Weidlich and Haag 1987; Weidlich 2000-2006). This is an individual centred adaptation (at the scale of the household and of the dwelling) of the model of Tannier and Frankhauser (2001) and Tannier et al. (2011). From a general point of view, the propensity of a household to move is a function of:

- its dissatisfaction in relation to its current residential location, which is a function of the household's daily mobility, and its socio-spatial use of the space;

- the match between its needs and the characteristics of the dwelling it occupies;

- the energy necessary to move dwelling: this factor is a brake on the decision to move. Following the approach of Moles and Rohmer (1977), an individual reacts when the benefits gained from an action (benefits more or less well understood over the long term) are discernibly greater than the internal resources that are required by the action;

- an event provoking a residential move (if one is possible): the birth of a child, the separation of a couple, a change in income, death, retirement.

In our model, following this logic, the propensity of a household to migrate results from a combination of three variables: residential satisfaction, individual residential mobility (a function of the stage in the lifecycle) and the general benefit of moving within the city being considered.

Ultimately, for each year of simulation, the model determines which households will move and their new residential location (i.e. a dwelling located in a residential environment). Over time, the characteristics of households change. This engenders a change in their preferences and their perceptions. At the same time, their residential environment changes (appearance of new residential buildings, departure and arrival of new households), which alters a household's residential satisfaction and the attractiveness of other available residential locations.

In our model, migration decisions are determined by both individual factors and collective knowledge. The role of collective knowledge is modelled through the introduction (direct or indirect, through the daily mobility simulation modules) of context variables: overall characteristics of the spatial urban structure (access time to town centre, accessibility to employment), the price of petrol etc. This collective knowledge represents a large part of the residential choice in the model, notably in the assessment of the overall interest to move within the urban region under consideration. This brings into play general variables in relation to the housing market: the quality and quantity of available dwellings. Thus, a household will be pushed more towards moving if the housing market offers it good opportunities.

The preceding part of the article has allowed us to present a set of hypotheses concerning household residential choices that are explicit and relatively simple to explain. The next task is to transcribe these into mathematical form in order to integrate them into a computer application. 


\section{The residential mobility model: formalization}

In the model, the complexity comes from the number of variables and their interactions but the rules generating the dynamics are simple. Rules correspond to disaggregated stylized facts. The less a phenomenon is known the more it is disaggregated into simple stylized facts. Then all these simple parts are re-aggregated (using aggregation rules) and linked (using interaction rules). Aggregation and interaction rules can be imprecise or uncertain.

\subsection{Variables}

Three sets of variables play a role in the residential mobility model:

$\mathbf{H}$ : the household characterized by its socio-economic situation and its life-style;

D: the dwelling; where the currently occupied dwelling is defined as $\mathrm{D}_{\mathrm{I}}$ and a possible future dwelling by $\mathrm{D}_{\mathrm{J}}$;

$\mathbf{E}$ : the residential environment.

\subsubsection{Variables characterizing the household $H$}

Each household is characterized by four socio-economic variables:

\begin{tabular}{|c|c|c|}
\hline Variable & Name & Modalities \\
\hline $\mathbf{H}_{\mathbf{y} \mathbf{i}}$ & income & $\mathbf{H}_{\mathbf{y} \mathbf{1}}$ : low income; $\mathbf{H}_{\mathbf{y} 2}$ : medium income; $\mathbf{H}_{\mathbf{y} 3}$ : high income \\
\hline $\mathbf{H}_{\mathrm{a}}$ & age of the household & $\begin{array}{l}\mathbf{H}_{\mathbf{a}} \text { : younger than } 30 ; \mathbf{H}_{\mathbf{a}} \text { : between } 30 \text { and } 44 ; \mathbf{H}_{\mathrm{a}} \text { : between } 45 \text { and } 60 ; \\
\mathbf{H}_{\mathbf{a}} \text { : older than } 60\end{array}$ \\
\hline $\mathbf{H}_{\mathbf{c}}$ & number of children & $\mathbf{H}_{\mathbf{c} \mathbf{1}}:$ none; $\mathbf{H}_{\mathbf{c} \mathbf{2}}:$ one or two children; $\mathbf{H}_{\mathbf{c} \mathbf{3}}:$ three or more \\
\hline $\mathbf{H}_{\mathrm{si}}$ & $\begin{array}{l}\text { household } \\
\text { composition }\end{array}$ & $\begin{array}{l}\mathbf{H}_{\mathbf{s} \mathbf{1}} \text { : single; } \mathbf{H}_{\mathrm{s}_{2}} \text { : couple; } \mathbf{H}_{\mathrm{s}_{\mathbf{3}}} \text { : family (with at least one child); } \mathbf{H}_{\mathrm{s}_{\mathbf{4}}} \text { : single } \\
\text { parent family }\end{array}$ \\
\hline
\end{tabular}

These variables were chosen because they appear frequently in the literature. The numerous possible combinations between the states of these four variables make it possible to distinguish 72 types of household, which maintains a certain degree of heterogeneity in the modelled residential behaviours.

Two other variables characterize the life-style of the household:

- Preferred transport mode $\mathbf{H}_{\mathbf{t} \mathbf{i}}$ : the household gets about, above all, using a private vehicle $\mathbf{H}_{\mathbf{t}}$; the household mainly uses other modes of transport (public transport, cycling or walking) $\mathbf{H}_{\mathbf{t}}$.

- Type of residential environment $\mathbf{H}_{\mathbf{r i}}$ : household living in a rural residential environment $\mathbf{H}_{\mathbf{r} 1}$; household living in an urban residential environment $\mathbf{H}_{\mathbf{r} 2}$.

The type of residential environment $\mathbf{H}_{\mathbf{r i}}$ allows us to distinguish between a lifestyle mainly orientated around an appreciation of urban amenities (particularly frequently used shops and services) and a lifestyle principally orientated around rural amenities (importance of landscape quality and of being close to natural areas). Initially, a household is characterised by a "rural" lifestyle $\mathrm{H}_{\mathrm{r}} 1$ when it is located in a rural residential environment and by an "urban" lifestyle $\mathrm{H}_{\mathrm{r} 2}$ when it is located in an urban residential environment. To determine if the residential environment of a building is rural, the make-up of land use is assessed in a radius of $300 \mathrm{~m}$ around it. An environment is rural if, on the one hand, a certain proportion (at 
least 65\%) of the surface is given over to natural or agricultural uses and, on the other hand, no more than a given proportion (10\%) is devoted to industrial uses and parking. An urban residential environment is simply one that is not rural. When a household arrives in the urban region under consideration, there is a 0.5 probability of it having previously lived in one or other of these two types of residential environment.

Concerning the variable $\mathbf{H}_{\mathbf{t} \mathbf{i}}$, when a household makes most of its journeys by car, its lifestyle is judged to be orientated principally around the use of the car. In the same way, when a household makes most of its journeys by public transport, cycling or walking its lifestyle is defined as orientated principally around these modes of transport. MobiSim generates the number of trips made by a household in a day and the mode of transport used thus permitting the model to distinguish between a car-based lifestyle $\mathbf{H}_{\mathbf{t} \mathbf{1}}$ and one based on public transport, cycling and walking $\mathbf{H}_{\mathbf{t} 2}$. A household is defined as $\mathbf{H}_{\mathbf{t}}$ if at least a given proportion (2/3) of journeys is made by car by adult household members. In all other cases, the household is classified as $\mathbf{H}_{\mathbf{t} 2}$.

\subsubsection{Variables characterizing the dwelling $D$}

\begin{tabular}{|l|l|l|}
\hline Variable & Name & Modalities \\
\hline $\mathbf{D}_{\mathbf{k} \mathbf{k}}$ & dwelling cost & $\mathbf{D}_{\mathbf{k} \mathbf{1}}:$ low cost; $\mathbf{D}_{\mathbf{k} \mathbf{2}}:$ medium cost; $\mathbf{D}_{\mathbf{k} \mathbf{3}}:$ high cost \\
\hline $\mathbf{D}_{\boldsymbol{\xi} \mathbf{k}}$ & dwelling size & $\begin{array}{l}\mathbf{D}_{\boldsymbol{\xi} \mathbf{1}}: \text { one or two rooms; } \mathbf{D}_{\xi \mathbf{2}}: \text { three or four rooms; } \mathbf{D}_{\xi \mathbf{3}}: \text { five rooms and } \\
\text { more }\end{array}$ \\
\hline $\mathbf{D}_{\lambda \mathbf{k}}$ & type of dwelling & $\mathbf{D}_{\lambda \mathbf{1}}:$ house; $\mathbf{D}_{\lambda \mathbf{2}}:$ flat \\
\hline $\mathbf{D}_{\boldsymbol{\theta} \mathbf{k}}$ & $\begin{array}{l}\text { occupancy } \\
\text { status }\end{array}$ & $\mathbf{D}_{\boldsymbol{\theta} \mathbf{1}}:$ owner; $\mathbf{D}_{\boldsymbol{\theta} \mathbf{2}}:$ private tenant; $\mathbf{D}_{\boldsymbol{\theta}_{\mathbf{3}}}:$ social tenant \\
\hline
\end{tabular}

Dwelling costs are approximate and are estimated using two variables: the floorspace of the dwelling (70\% of costs) and the median income of neighbouring households (30\% of costs) (Baumont, 2009; Bénabou, 1993; Charlot et al., 2009; Décamps et Gaschet, 2013; NguyenLuong and Boucq, 2011; Nicolas et al., 2009). The evaluation of the cost of the dwelling $\mu$ (cost) is calculated as follows:

$$
\mu(\text { cost })=[0.7 \times \mu(\text { cost } \mid \text { floorspace })]+[0.3 \times \mu(\text { cost } \mid \text { neighbourhood })]
$$



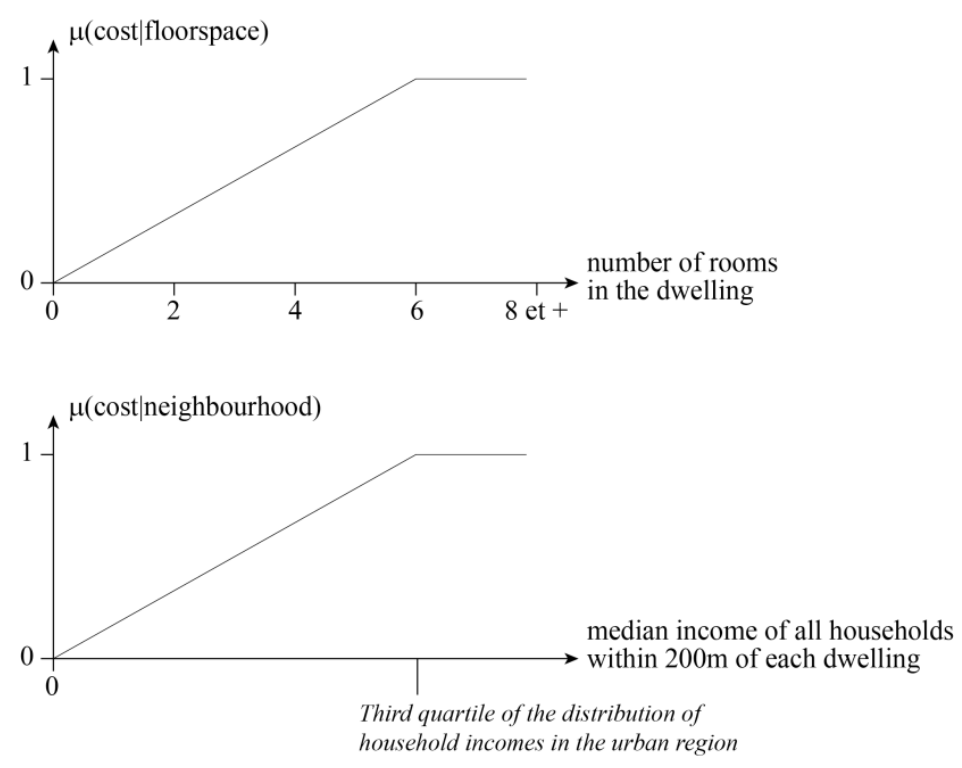

Figure 3. Definition of the two variables $\mu(\operatorname{cost} \mid$ floorspace) and $\mu(\operatorname{cost} \mid$ neighbourhood).

Where dwellings are classified as being in owner occupation (state $\theta_{1}$ ), the evaluation of dwelling costs takes also into account local real estate values per $\mathrm{m}^{2}$ in the form of the variable $\delta$.

$$
\mu\left(\operatorname{cost} \mid \theta_{1}\right)=\mu(\cos t)^{\delta}
$$

Three real estate values are defined for each urban area.

If real estate prices are generally low, $\delta=3$

If real estate prices are average, $\delta=1$

If real estate prices are high, $\delta=0.2$

For social tenants (state $\theta_{3}$ ), the evaluation of the cost of the dwelling does not take into account the income of households in surrounding housing.

$$
\mu\left(\operatorname{cost} \mid \theta_{3}\right)=0.7 \times \mu(\operatorname{cost} \mid \text { floorspace })
$$

In this way, a socially advantaged neighbourhood does not increase the cost of the dwelling. Moreover, the evaluation of the maximum cost of housing is at most equal to 0.7 for a large dwelling.

According to the value of $\mu$ (cost), a probability mass function attributes to each dwelling a state for the variable “Dwelling cost” $D_{\mathrm{k}_{\mathrm{k}}}$ : low $\kappa_{1}$, medium $\kappa_{2}$, high $\kappa_{3}$ (Figure 4). 


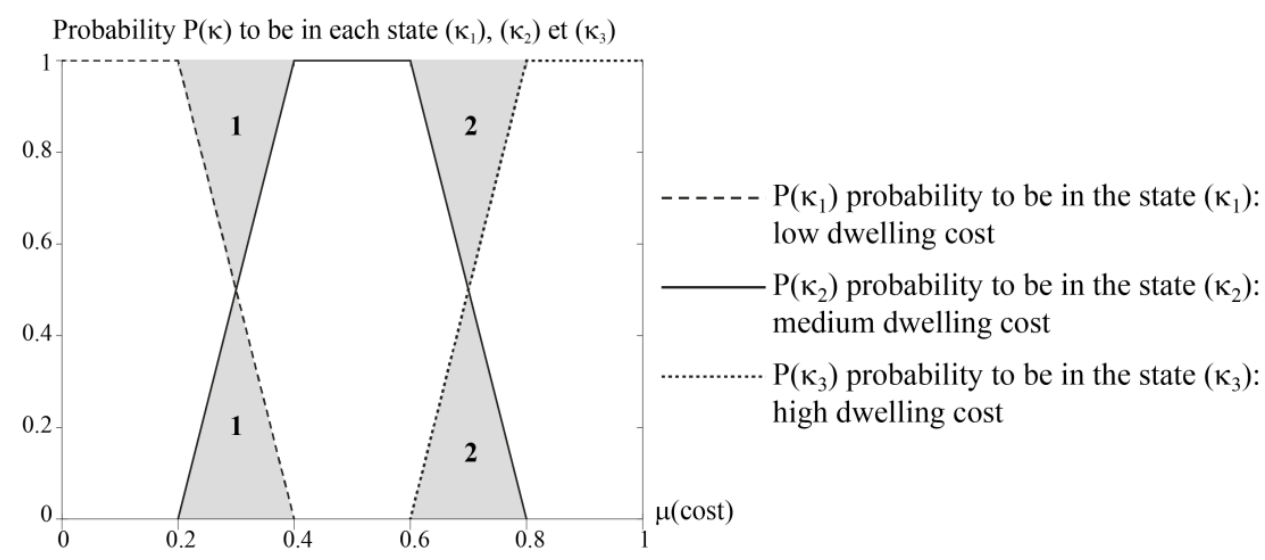

If the dwelling is the zone 1 of the figure: random drawing attributes the dwelling to one or other of the states $\left(\kappa_{1}\right)$ or $\left(\kappa_{2}\right)$ according to probabilities $\mathrm{P}\left(\kappa_{1}\right)$ and $\mathrm{P}\left(\kappa_{2}\right)$.

If the dwelling is the zone 2 of the figure: random drawing attributes the dwelling to one or other of the states $\left(\kappa_{2}\right)$ or $\left(\kappa_{3}\right)$ according to probabilities $\mathrm{P}\left(\kappa_{2}\right)$ and $\mathrm{P}\left(\kappa_{2}\right)$.

Figure 4. Probabilistic definition of dwelling cost

\subsubsection{Variables characterizing the environment $[E \mid D]$ of the dwelling $D$}

At a local level, the environment $[\mathrm{E} \mid \mathrm{D}]$ is characterized by:

- the number of shops and services visited daily $\left[\mathrm{E}_{\mathrm{df}} \mid \mathrm{D}\right]$ and weekly $\left[\mathrm{E}_{\mathrm{wf}} \mid \mathrm{D}\right]$;

- the number of public transport stops $\left[\mathrm{E}_{\mathrm{ts}} \mid \mathrm{D}\right]$;

- the distance to the nearest square or park $\left[E_{\mathrm{ds}} \mid \mathrm{D}\right]$ and the distance to the edge of the urban area $\left[\mathrm{E}_{\mathrm{ub}} \mid \mathrm{D}\right]$ (at the edge of the urban area a household is judged to have access to a green and natural environment);

- the landscape quality of the residential environment: wooded landscape $\left[E_{\mathrm{fl}} \mid \mathrm{D}\right]$, built landscape $\left[\mathrm{E}_{\mathrm{b}} \mid \mathrm{D}\right]$;

- the proportion of high income households in the residential environment of the dwelling $\left[\mathrm{E}_{\mathrm{hi}} \mid \mathrm{D}\right]$.

These variables characterise access from the dwelling to local amenities, and its social environment (Brueckner et al. 1999). Numerous studies have shown that access to shops and services is a factor in residential satisfaction (Bramley and Power 2009); other studies have shown that proximity to green spaces and natural areas is also a factor of residential satisfaction (Kweon et al., 2010).

The average distance to a given set of amenities indicates the proximity of the residents to those amenities whereas the average number of amenities at a given distance indicates the supply of amenities in the neighbourhood (Apparicio and Séguin, 2006).

The variable $\left[E_{\mathrm{hi}} \mid \mathrm{D}\right]$ (proportion of high income households in the residential environment), which is often a feature of classic economic models, allows the preference of households to be close to other households similar to them to be taken into account. We have chosen only to consider the effect of well-off households in the neighbourhood: a high proportion of well-off households in the immediate neighbourhood is attractive to well-off households and offputting for households of more modest means. 
Various studies have examined more closely the role of the landscape in individual residential preferences (Kaplan et al., 1989; Ratiu, 2003). Three major methodological approaches allow the consideration of the landscape environment: the distance between a dwelling and a particular landscape element (Tyrväinen and Miettinen, 2000); the composition or the configuration of the landscape surrounding a dwelling, seen "from above" (Kestens et al., 2004; Cho et al., 2008); the view from a dwelling of different elements of a landscape seen "from within" in three dimensions (Cavailhès et al., 2009). In all these studies, there is a certain recurrence of satisfaction generated by the presence of wooded or "natural" elements in the residential environment of the individual. In contrast, buildings, roads, and industrial or agricultural features in the landscape tend to generate dissatisfaction.

At a global level, the environment [E|D] is characterized by:

- the cost of access to the urban centre by car $\left[\mathrm{E}_{\text {ccar }} \mathrm{D}\right]$ or by public transport, cycling or walking $\left[\mathrm{E}_{\mathrm{cpt}} \mid \mathrm{D}\right]$;

- the general access to employment via the road network [ $E_{w c a r}[D]$ or via the public transport network $\left[\mathrm{E}_{\mathrm{wpt}} \mid \mathrm{D}\right]$.

The cost of access to the urban centre is a proxy for the accessibility of cultural and historical amenities. It is calculated in the following way (in the case of car access):

$$
\left[\mathrm{E}_{\mathrm{ccar}}[\mathrm{D}]=\mathrm{Cd}_{\mathrm{car}} \times \mathrm{d}_{\mathrm{car}}(\mathrm{Jc})+\mathrm{Ct}_{\mathrm{H}(\mathrm{y})} \times \mathrm{t}_{\mathrm{car}}(\mathrm{Jc})\right.
$$

Where $\mathrm{Cd}_{\text {car }}$ represents the cost of the distance when travelling by car, $\mathrm{Ct}_{\mathrm{H}(\mathrm{y})}$ the value of time for each household (as a function of income), $\mathrm{d}_{\mathrm{car}}(\mathrm{Jc})$ the distance by car between the dwelling $\mathrm{J}$ and the urban centre $\mathrm{c}, \mathrm{t}_{\mathrm{car}}(\mathrm{Jc})$ the travel time by car between the dwelling $\mathrm{J}$ and the urban centre c.

The general access to employment consists of measuring the cost of access from a residential location $\mathrm{J}$ to each employment area $\mathrm{W}$, combined with the number of jobs in each zone $\mathrm{m}_{\mathrm{W}}$. This is calculated as follows (in the case of access by car):

$$
\left[\mathrm{E}_{\mathrm{wcar}} \mid \mathrm{D}\right]=\Sigma \mathrm{mW} \cdot \mathrm{e}^{-\alpha . \mathrm{CcarJW}}
$$

Where CcarJW represents the cost of the distance between a residential location $\mathrm{J}$ to each employment zone $\mathrm{W}$ when travelling by car, and mW represents the number of jobs in each employment zone. Employment zones are mapped in the form of $50 \mathrm{~m}$ by $50 \mathrm{~m}$ cells, each containing a certain number of jobs.

In the model, households do not seek to minimise their commuting costs: the proximity of their home to their current place of work is not a factor of residential choice and equally a change of work place will not provoke a residential move (Lévy, 2009; Carpentier and Gerber 2009). However, in the choice of a new residential location, general access to employment plays a significant role especially for lower income households. For their part, well-off households are able to overcome accessibility constraints because their income allows them to travel easily even when transport costs are high.

\subsection{Appreciation levels and weightings}

For a given dwelling, each household appraises its attributes and those of the residential environment. The rules for calculating levels of appreciation reflect the norms, the typical behaviours, from which are derived the household's subjective appreciation. The appreciation values have been established by expert opinion following a detailed analysis of the scientific 
literature in this area. These values have not been derived directly from survey data, but nevertheless, statistical (or survey) data helped to set realistic value ranges for household appreciation levels.

Dwelling appreciation values and residential environment appreciation values are treated differently because the variables concerned are of a different nature: discrete in relation to dwellings and continuous for the residential environment.

\subsubsection{Appreciation and weighting of dwelling attributes}

The literature does not allow a value to be attributed to the appreciation of every dwelling state for every type of household. For this reason, the model considers the relationships between:

- $\quad$ on the one hand, each state of the different attributes of a dwelling,

- on the other hand, each state of the different characteristics of a household.

Each "characteristic-attribute" pair is considered in the form: $A_{\mathrm{Hai}}\left(D_{\lambda \mathrm{k}}\right)$.

Taking the example of someone's age and their status in terms of housing occupation, we consider the evaluation of each of the four age classes for the two possible housing occupation states, i.e. renter and owner (Figure 5).

\begin{tabular}{|c|c|c|c|}
\hline CARACTERISTICS & MODALITY & & \\
\hline \multirow{4}{*}{ Age of the household } & younger than 30 & \multirow{2}{*}{ MODALITY } & \multirow{2}{*}{ ATTRIBUTE } \\
\hline & between 30 and 44 & & \\
\hline & between 45 and 60 & one or two rooms & \multirow{6}{*}{$\begin{array}{l}\text { Dwelling } \\
\text { cost }\end{array}$} \\
\hline & older than 60 & three or four rooms & \\
\hline \multirow{4}{*}{$\begin{array}{l}\text { Household } \\
\text { composition }\end{array}$} & single & five rooms and more & \\
\hline & couple & low cost & \\
\hline & family & medium cost & \\
\hline & single parent family & high cost & \\
\hline \multirow{3}{*}{$\begin{array}{l}\text { Number of } \\
\text { children }\end{array}$} & none & owner & \multirow{3}{*}{ Tenure } \\
\hline & one or two & private tenant & \\
\hline & three or more & social tenant & \\
\hline \multirow{2}{*}{$\begin{array}{l}\text { Household } \\
\text { income }\end{array}$} & low income & house & \multirow{2}{*}{$\begin{array}{l}\text { Dwelling } \\
\text { type }\end{array}$} \\
\hline & medium income & flat & \\
\hline
\end{tabular}

Figure 5. Relationships between the state "owner" of the dwelling attribute "tenure" and each of the four possible household age classes

The values given to the appreciations of the attributes of the current dwelling I are presented in table 1 . They are between 0 and 1 corresponding respectively to a very poor appreciation and a very good one. Not all cells in the table are filled in because we have chosen to retain only the most relevant relationships between dwelling attributes and household characteristics suggested by the literature. 


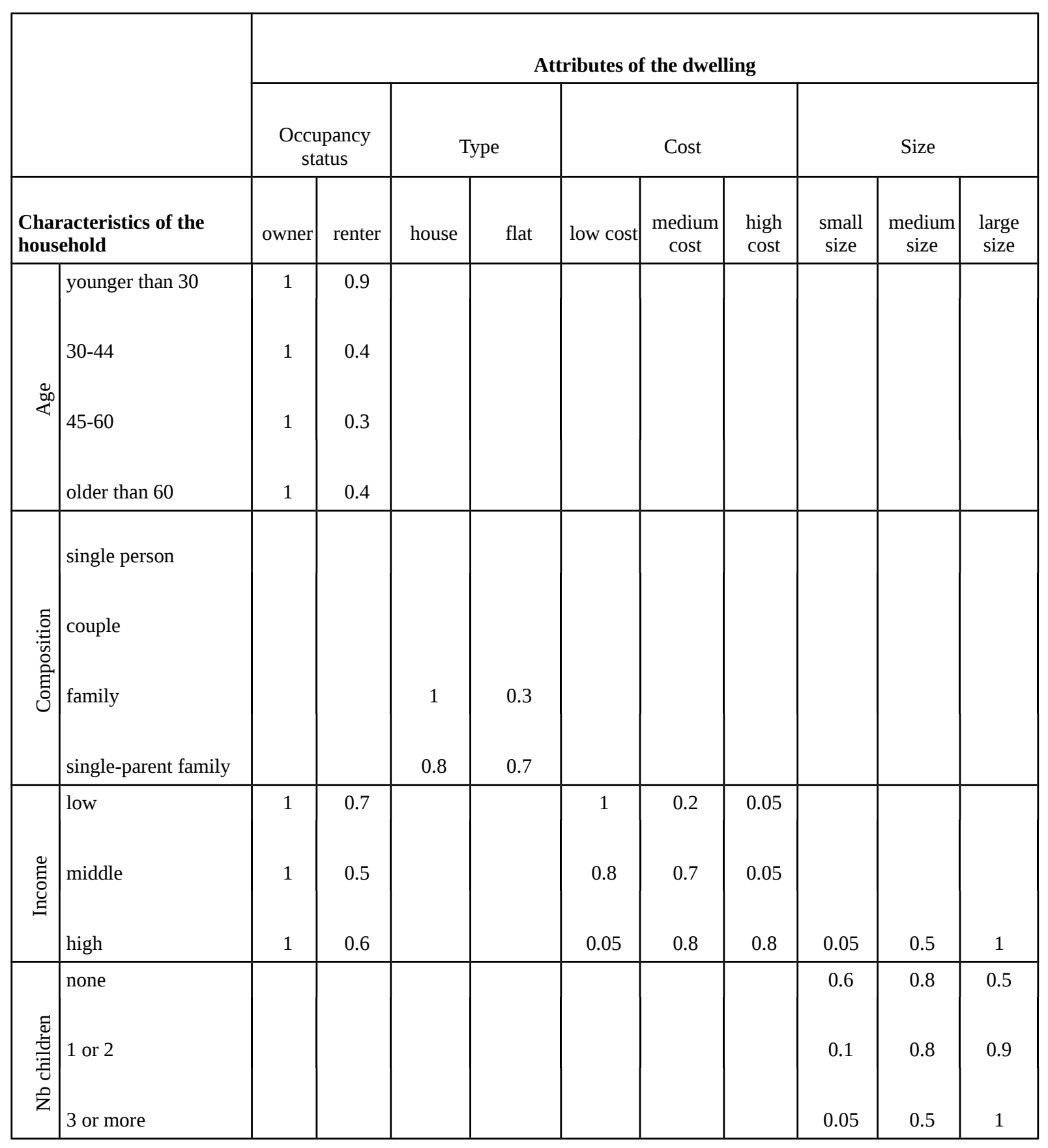

Table 1. Appreciation of the attributes of current dwelling I 
The value given to the appreciation of the attributes of a potential future dwelling $\mathrm{J}$ is different from those of the current dwelling I: cf. table 2.

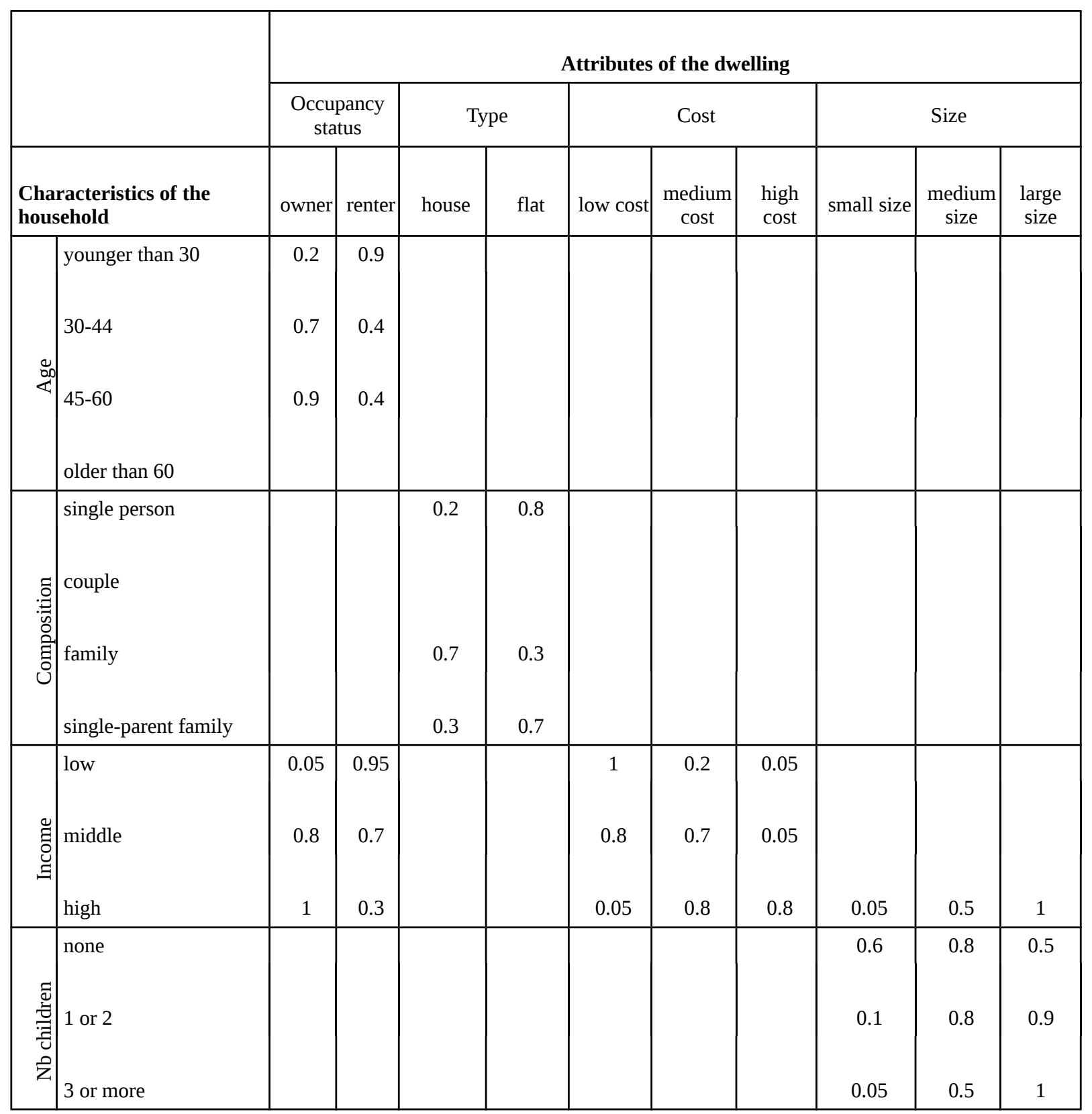

Table 2. Appreciation of the attributes of each potential future dwelling $\mathbf{J}$

Not all attributes have the same importance in the eyes of a given household. Their importance also depends on household characteristics. For example, the importance of the size of a dwelling will potentially be different for single persons or single parent families. In contrast to appreciation, it is the attributes of dwellings themselves that are concerned and not their states (Figure 6). 


\begin{tabular}{|c|c|c|}
\hline CARACTERISTICS & MODALITY & \\
\hline \multirow{4}{*}{ Age of the household } & younger than 30 & \multirow{2}{*}{ ATTRIBUTE } \\
\hline & between 30 and 44 & \\
\hline & between 45 and 60 & \multirow{3}{*}{$\begin{array}{l}\text { Dwelling } \\
\text { size }\end{array}$} \\
\hline & older than 60 & \\
\hline \multirow{4}{*}{$\begin{array}{l}\text { Household } \\
\text { composition }\end{array}$} & single & \\
\hline & couple & \multirow{3}{*}{$\begin{array}{l}\text { Dwelling } \\
\text { cost }\end{array}$} \\
\hline & family & \\
\hline & single parent family & \\
\hline \multirow{3}{*}{$\begin{array}{l}\text { Number of } \\
\text { children }\end{array}$} & none & \multirow{2}{*}{ Tenure } \\
\hline & one or two & \\
\hline & three or more & \multirow{3}{*}{$\begin{array}{c}\text { Dwelling } \\
\text { type }\end{array}$} \\
\hline \multirow{2}{*}{$\begin{array}{l}\text { Household } \\
\text { income }\end{array}$} & low income & \\
\hline & medium income & \\
\hline
\end{tabular}

Figure 6. Relationships between the dwelling attribute "housing cost" and each of the four household compositions

Weighting of a dwelling attribute $D_{\theta}$ for household $H$ is noted: $\omega_{H}\left(D_{\theta}\right)$. As for appreciation, weightings of the attributes of the current dwelling I and those of the potential future dwelling $\mathrm{J}$ are different: cf. tables 3 and 4.

\begin{tabular}{|c|c|c|c|c|c|}
\hline & & \multicolumn{4}{|c|}{ Attributes of the dwelling } \\
\hline \multicolumn{2}{|c|}{$\begin{array}{l}\text { Characteristics of the } \\
\text { household }\end{array}$} & Occupancy status & Type & Cost & Size \\
\hline$\stackrel{\infty}{<}$ & $\begin{array}{l}\text { younger than } 30 \\
30-44 \\
45-60 \\
\text { older than } 60\end{array}$ & $\begin{array}{c}\text { Moderately important } \\
\text { Important } \\
\text { Important } \\
\text { Very important }\end{array}$ & & & \\
\hline 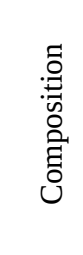 & \begin{tabular}{|l|} 
single person \\
couple \\
family \\
single-parent family
\end{tabular} & & Important & & \\
\hline 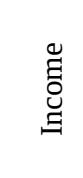 & $\begin{array}{l}\text { low } \\
\text { middle } \\
\text { high }\end{array}$ & $\begin{array}{c}\text { Moderately important } \\
\text { Important } \\
\text { Moderately important }\end{array}$ & & $\begin{array}{c}\text { Very important } \\
\text { Very important } \\
\text { Moderately important }\end{array}$ & Very important \\
\hline 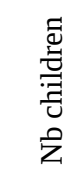 & $\begin{array}{l}\text { none } \\
1 \text { or } 2 \\
3 \text { or more }\end{array}$ & & & & $\begin{array}{l}\text { Of little importance } \\
\text { Important } \\
\text { Important }\end{array}$ \\
\hline
\end{tabular}

Table 3. Importance of attributes of current dwelling I 


\begin{tabular}{|c|c|c|c|c|c|}
\hline & & \multicolumn{4}{|c|}{ Attributes of the dwelling } \\
\hline \multicolumn{2}{|c|}{$\begin{array}{l}\text { Characteristics of the } \\
\text { household }\end{array}$} & Occupancy status & Type & Cost & Size \\
\hline$\underset{\&}{\infty}$ & \begin{tabular}{|l} 
younger than 30 \\
$30-44$ \\
$45-60$ \\
older than 60
\end{tabular} & $\begin{array}{c}\text { Important } \\
\text { Moderately important } \\
\text { Important }\end{array}$ & & & \\
\hline 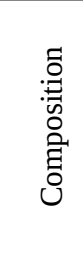 & $\begin{array}{l}\text { single person } \\
\text { couple } \\
\text { family } \\
\text { single-parent family }\end{array}$ & & $\begin{array}{l}\text { Important } \\
\text { Important } \\
\text { Important }\end{array}$ & & \\
\hline $\begin{array}{l}\stackrel{\Xi}{0} \\
\text { : }\end{array}$ & $\begin{array}{l}\text { low } \\
\text { middle } \\
\text { high }\end{array}$ & $\begin{array}{c}\text { Very important } \\
\text { Moderately important } \\
\text { Moderately important }\end{array}$ & & $\begin{array}{l}\text { Very important } \\
\text { Very important } \\
\text { Important }\end{array}$ & Very important \\
\hline 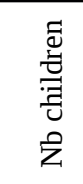 & $\begin{array}{l}\text { none } \\
1 \text { or } 2 \\
3 \text { or more }\end{array}$ & & & & $\begin{array}{l}\text { Of little importance } \\
\text { Important } \\
\text { Important }\end{array}$ \\
\hline
\end{tabular}

Table 4. Importance of attributes of possible future dwelling $\mathbf{J}$

To quantify the weightings attributed to different attributes, we use the pairwise comparison of Saaty $(1977,1990)$. The importances of attributes (Table 4) are first compared pair by pair according to Table 5.

\begin{tabular}{|l|c|}
\hline \multicolumn{1}{|c|}{ Pair comparison } & Weighting $\boldsymbol{~}_{\mathbf{A B}}$ \\
\hline A and B are of equal importance & 1 \\
\hline A is slightly more important than B & 3 \\
\hline A is moderately more important than B & 5 \\
\hline A is clearly more important than B & 7 \\
\hline Intermediate values & $2,4,6$ \\
\hline
\end{tabular}

Table 5. Weightings associated to the importance of an attribute A compared to the importance of an attribute $B$ 
Table 6 gives an example of determining the relative weighting of three criteria $(\mathrm{X}, \mathrm{Y}, \mathrm{Z})$ by pairwise comparison. Because criterion $\mathrm{X}$ has less weight than criterion $\mathrm{Y}, \mathrm{X}$ is given the weighting $\omega_{\mathrm{XY}}=\left[1 / \omega_{\mathrm{YX}}\right]$.

\begin{tabular}{|l|l|l|}
\hline \multicolumn{1}{|c|}{$\begin{array}{c}\text { Weighting of one criterion compared } \\
\text { to another }\end{array}$} & \multicolumn{1}{|c|}{$\begin{array}{c}\text { Weighting for the first } \\
\text { criterion compared to the } \\
\text { second }\end{array}$} & $\begin{array}{c}\text { Weighting for the second } \\
\text { criterion compared to the } \\
\text { first }\end{array}$ \\
\hline $\mathrm{Y}$ has a slightly higher weighting than $\mathrm{X}$ & ${ }^{\omega_{\mathrm{YX}}}=3$ & ${ }^{\omega_{\mathrm{XY}}}=1 / 3$ \\
\hline $\begin{array}{l}\mathrm{Z} \text { has a weighting equal to or slightly } \\
\text { greater than } \mathrm{X}\end{array}$ & ${ }^{\omega_{\mathrm{ZX}}}=2$ & ${ }^{\omega} \mathrm{XZ}=1 / 2$ \\
\hline $\mathrm{Y}$ has a slightly higher weighting than $\mathrm{Z}$ & ${ }^{\omega_{\mathrm{YZ}}=3}$ & ${ }^{\omega_{\mathrm{ZY}}=1 / 3}$ \\
\hline
\end{tabular}

Table 6. Example of determining the relative weighting of three criteria $(\mathrm{X}, \mathrm{Y}, \mathrm{Z})$ by pairwise comparison

From this table, a matrix comparing weightings is created ((X, Y, Z) in lines and in columns; $\left.\omega_{\mathrm{XX}}=\omega_{\mathrm{YY}}=\omega_{\mathrm{ZZ}}=1\right)$.

$$
\left[\begin{array}{ccc}
1 & 1 / 3 & 1 / 2 \\
3 & 1 & 3 \\
2 & 1 / 3 & 1
\end{array}\right]
$$

The calculation of the eigenvector for this matrix gives the weight $\omega$ to each criterion: $\omega_{X}=0.16, \omega_{Y}=0.59$ and $\omega_{Z}=0.25$. In certain cases, rather than the weight $\omega$ of each criterion, we use the weight $\mathrm{w}$ corresponding to the eigenvector values multiplied by the number of attributes considered (equal to 3 in the above example) (cf. section 3.3), which gives: $\mathrm{wX}=0.48, \mathrm{w} Y=1.77$ and $\mathrm{wZ}=0.75$.

Values of appreciation and weighting intervene jointly in the evaluation of a given attribute of a dwelling $\mathrm{D}$. Taking the example of the attribute $\lambda$ (housing type: house or flat) of dwelling $D_{\text {I }}$ for a young household $\left(a_{1}\right)$ with one or two children $\left(c_{2}\right)$ : for a young household $\left(a_{1}\right)$, living in a house rather than a flat is not of great importance, but, given the presence of children $\left(c_{2}\right)$, the importance given to living in a house is quite high. Thus: $\mathrm{w}_{\mathrm{a} 1}\left(\mathrm{D}_{\mathrm{I}} \lambda\right)<\mathrm{w}_{\mathrm{c} 2}\left(\mathrm{D}_{\mathrm{I}} \lambda\right)$. The satisfaction gained from living in a house $\left(\lambda_{1}\right)$ will thus arise from the number of children in the household and not its age: $\mathrm{s}_{\mathrm{H}}\left(\mathrm{D}_{\mathrm{I} \lambda 1}\right)=\mathrm{A}_{\mathrm{Hc}}\left(\mathrm{D}_{\mathrm{I} \lambda 1}\right)$.

If, on the other hand, the household had attributed as much importance to attribute $\lambda$ because of its age $a_{1}$ as because of the number of children $c_{2}$, in other words $w_{a 1}\left(D_{I} \lambda\right)=w_{c 2}\left(D_{I} \lambda\right)$, then attribute $\lambda_{1}$ of the dwelling would have been judged according to the characteristics with the lowest appreciation: $\mathrm{s}_{\mathrm{H}}\left(\mathrm{D}_{\mathrm{I} \lambda 1}\right)=\operatorname{MIN}\left[\mathrm{A}_{\mathrm{Ha} 1}\left(\mathrm{D}_{\mathrm{I} \lambda 1}\right), \mathrm{A}_{\mathrm{Hc} 2}\left(\mathrm{D}_{\mathrm{I} \lambda 1}\right)\right]$.

\subsubsection{Appreciation and weighting of the attributes of residential environment}

In contrast to dwellings, values for the appreciation of the residential environment are identical for all households, with two exceptions (see Figure 7). In the same way, the household appreciation functions in relation to the attributes of the future residential environment and for its current residential environment are identical. It is the importance given in one case or another to each attribute that generates a difference in appreciation. For example, the variables characterising access to local amenities are less important in the choice of a new residential location $\left[\mathrm{E} \mid \mathrm{D}_{J}\right]$ than those determining satisfaction with the current 
residential environment $\left[E \mid D_{I}\right]$. The weightings of the attributes of the residential environment of current dwelling I and of possible future dwelling $J$ are presented in Appendix 2. They are quantified using the same pairwise comparison as that used for calculating the weightings of dwelling attributes.

In the composition of residential environments, two types of facilities are distinguished according to how often people potentially use them: facilities that are used daily -shops and services (butchers, bakers, schools, newsagents and super- or hypermarkets), parks and squares; facilities that are used weekly- shops and services (car repairs, hypermarketssupermarkets, doctors, mini-markets, pharmacists, post-offices, cafés) and countryside (urban boundary).

A distance threshold of $400 \mathrm{~m}$ for evaluating the accessibility to shops and services used daily corresponds to thresholds found in the literature, in particular (Kweon et al 2010; Handy et al, 2005; Cao et al 2009; Föbker et al., 2006; Jago et al, 2005; Forsyth et al., 2008; Hoshino, 2010). The distance threshold of $2 \mathrm{~km}$ for evaluating the accessibility to shops and services used weekly is mainly based on the empirical knowledge of experts (people working in French local or national planning agencies), who usually consider a maximum distance of $2 \mathrm{~km}$ an acceptable commuting distance by bike. Distances are calculated as the crow flies.

As far as the urban boundary is concerned $\left[E_{u b} \mid D\right]$, a household will be willing to make a much longer trip to reach it if the car is used in preference to public transport, cycling or walking. The urban boundary is defined as the envelope (limit) of different built-up zones present in the study area. Certain built-up zones can be very spread out, corresponding to the central urban area of an agglomeration. Other built-up areas can be very small, in the case for example of small groupings of houses at the edge of a town. In MobiSim, the envelope of each built-up zone is identified using the method presented in Tannier et al. (2011). For the urban area of Besançon, this method identifies a threshold of $276 \mathrm{~m}$ as the maximum distance between buildings defined as belonging to the same built-up zone: all buildings within $276 \mathrm{~m}$ of each other are regarded as being part of the same built-up zone.

As far as landscape quality variables for the residential environment are concerned, studies carried out in a periurban sector of Besançon have quantified the role played by certain features of the landscape in personal residential satisfaction (Youssoufi and Foltête, 2013). A thousand households were questioned about their degree of satisfaction with the landscape, and the study revealed the importance attributed by individuals to the amount of woodland within $1700 \mathrm{~m}$ of their home and to the amount of residential buildings within a distance of a $100 \mathrm{~m}$. The presence of woodland is viewed positively, but the presence of other housings is viewed negatively. An important point to bear in mind is that satisfaction in relation to landscape features does not depend on social class. 

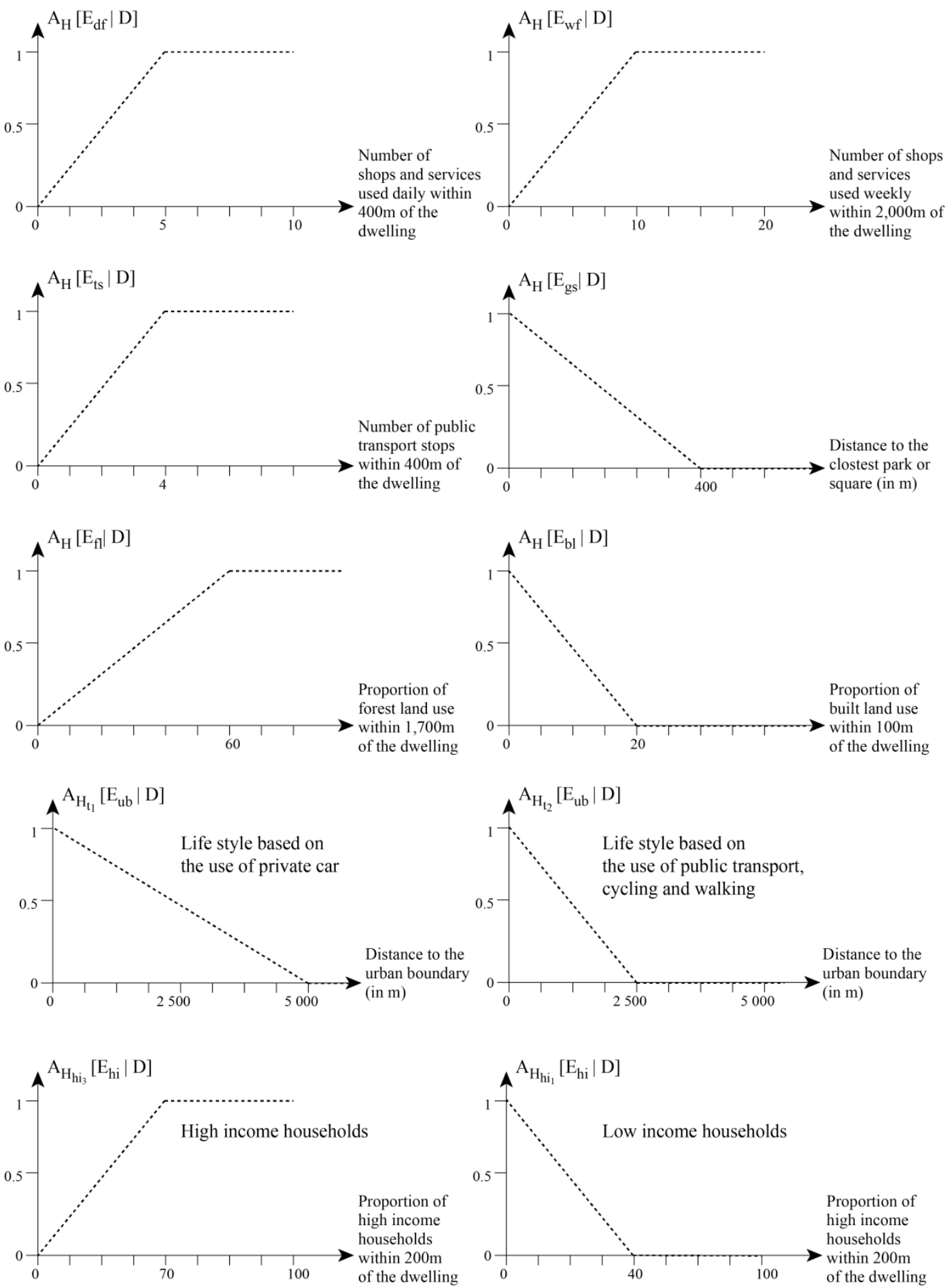

Figure 7. Appreciation of local residential environment attributes 


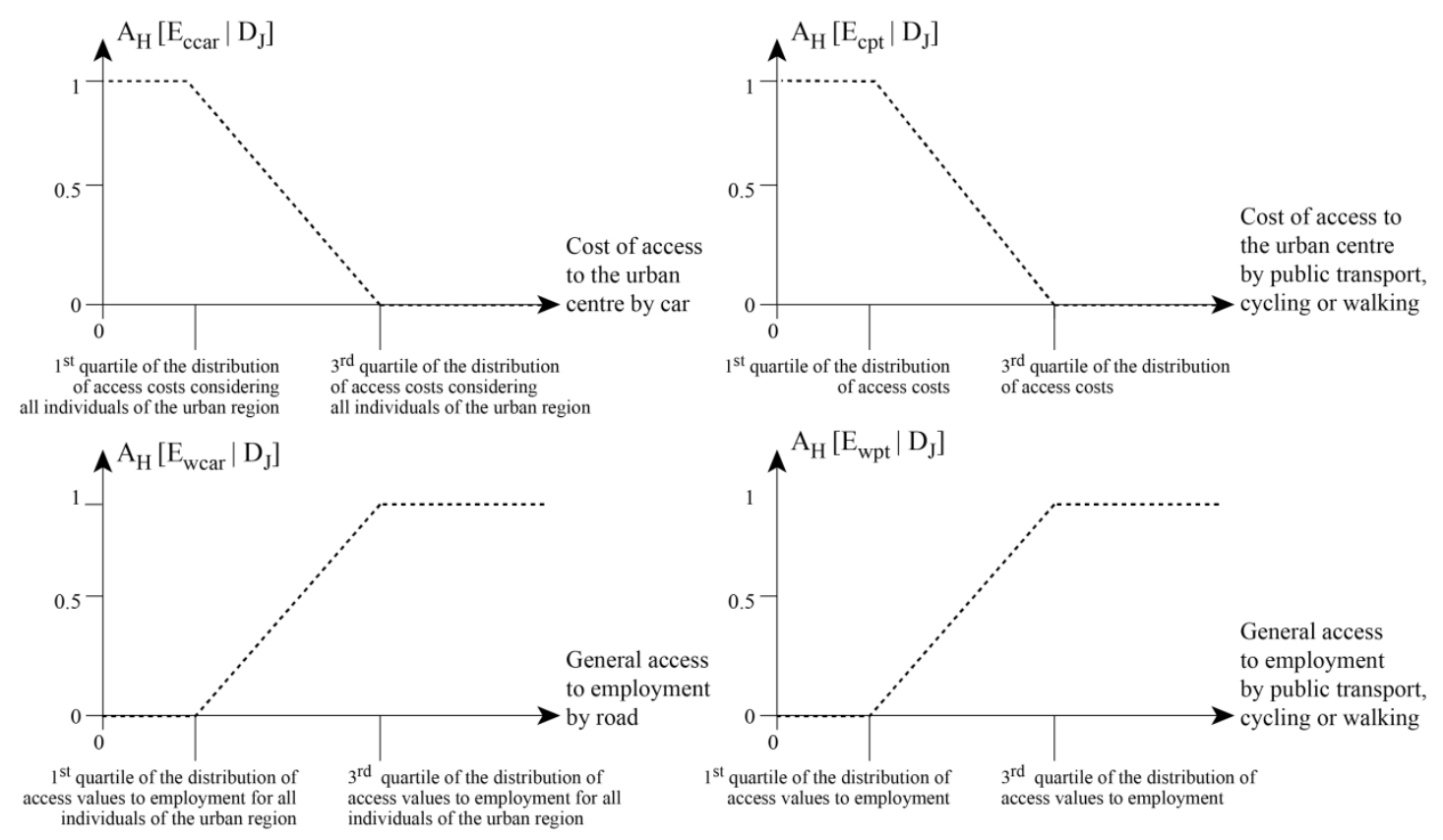

Figure 8. Appreciation of the attributes of the overall residential environment

The rules for the appreciation of variables characterising the overall residential environment (cost of access to the urban centre by car $\left[\mathrm{E}_{\text {ccar }}[\mathrm{D}]\right.$ or by public transport, cycling or walking $\left[\mathrm{E}_{\mathrm{cpt}} \mathrm{D}\right]$; general access to employment by road [ $\mathrm{E}_{\mathrm{wcar}}[\mathrm{D}]$ or using the public transport network $\left.\left[E_{\mathrm{wpt}} \mid \mathrm{D}\right]\right)$ are fixed in relation to the accessibility of all individuals in the study area in its initial state. The minimum and maximum values of appreciation functions correspond, respectively, to the first and third quartiles of the distribution of access costs calculated from simulated daily mobility levels at the outset of the simulation (Figure 8).

\subsection{Satisfaction and interest of a household $\mathbf{H}$ for residential locations $\mathbf{I}$ and $\mathbf{J}$}

The objective here, is to formalise the satisfaction that each household gains from its dwelling and its current residential environment I, as well as the interest held for each potential future residential location J (Figure 9).

\subsection{1 $\mathrm{S}_{\mathrm{H}}(\mathrm{I})$ : residential satisfaction of the household $\mathrm{H}$ in its current location $\mathrm{I}$}

The current residential satisfaction of a household at time t, has two aspects: satisfaction with the residential environment $S_{H}\left[E \mid D_{I}\right]$ and satisfaction with the dwelling $S_{H}\left(D_{I}\right)$ (Figure 9). The main motivations for moving are in reality subject to a degree of variation, but are generally linked to the characteristics of a dwelling (size and comfort), the desire to move from a flat to a house, the desire to purchase a dwelling, and, finally, the desire to leave a currently poor residential environment (Dieleman et Mulder, 2002; Onaka et Clark, 1983; van Ommeren et al., 1999). These arguments are the basis for giving a weighting of 0.6 to the dwelling and 0.4 to the residential environment.

Current household satisfaction with a dwelling $S_{H}\left(D_{I}\right)$

Household satisfaction for a current dwelling corresponds to the dwelling attribute that is the least satisfying taking into account its appreciation and the weight attributed to it by the 
household (Yager, 1977). Reminder: according to the type of household, only certain dwelling attributes enter into the calculation of dwelling satisfaction (cf. section 3.2.1).

Current household satisfaction with a residential environment $S_{H}\left[E \mid D_{I}\right]$

This is calculated from the average of the values given to the appreciation of attributes in the residential environment weighted by the weight $\omega$ of each attribute. Thus, it is assumed that certain negative aspects of the household residential environment are balanced by other positive aspects.

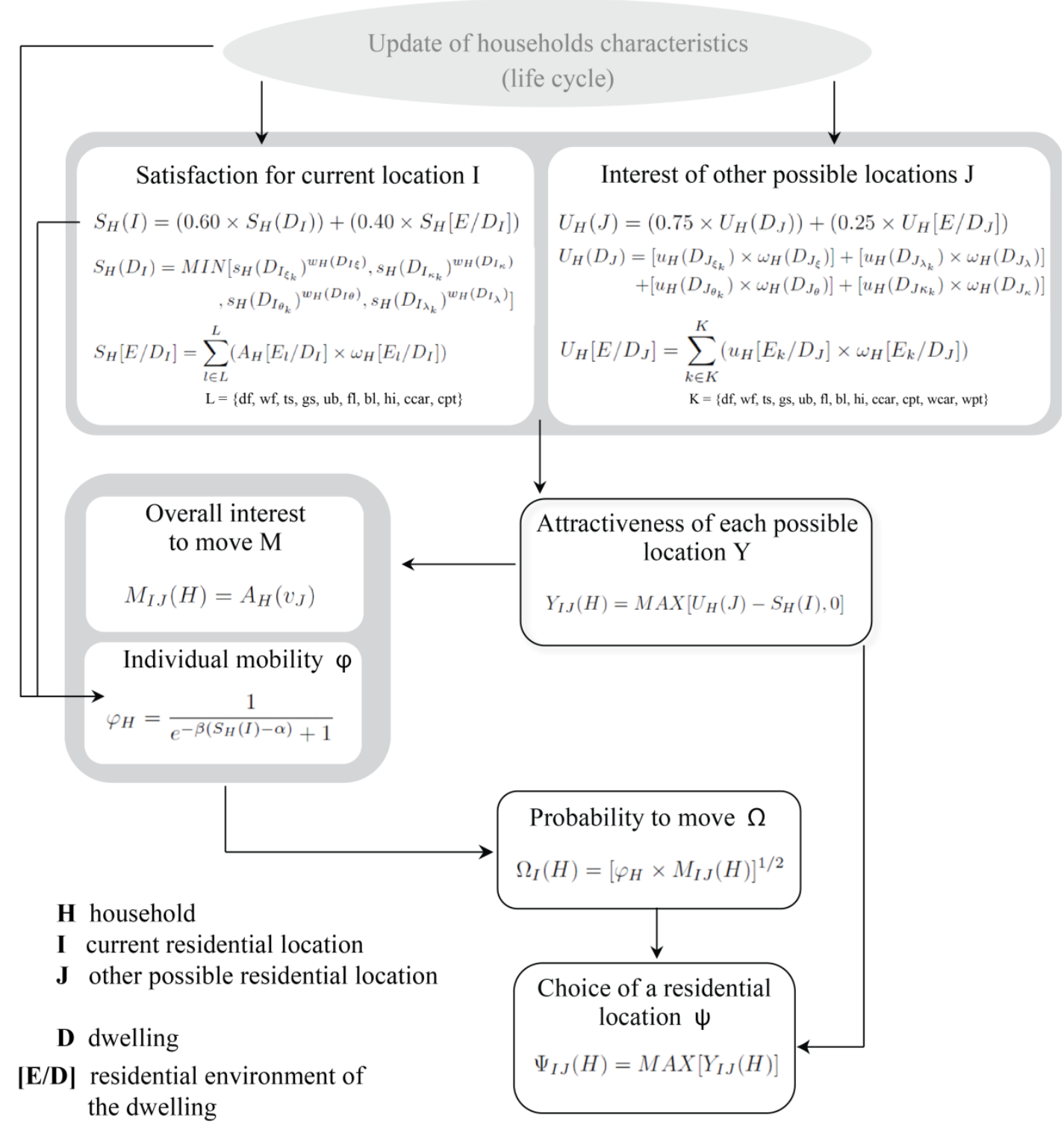

Figure 9. Formalisation of the model

\subsubsection{Interest $U_{H}(J)$ of residential destination $J$ for the household $H$}

The interest for the residential location $\mathrm{J}$ for household $\mathrm{H}$ is a measure of what the household could gain, what it could experience in the location $\mathrm{J}$ which is different to what it currently experiences. This calculation of interest uses the same individual characteristics and the same dwelling attributes as those used in the calculation of current residential satisfaction. The 
attributes of the residential environment taken into account are, in part, different. Moreover, the importance each household gives to the characteristics of the dwelling is higher $(0.75)$ than in the case of satisfaction (0.6). The importance given to the residential environment, on the other hand, is lower (0.25). These weightings correspond to the values generally found by studies of revealed preferences that consider, for French urban areas, the variables determining house prices (Baumont, 2009; Bénabou, 1993; Charlot et al., 2009; Décamps et Gaschet, 2013; Nguyen-Luong et Boucq, 2011; Nicolas et al., 2009).

\section{Interest $U_{H}\left(D_{J}\right)$ of the dwelling $D_{J}$ for the household $H$}

The interest of dwelling $D_{J}$ for household $H$ is calculated as the average of the appreciations given to each dwelling attributes, weighted by their weight $\omega$. Thus, it is assumed that certain negative aspects of the dwelling are balanced by other positive aspects. This cancelling effect comes into play here, but does not play a role in the calculation of overall satisfaction with the original dwelling $D_{\mathrm{I}}$. The household thus compares different potential locations $\mathrm{J}$ whereas it only evaluates a single origin I. It is assumed that the household makes a compromise between the different attributes of each possible location $\mathrm{J}$ by comparing them, whereas it makes no compromise between the different attributes of its location of origin I. Thus, household $\mathrm{H}$ has a pessimistic attitude (is demanding) in relation to its current dwelling I and an optimistic attitude towards dwellings in location J. This may seem counter-intuitive, but in this way we are modelling the fact that it is often a particularly unsatisfying attribute of a current dwelling I that will push a household to move.

\section{Interest $U_{H}\left[E \mid D_{J}\right]$ of the residential environment $E_{J}$ for the household $H$}

This value is the average of the values given to the appreciation of residential environment attributes weighted by the weights $\omega$ of each attribute. In this way, we assume that certain negative aspects of the residential environment of the household are balanced by other positive aspects. Car based access to employment $E_{\text {wcar }}$ or access by public transport $E_{\text {wpt }}$ enter into the calculation of the interest with regard to the residential environment $U_{H}\left[E \mid D_{J}\right]$ but do not enter into the calculation of satisfaction with regard to the current residential environment $\mathrm{S}_{\mathrm{H}}\left[\mathrm{E} \mid \mathrm{D}_{\mathrm{I}}\right]$.

\subsection{Push-pull attractiveness of each destination $\mathbf{Y}_{\mathrm{IJ}}(\mathrm{H})$}

$\mathrm{Y}_{\mathrm{IJ}}(\mathrm{H})$ represents the attractiveness of a given residential destination $\mathrm{J}$. It is a push-pull indicator resulting from the confrontation between the current residential satisfaction $S_{H}\left(D_{I}\right)$ and the interest of the residential destination $\mathrm{U}_{\mathrm{H}}\left(\mathrm{D}_{\mathrm{J}}\right)$. Negative values of attractiveness are excluded: when the satisfaction is higher than the interest, the attractiveness $\mathrm{Y}_{\mathrm{IJ}}(\mathrm{H})$ is equal to 0 .

\subsection{Individual mobility $\varphi_{H}$ of the household $H$}

The individual mobility $\varphi_{\mathrm{H}}$ of a household measures the individual propensity to move. It represents the moving behaviour of a household confronted with its current situation. It strongly depends on the situation of the household in the family lifecycle. Thus, we know that all sources of dissatisfaction being equal, a young household will have a greater propensity to move than an old household or one with a large family. Residential mobility, therefore, represents a relationship between the current residential satisfaction of a household $S_{H}(I)$ and its desire to move. This relationship varies according to household characteristics (age and number of children). In this way the fact that, for an equivalent level of residential satisfaction 
and independent of all other factors, old households are clearly less mobile than young or middle-aged households is represented.

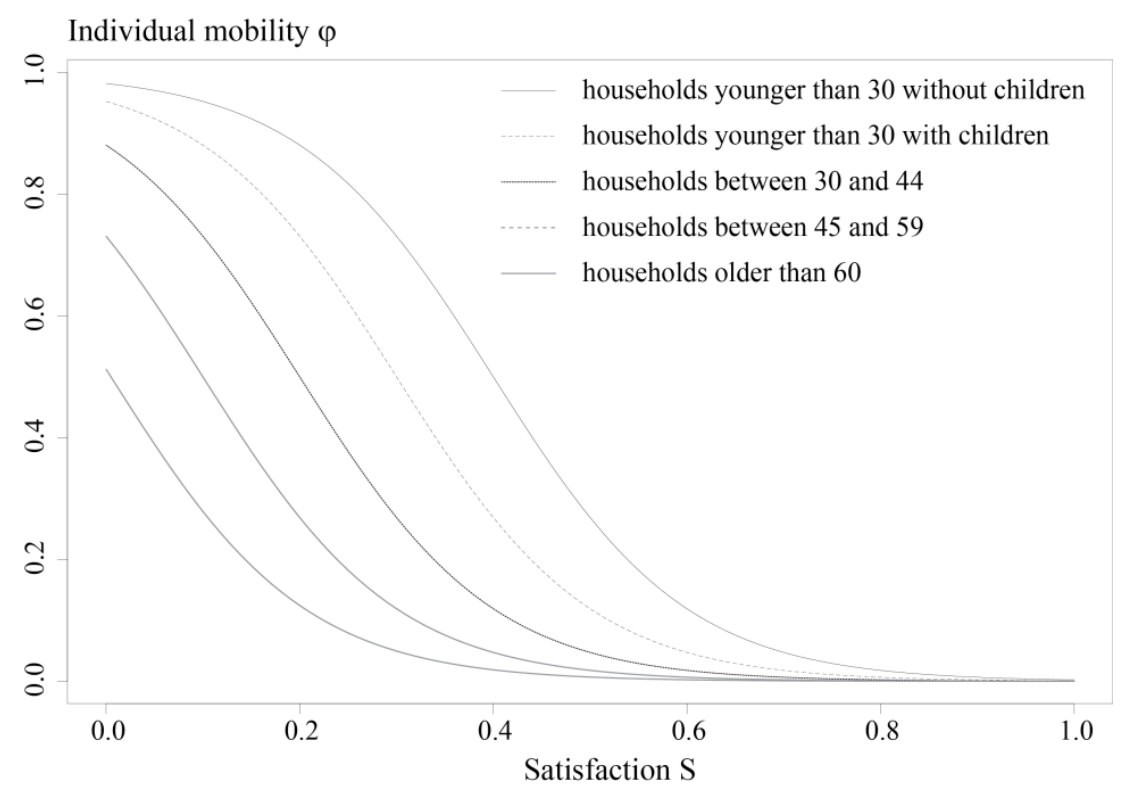

Figure 10. Relation between satisfaction $S$ and individual mobility $\varphi$

French inter-commune residential migration data (INSEE MIGCOM 2008 in which the level of inter-communal migration is calculated based on the location of households in 2003 and in 2008) allows the identification of five types of household with different levels of individual mobility; each of these five types corresponds to a different individual mobility variable $\varphi_{H}$ in the model (Figure 10). These variables have been defined by varying the parameter $\alpha$ in the calculation of $\varphi_{\mathrm{H}}$. Cf. Figure $9-\alpha$ equal to 0.4 for the most mobile households (households younger than 30 with children), 0.3 for households younger than 30 without children, 0.2 for households between 30 and 44, 0.1 for households between 45 and 49 and 0.05 for the least mobile (older than 60) -the value of parameter $\beta$ remains constant $(\beta=-10)$.

\subsection{Overall interest to move within the urban region $\mathrm{M}_{\mathrm{IJ}}(\mathrm{H})$}

The overall interest to move represents the expected benefit from moving for a given household type, in the urban region considered. It takes into account all the attractive dwellings in the urban region. The more numerous the attractive dwellings, the more chance a household will have to improve its residential satisfaction, and thus an interest in moving.

A dwelling judged "interesting" here is a vacant dwelling with an attractiveness value greater than 0 . Among the vacant attractive dwellings, only a certain number $\mathrm{n}_{\mathrm{J}}$ are known to the household (or visited). In this way the household's imperfect knowledge of the housing market is represented. The median of attractiveness values $\mathrm{vJ}$ is calculated for the $\mathrm{n}_{\mathrm{J}}$ known dwellings. The overall interest to move $\mathrm{MIJ}_{\mathrm{J}}(\mathrm{H})$ corresponds to the appreciation of the value $\mathrm{v}_{J}$ for household $\mathrm{H}$ with respect to attractiveness values $\mathrm{Y}_{\mathrm{IJ}}$ of all the households in the urban area. If the median attractiveness value $\mathrm{vJ}$ of $\mathrm{nJ}$ dwellings known to the household is high, then the appreciation will be good (close to 1) and will represent a strong interest to move; otherwise it will be poor (close to 0 ) and the overall interest to move will be low. The calibration of the model allows the value $\mathrm{v}_{\mathrm{J}}$ to be fixed in such a way that the variable $\mathrm{M}_{\mathrm{IJ}}(\mathrm{H})$ is equal to 1 (cf. section 4.5). 


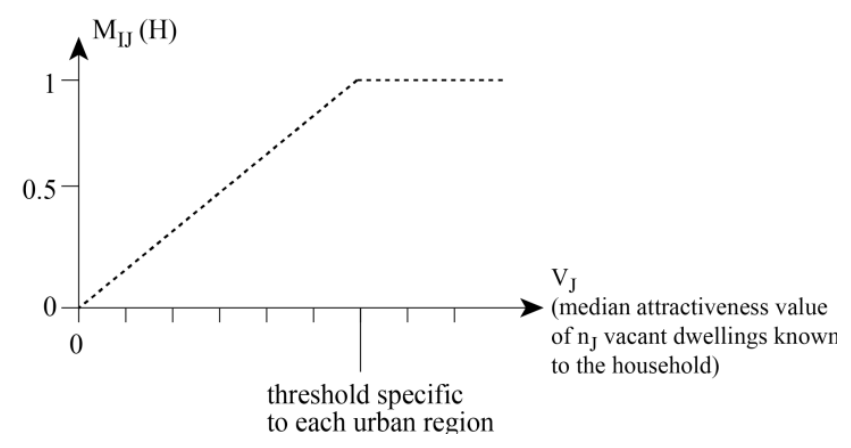

Figure 11. Variable defined for the calculation of the overall interest to move

\subsection{Probability to move $\Omega_{\mathrm{I}}(\mathrm{H})$}

The probability to move of a household is crucial in our model. It represents unknowns that play a role in the choice to move, in addition to the known choices. Since these are unknowns; they can only be estimated. This probability depends jointly on two independent terms: the overall interest to move $\mathrm{M}_{\mathrm{IJ}}(\mathrm{H})$ and the individual mobility $\varphi_{\mathrm{H}}$. A household is thus more or less pushed to leave location I and at the same time more of less attracted by a group of other known locations $J$ (but not by a specific $J$ ). Because we consider the satisfaction with the current dwelling I through $\varphi_{\mathrm{H}}$ and the global interest of possible destinations $J$ via $\mathrm{M}_{\mathrm{IJ}}(\mathrm{H})$, the probability to move $\Omega_{\mathrm{I}}(\mathrm{H})$ is a combined push and pull variable.

The values $\Omega_{\mathrm{I}}(\mathrm{H})$ (probability of the household $\mathrm{H}$ to leave I) and 1- $\Omega_{\mathrm{I}}(\mathrm{H})$ (probability of the household $\mathrm{H}$ to stay in I) define the probability mass function of the events "moving" and "not moving". On this basis, the computer application makes a Random Drawing according to the defined probability mass function, which determines the realization of one of the two events.

As far as this formalisation is concerned, a household for which the highest attractiveness of a residential destination is very low may still move while a household for which the highest attractiveness of a residential destination is very high may nevertheless not move.

\subsection{Choice of a residential destination $\Psi_{I J}(\mathrm{H})$}

Once a household moves, it chooses its new residential location. For this, it simply identifies the most attractive location $\mathrm{J}$ among the $\mathrm{nJ}$ dwellings visited with respect to its actual location I.

\section{Quantification of variables for the 'Business as usual' scenario}

This quantification is an important stage in the experiment: the values must be realistic in order for the results of the simulation to be useful for planning and at the same time fixed using a consistent and reproducible protocol to be acceptable to researchers.

The 'Business as usual' scenario simply extends existing trends from 2010 to 2030. The initial situation in 2010 is defined using socio-economic data characterizing individuals, households and dwellings at the level of neighbourhoods (in intra-urban zones) and communes (in 
periurban zones) (Source data: INSEE population census, 2009). These data are used to generate an artificial population of individuals and dwellings. Individuals are grouped into households and located into dwellings in accordance with the statistical data distribution at the scale of neighbourhoods and communes.

Very detailed cartographic data (vectorial maps) are used to represent the spatial configuration of the study area in 2010:

- existing buildings, characterised by their use (residential, industrial, commercial or other), are represented as polygons (BD Topo® IGN, 2010);

- areas where building is not permitted are also represented as polygons: protected countryside areas and groundwater protection areas (Source : DREAL, 2009), steeply sloping areas (BD Topo DEM® ${ }^{\circledR}$ IGN, 2010), bodies of water (BD Topo ${ }^{\circledR}$ IGN, 2010), flood zones (Ministère de l'Écologie, du Développement Durable et de l'Énergie http://cartorisque.prim.net/, accessed August 2012);

- parks and squares equate to green spaces greater than $2500 \mathrm{~m}^{2}$ in area (to exclude private gardens) identified in the layer "Vegetation" of the BD Topo IGN 2010. Only green spaces within the built-up area are considered as parks and squares;

- the network of roads and paths (lines - BD Topo® IGN, 2010) includes the functional characteristics of the segments (capacity, speed restriction, traffic direction, sinuosity, slope); the bypass known as "les Mercureaux" has been included although in reality it only opened to traffic in 2011;

- the public transport network (bus, tram and local trains) is represented by stops (points) linked to their timetables (data entered manually from plans supplied by the intercommunal authority of the Greater Besançon area).

- economic activities (factories, shops, services etc.) correspond to establishments in the SIRENE INSEE database 2012 (geolocated to postal address for this study), classified according to activity type and number of employees.

Using existing (cartographic) or simulated data (simulated population of individuals, households and dwellings), dwellings and economic activities were associated with the buildings. The daily individual mobility simulation model was then calibrated for this initial state using data from the urban mobility survey 2004/2005 (Grand Besançon, INSEE, CERTU method).

The changes integrated into MobiSim for the 'Business as usual' scenario for each year of the simulation, from 2011 to 2030, are as follows:

- trend based simulated demographic change;

- household characteristic changes (age, number of children, and composition). Household income changes endogenously through the change in the composition of the households (unions, separations, births, deaths) but the income of individuals does not change. Household lifestyles change endogenously according to changes in their residential environment (urban or rural) and/or changes in the preferred transport mode (car or public transport, bike and foot);

- changes in housing supply (residential development);

- fuel price increases;

- introduction of the tram in 2015, changes in the bus network and creation of two new rail stops. 
Certain variables remain unchanged during the simulation:

- the number and location of jobs, shops and services does not change;

- the calculation of housing costs is based on the observation of the outcomes of the housing market as it is now;

- household choices in relation to housing and daily mobility behaviour remain unchanged throughout the simulation.

\subsection{Variable settings for the residential migration model}

\section{Household income $\mathbf{H}_{\mathbf{y i}}$}

The distribution of all household incomes at the outset of the simulation gives a first quartile at 16,944 euros and a third quartile at 35,973 euros. On this basis, household incomes are divided into three classes as follows: low income: less than 16,944 euros $\left(\mathrm{y}_{1}\right)$; middle incomes: from 16,944 to 35,973 euros ( $\left.\mathrm{y}_{2}\right)$; high income: over 35,973 euros $\left(\mathrm{y}_{3}\right)$.

\section{Housing costs}

To quantify the parameter $\delta$ used in the calculation of housing costs, we have used the database www.meilleursagents.com (accessed December 2013). This database allowed us to identify three housing price levels for Besançon:

low housing price: below 1660 euros per $\mathrm{m}^{2}$;

medium housing price: between 1660 and 1850 euros per $\mathrm{m}^{2}$;

high housing price: over 1850 euros per $\mathrm{m}^{2}$.

The function $\mu$ (cost|neighbourhood) (cf. Figure 3) sets housing costs according to the social neighbourhood. The median income of all households within $200 \mathrm{~m}$ of each dwelling is calculated for the simulated year 2011. The third quartile of this distribution of median household incomes is 31260 euros. Above this value the dwelling is considered as being situated in a socially advantaged neighbourhood.

\section{Appreciation of the overall residential environment}

The simulation of daily mobility at the model's initial state allowed us to fix the values of the thresholds corresponding to the 1st and 3rd quartiles of the distributions of access costs for all individuals in the study area (Figure 12).
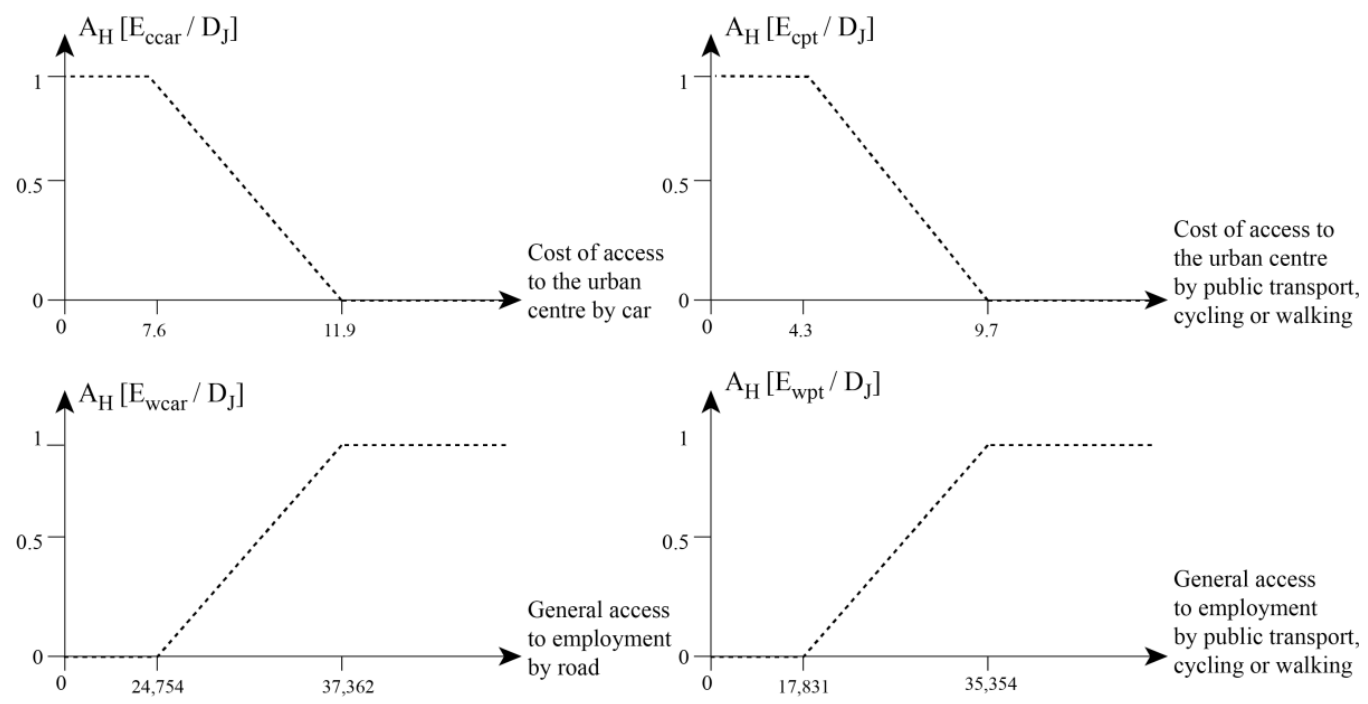

Figure 12. Settings for the appreciation of attributes of the overall residential environment 


\section{Overall interest to move $\mathbf{M}_{\mathrm{IJ}}(\mathrm{H})$}

The number n $\mathrm{J}$ of dwellings visited by each household is fixed at 30 . The value of the variable $\mathrm{M}_{\mathrm{IJ}}(\mathrm{H})=1$ is the median of the distribution of attractiveness values $\mathrm{Y}_{\mathrm{IJ}}(\mathrm{H})$ for all households in the agglomeration at the outset of the simulation, which is 0.12 for the agglomeration of Besançon in 2010 (Figure 13).

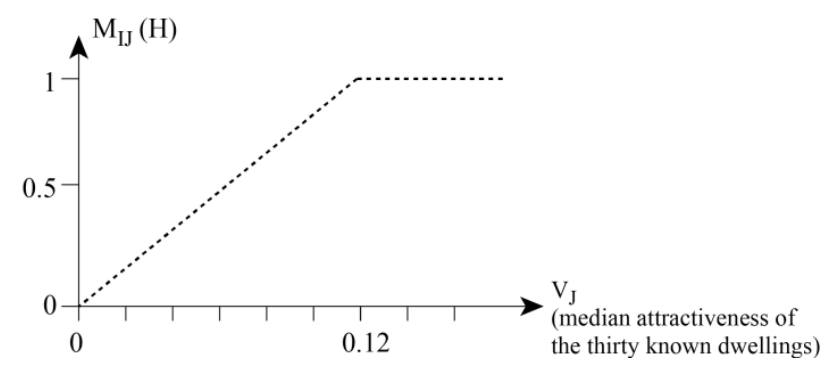

Figure 13. Quantification of the variable for calculating the overall interest to move $\mathbf{M}_{\mathrm{IJ}}(\mathbf{H})$

\subsection{Setting values for residential development}

The settings chosen relate to the recommendations in the SCoT (Territorial Coherence Framework, 2011) and the PLH (Local Housing Plan, 2010). For the whole area, 850 dwellings are built a year; of these 35\% are houses and 65\% are flats. Houses have 5 or more rooms. Flat sizes are divided as follows: $10 \%$ one room, $20 \%$ two rooms, $25 \%$ three rooms, $25 \%$ four rooms and $20 \%$ five (or more) rooms. The distribution according to dwelling type is shown in the table 7.

\begin{tabular}{llr} 
Dwelling type & Occupancy status & \\
\hline house & owner-occupier & $35 \%$ \\
& private renter & $8 \%$ \\
& social renter & $0 \%$ \\
\hline \multirow{2}{*}{ flat } & owner-occupier & $20 \%$ \\
& private renter & $21 \%$ \\
& social renter & $16 \%$ \\
\hline & TOTAL & $\mathbf{1 0 0 \%}$
\end{tabular}

Table 7. Distribution according to type of dwelling and occupancy status

At the local level, 500 dwellings are built each year within the city of Besançon; 350 dwellings are built each year in periurban zones distributed in proportion to the population of each 'commune' in 2010. In the city of Besançon, 14\% of dwellings are houses and 86\% are flats. Outside Besançon city, 100\% of dwellings constructed in very small communes are houses, compared to $90 \%$ in small communes, $86 \%$ in medium-sized communes and $80 \%$ in medium-sized communes appropriate for social housing construction. 


\subsection{Other settings}

\subsubsection{Demographic changes}

Within MobiSim demographic changes are simulated using a microsimulation model (Figure 1). Demographic microsimulation models can simulate the renewal of socio-economic characteristics of a sample of individuals and households over the long term, using a combination of deterministic behavioural rules and random selection. This approach favours individual heterogeneity over the idea of the representative individual (Bonnet et al. 1999). The first demographic microsimulation model was DYNASIM (Orcutt et al. 1976), and this type of model was widely adopted (van Imhoff and Post 1997; Murphy 2003; Holm et al. 2006; Zaidi and Rake 2001; Morand et al. 2010; Ravulaparthy and Goulias 2011; Chingcuanco and Miller 2013). The principal difference between the different types of demographic model resides in the level of disaggregation used when applying probabilities. Certain models consider individuals (Wegener 1985; Chingcuanco and Miller 2013), while others only consider households (Cornelis et al. 2012). In all cases, the microsimulation involves disaggregated data inputs for the model and generates disaggregated output data.

The demographic microsimulation model used in MobiSim is a retake on INSEE's Destinie model (Bonnet et al. 1999). The unit of reference is the individual: individual changes are modelled and, through the links between individuals, household changes are generated. The demographic events modelled in MobiSim were chosen on the basis of their impact on household residential needs:

- ageing,

- leaving the parental home,

- forming a couple,

- separation of a couple,

- birth,

- death.

Migration (entering and leaving the area) is also incorporated, in order to simulate the general population dynamics in the area.

All probabilities are applied to individuals with the exception of separation probabilities which are applied to "couples", affecting both individuals in a household in the same way, and migration probabilities which are applied to households. The simulations are iterative: the probabilities are applied to each agent (individual or household according to the event simulated) according to their situation at the end of the previous iteration to update their situation at the next iteration. Table 8 summarises the different demographic events modelled in MobiSim.

\begin{tabular}{|l|l|l|l|l|}
\hline Event & $\begin{array}{c}\text { Factor determining } \\
\text { the event }\end{array}$ & Formalisation & $\begin{array}{c}\text { Impact on the } \\
\text { household }\end{array}$ & \multicolumn{1}{|c|}{ Data used } \\
\hline Birth & $\begin{array}{l}\text { Age of mother, } \\
\text { number of children }\end{array}$ & Probability & $\begin{array}{l}\text { Modification of } \\
\text { characteristics }\end{array}$ & $\begin{array}{l}\text { Family history survey } \\
\text { (1999 - INSEE) }\end{array}$ \\
\hline Death & Age & Probability & $\begin{array}{l}\text { Change or } \\
\text { removal }\end{array}$ & $\begin{array}{l}\text { Death rates (2008 - } \\
\text { INSEE) }\end{array}$ \\
\hline
\end{tabular}




\begin{tabular}{|l|l|l|l|l|}
\hline $\begin{array}{l}\text { Leaving } \\
\text { home }\end{array}$ & Age & Probability & Change & Ad hoc calibration \\
\hline $\begin{array}{l}\text { Couple } \\
\text { creation }\end{array}$ & $\begin{array}{l}\text { Marital status, sex, } \\
\text { age, age at end of } \\
\text { studies }\end{array}$ & $\begin{array}{l}\text { Probability and minimisation of } \\
\text { difference between age and age at } \\
\text { the end of studies for members of } \\
\text { a couple }\end{array}$ & $\begin{array}{l}\text { Creation of a } \\
\text { household }\end{array}$ & $\begin{array}{l}\text { Family history survey } \\
\text { (1999 - INSEE) }\end{array}$ \\
\hline Separation & $\begin{array}{l}\text { Marital status, } \\
\text { duration of union }\end{array}$ & Probability & $\begin{array}{l}\text { Change and } \\
\text { creation }\end{array}$ & $\begin{array}{l}\text { Divorce rates 2009 } \\
\text { (INSEE) }\end{array}$ \\
\hline In-migration & $\begin{array}{l}\text { Marital status, age of } \\
\text { household } \\
\text { representative }\end{array}$ & Probability & $\begin{array}{l}\text { Duplication of } \\
\text { an existing } \\
\text { household }\end{array}$ & $\begin{array}{l}\text { Inter-communal } \\
\text { migration MIGCOM } \\
\text { (2008 - INSEE) }\end{array}$ \\
\hline $\begin{array}{l}\text { Out- } \\
\text { migration }\end{array}$ & $\begin{array}{l}\text { Marital status, age of } \\
\text { the household } \\
\text { representative }\end{array}$ & Probability & $\begin{array}{l}\text { Removal of a } \\
\text { household }\end{array}$ & $\begin{array}{l}\text { Intercommunal } \\
\text { migration MIGCOM } \\
\text { (2008 - INSEE) }\end{array}$ \\
\hline
\end{tabular}

Table 8. Demographic events modelled in MobiSim

In the context of this trial, we use the demographic change simulation model to make a demographic projection by extrapolation up to 2030. Such a projection is based on a single hypothesis, that the future will be a continuation of the past. This is a strong assumption and rather risky, as we know that demographic changes are dependent on economic, social and political changes or even changes in public health, and that they can happen rapidly (Booth 2006). The main characteristic of the extrapolation is thus to continue existing tendencies without taking into account any exogenous variable, and thus the simulation makes no claim to predict future demographics.

In concrete terms, for the calibration of the model we consider that fertility, mortality and migration rates taken from the different surveys available remain constant over time. Thus, the principal trends modelled are a faster growth of household numbers than growth in population, a growth in the share of single person households and a growth in the proportion of households over 60 .

We have extrapolated the linear trends from two national censuses (INSEE) in 1990 and 2009. We are primarily interested by the total population and total number of households, as well as the numbers of different types of household (Table 9). The rate of change in the population projected over 20 years (2009-2029) is 9.09\%; the rate of change in household numbers is $25.62 \%$; the number of people per household in 2029 is 1.84. The calibration of the demographic microsimulation model allows us to come close to these values. The simulated rate of change in population over 20 years (2010-2030) is $8.84 \%$; the rate of change in household numbers is 23.34\%; the simulated number of households in 2030 is 1.86 . 


\begin{tabular}{|c|c|c|c|c|c|}
\hline & \multicolumn{2}{|c|}{ RGP INSEE } & $\begin{array}{c}\text { Annual breakdown } \\
\text { of growth } \\
1990-2009\end{array}$ & $\begin{array}{l}\text { Linear } \\
\text { projection for } \\
2029\end{array}$ & $\begin{array}{l}\text { Change simulated } \\
\text { with MobiSim for } \\
2030\end{array}$ \\
\hline Population & 161730 & 177016 & 805 & 193107 & 192668 \\
\hline Households & 63376 & 83766 & 1073 & 105229 & 103319 \\
\hline Single person households & 19924 & 36571 & 876 & 54094 & 55920 \\
\hline Couples without children & 13132 & 19343 & 327 & 25881 & 20298 \\
\hline Couples with children & 22844 & 17964 & -257 & 12827 & 15370 \\
\hline Single parent families & 5424 & 7061 & 86 & 8784 & 7974 \\
\hline Not in households & 2052 & 2825 & 41 & 3639 & 3757 \\
\hline
\end{tabular}

Table 9. Extrapolated demographic trends: projection and simulation

To generate migration in and out of the study area, the probabilities of arrivals and departures from the study area were calculated using INSEE MIGCOM 2008 data, which allows a comparison of the residential situation of households in 2003 and 2008. The first step consists of defining, for each family state, the proportion of households leaving the study area each year, and in parallel the proportion of households arriving in the study area (Table 10). These proportions were applied to the initial MobiSim artificial population (in 2010). The second stage involves the regrouping of MIGCOM data according to five year age cohorts, for each family state, so as to establish a frequency distribution of in and out-migrants by age cohort (Table 11). The MobiSim simulation of a new arrival in the agglomeration involves the duplication of an existing household in the same age cohort with same family state. A departure from the agglomeration involves the removal of a household from an age cohort and family state chosen randomly according to the probability distributions of Tables 10 and 11 .

\begin{tabular}{|l|c|c|}
\hline \multicolumn{1}{|c|}{ Type of household } & $\begin{array}{c}\text { Probability of out-migration from study } \\
\text { area }\end{array}$ & $\begin{array}{c}\text { Probability of in-migration to the study } \\
\text { area }\end{array}$ \\
\hline Single person household & 0.0322178875 & 0.0575248333 \\
\hline $\begin{array}{l}\text { Single person in shared } \\
\text { dwelling }\end{array}$ & 0.0449217238 & 0.088481443 \\
\hline Couple with children & 0.0452642276 & 0.0309270621 \\
\hline Couple without children & 0.034122983 & 0.0266178718 \\
\hline Not in a household & 0.0329353277 & 0.0824155632 \\
\hline Single parent household & 0.0195002444 & 0.0259717646 \\
\hline
\end{tabular}

Table 10. Probabilities of in- and out-migration of households for the study area according to type of household.

\begin{tabular}{|c|r|}
\hline Five year age bands & Distribution by age band \\
\hline 15 & 0.7116948616 \\
20 & 16.0679569508 \\
25 & 118.6651468244 \\
30 & 261.8274919661 \\
35 & 185,2466788835 \\
40 & 101.9706805297 \\
45 & 67.3822827444 \\
50 & 34.8904171554 \\
55 & 18.4073847574 \\
\hline
\end{tabular}




\begin{tabular}{|l|l|}
60 & 5.3361504497 \\
65 & 0.9341313264 \\
70 & 1.5748566702 \\
80 & 0.2022400875 \\
\hline
\end{tabular}

Table 11. Distribution of frequencies by age band: example of couples with children leaving the study area each year

\subsubsection{Fuel price increases}

The price of a barrel of oil used in the simulation is 78\$ (2009 dollars) in 2010 and reaches $123.2 \$$ in 2030 (projection for the reference scenario, U.S. Energy Information Administration, International Energy Outlook 2011, DOE/EIA-0484(2011)). Based on figures proposed by the consultancy ADETEC (http://www.adetec-deplacements.com/ Accessed December 2012), the real cost of using a car is $0.34 € / \mathrm{km}$; fuel costs represent $30 \%$ of this figure.

\section{Simulation results for the 'Business as usual' scenario}

MobiSim involves a series of random draws. Consequently, for multiple simulations of the same scenario, moving households are not always the same and simulation results may vary. Considering this, a stability analysis of the model has been performed for a hundred replications of the same simulated scenario (a paper dedicated to the presentation of the stability and sensitivity analysis of the model is currently in preparation). This analysis has showed that the simulation results are stable: the variation within the simulation results obtained for the hundred replications of the same simulated scenario was lower than $3 \%$ in 2030, whatever the variable considered (average residential satisfaction, number of moving households, share of migrants from the centre city to periurban areas...). Moreover, calculating the average of simulation results for only ten replications of the same scenario gives reliable results at an aggregated level (e.g. Besançon versus periurban areas or large neighbourhoods) (Hirtzel, 2015). Accordingly, results presented in the following part of the paper are based on the average of the simulation results for ten replications of the 'Business as usual' scenario on the one hand (current section), and of the 'Pro-active housing construction policy' scenario in the city of Besançon on the other hand (next section).

\subsection{Overall results}

We begin with the presentation of simulation results taking into account all households of the urban region. Figure 14 shows an annual moving rate of $18 \%$ at the initial state of the simulation, which is high compared to the rate of $13.7 \%$ in 2005 given by local data (Source: Local Housing Plan, 2005). However, this moving rate decreases in the course of the simulation and becomes stable around $15 \%$ in the simulated year 2020. Hence, the simulated moving rate seems to be realistic except for the first simulated years. 


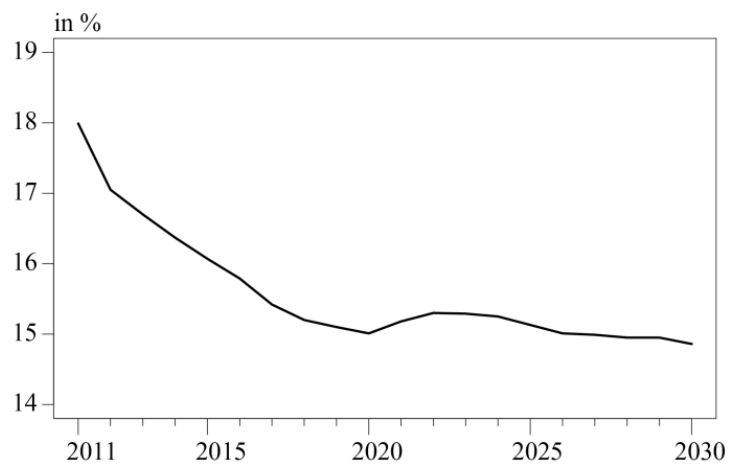

Figure 14. Scenario 'Business as usual': annual rate of households moving within the urban region
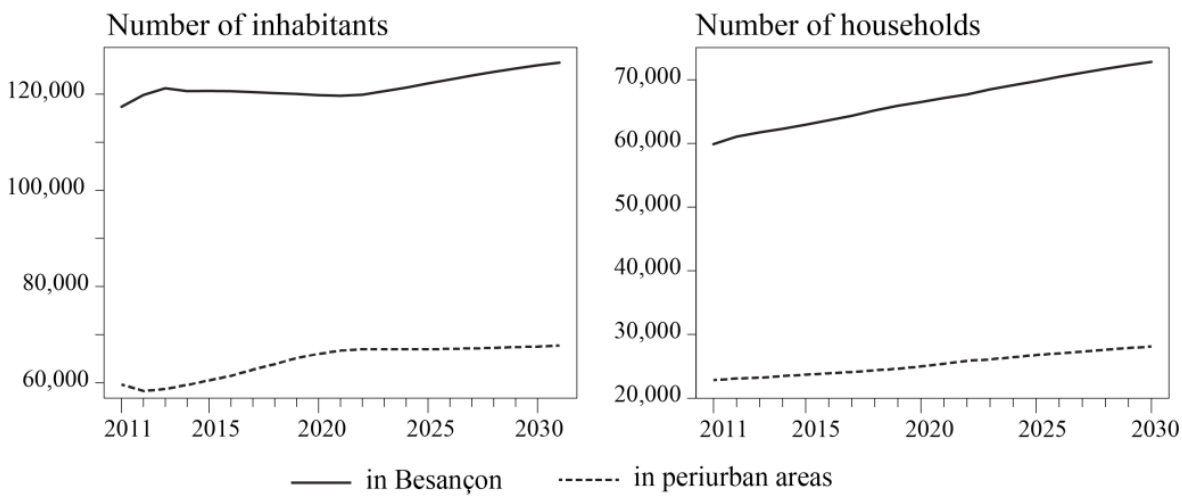

Figure 15. Scenario 'Business as usual’: evolution of the number of inhabitants and households

The number of both inhabitants and households increases in the course of the simulation in Besançon and in periurban areas (Figure 15). The number of inhabitants only increases during the first ten simulated years in periurban areas whereas it only increases during the last ten simulated years in Besançon. The number of households increases regularly during the whole simulation period. This increase is stronger for Besançon than for periurban areas.

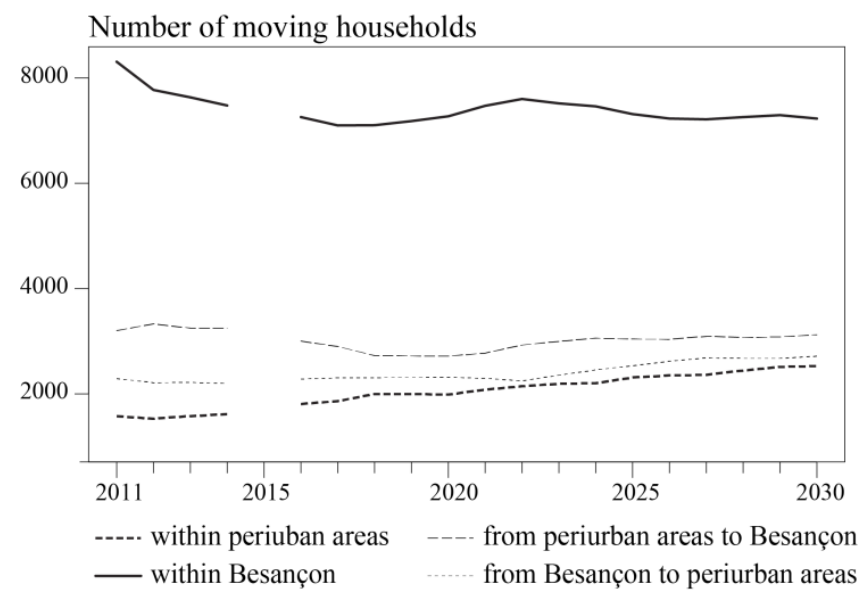

Figure 16. 'Business as usual' scenario: migration flows within the urban region. NB: the number of migrants has not been calculated for the year 2015 because of the suspension of the simulation for the introduction of the tram system at that date.

Most moves occurring each year within the urban region take place within the municipality of Besançon (Figure 16). But more households leave the periurban areas to move to Besançon than vice versa. 


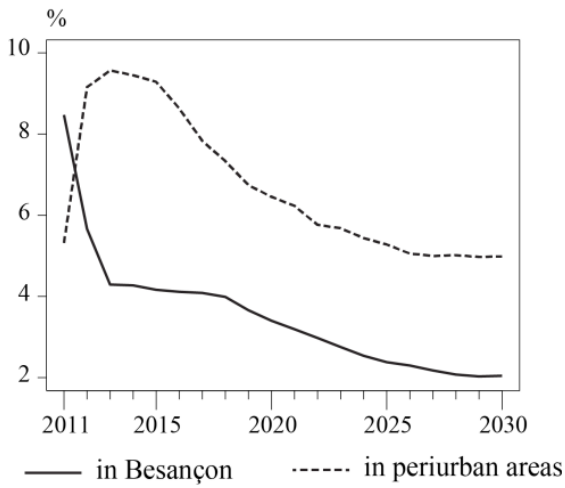

Figure 17. Scenario 'Business as usual': vacancy rates of dwellings

The vacancy rate of dwellings changes a lot during the first simulated years: it increases quite sharply in periurban areas and decreases in the same proportion in Besançon (Figure 17). Then after this peak the overall tendency is a decrease. After 2020, the vacancy rate in periuban areas is about 6\%, which reflects a situation described as 'normal' by specialists in the field: a percentage of unoccupied dwellings is necessary for the housing market to operate correctly (Source: SCoT du Grand Besançon, 2011). In Besançon, however, the simulated vacancy rate is too low, especially at the end of the simulation time but even at the beginning.

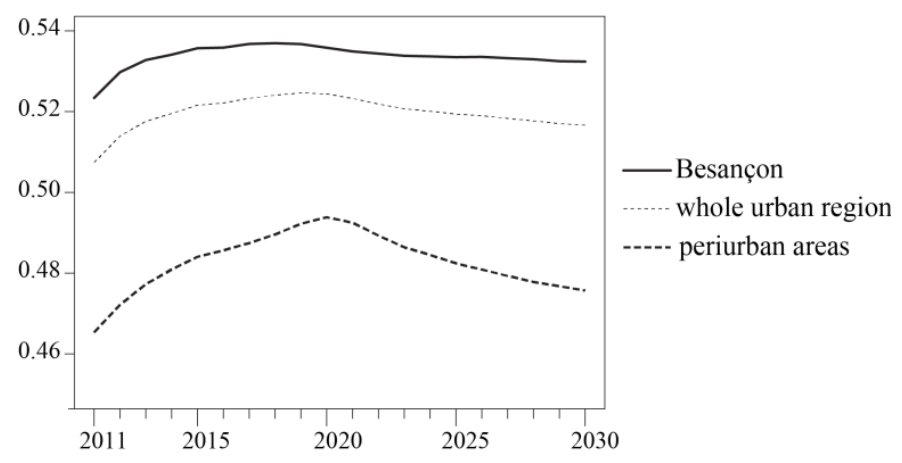

Figure 18. Scenario 'Business as usual': evolution 2011-2030 of average residential satisfaction.

Overall residential satisfaction of households is on average higher in Besançon than in periurban areas. In periurban areas, residential satisfaction increases from 2011 to 2020; then it decreases. This may result, at least partly, from the increase of fuel price. 

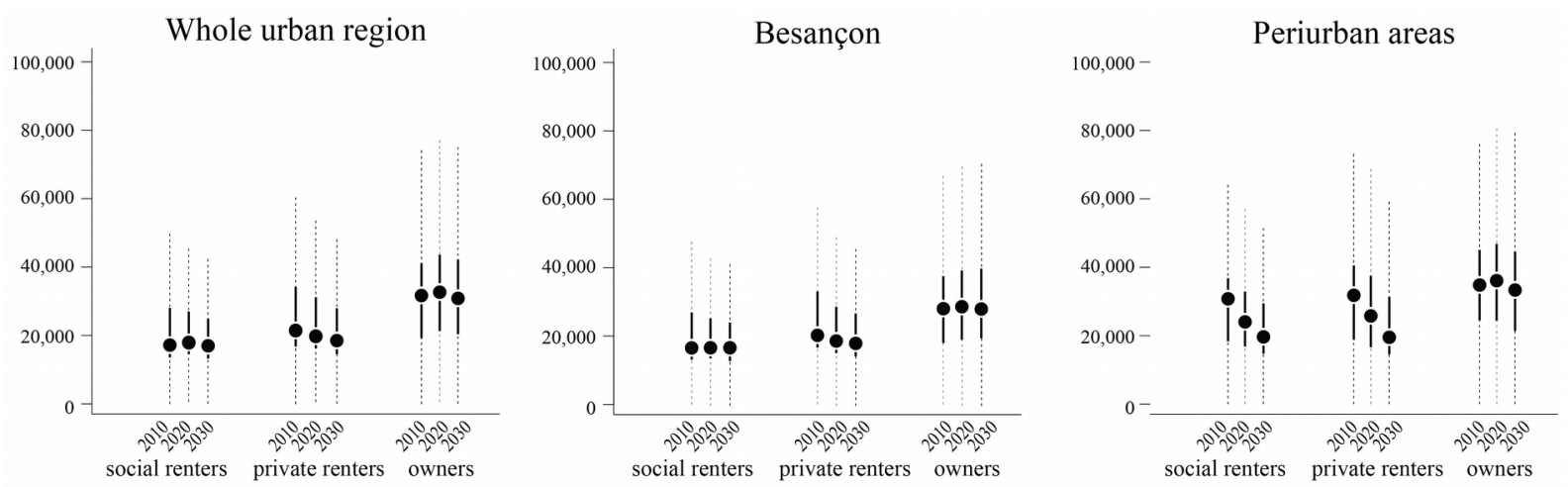

Figure 19. Scenario 'Business as usual': distribution of households' income (in euros) according to the occupancy status of their dwelling. This graphical representation of statistical measures of dispersion is inspired from E.Tufte's alternative to the classical box and whiskers plots (Tufte, 2001). The black dot represents the median; the ends of the thick lines towards the black dot are the lower and upper quartile, respectively; the ends of the dotted lines towards the borders are the minimum and maximum values unless these values exceed 1.5 times the inter-quartile range (distance between the lower and upper quartiles). Outliers outside 1.5 times the inter-quartile range are not represented.

Owners often have higher incomes than the other types of dwelling occupiers (Figure 19). About 25\% of the owners, however, have low incomes. The distribution of incomes of households living in social dwellings is the lowest but incomes of private renters are often similarly low. Incomes of households are generally higher in periurban areas than in Besançon, especially in the case of social renters and private renters. Income distributions within dwelling occupancy status groups do not change in the course of simulation, except for a decrease among periurban private and social renters. 

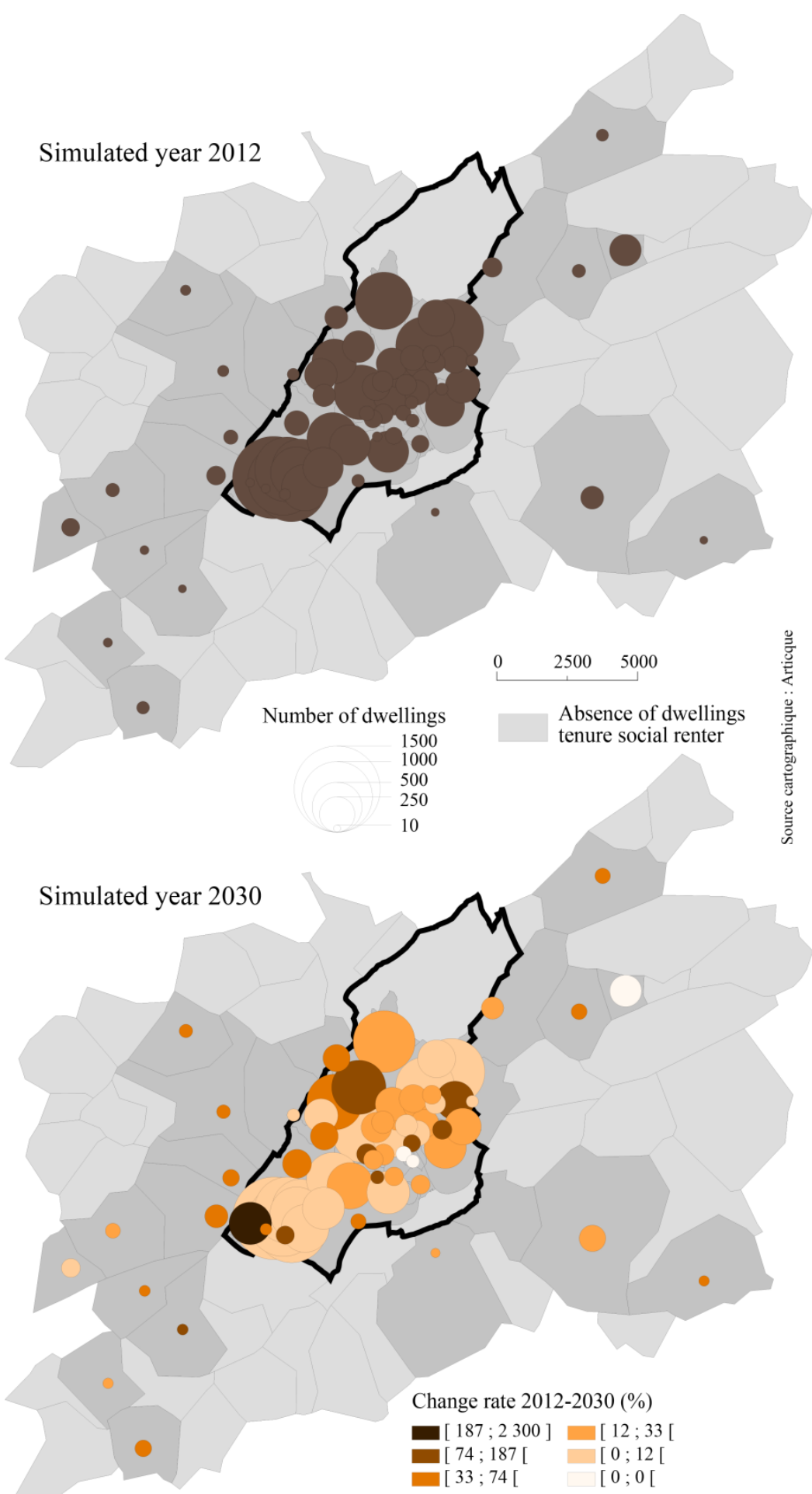

Figure 20. Scenario 'Business as usual': location of socially rented dwellings. Thick black line: limit of the city of Besançon. 

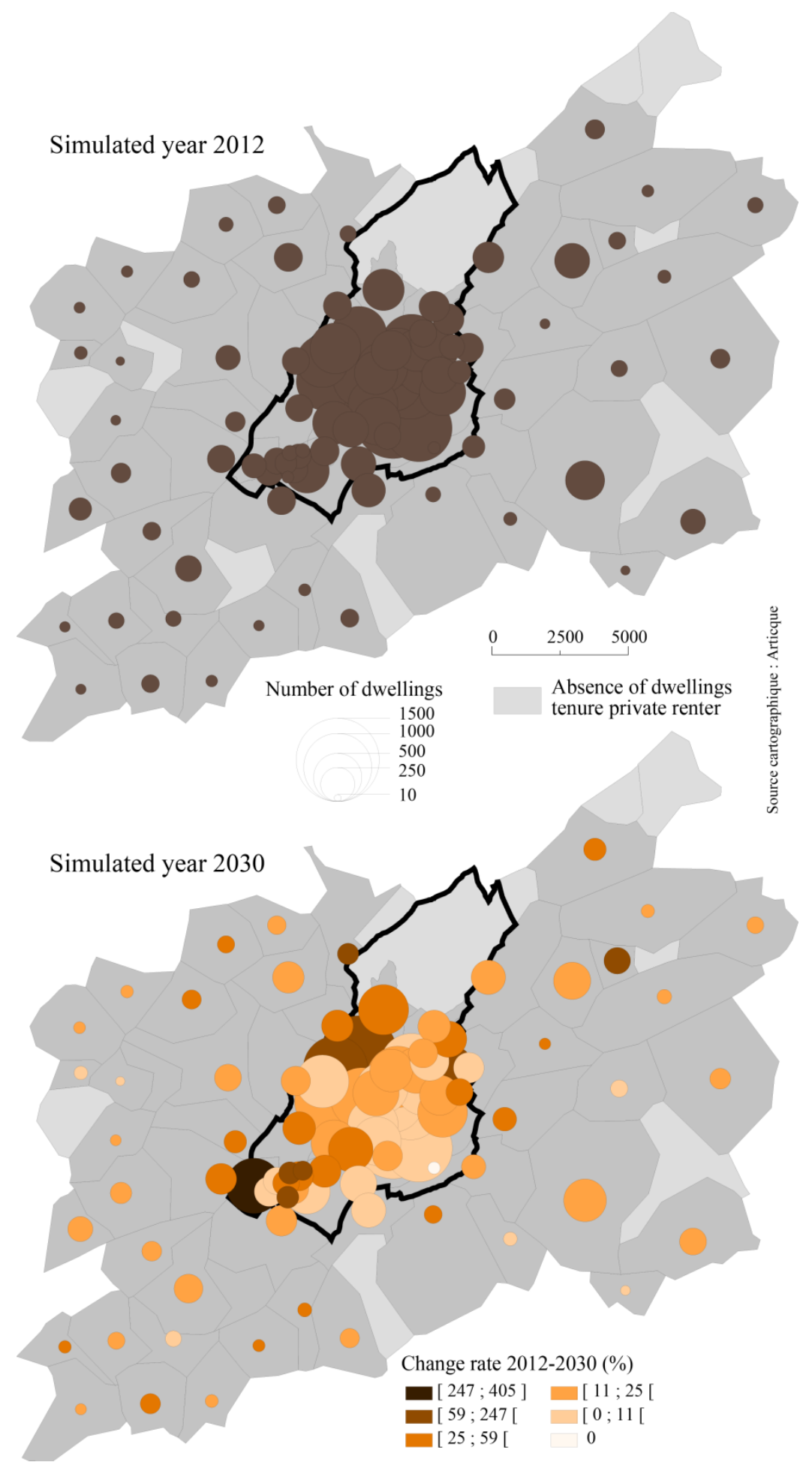

Figure 21. Scenario 'Business as usual': location of privately rented dwellings. Thick black line: limit of the city of Besançon.

The spatial configuration of dwelling offer does not change a lot in the course of simulation: rented dwellings (private or social renting) remain concentrated in the city of Besançon (Figures 20 and 21); while owner-occupied dwellings are distributed more uniformly in the whole urban region (Figure 22). In the course of simulation, the number of owner-occupied dwellings increases much more than the number of rented dwellings (private or social renting), both in Besançon and in several periurban communities. 

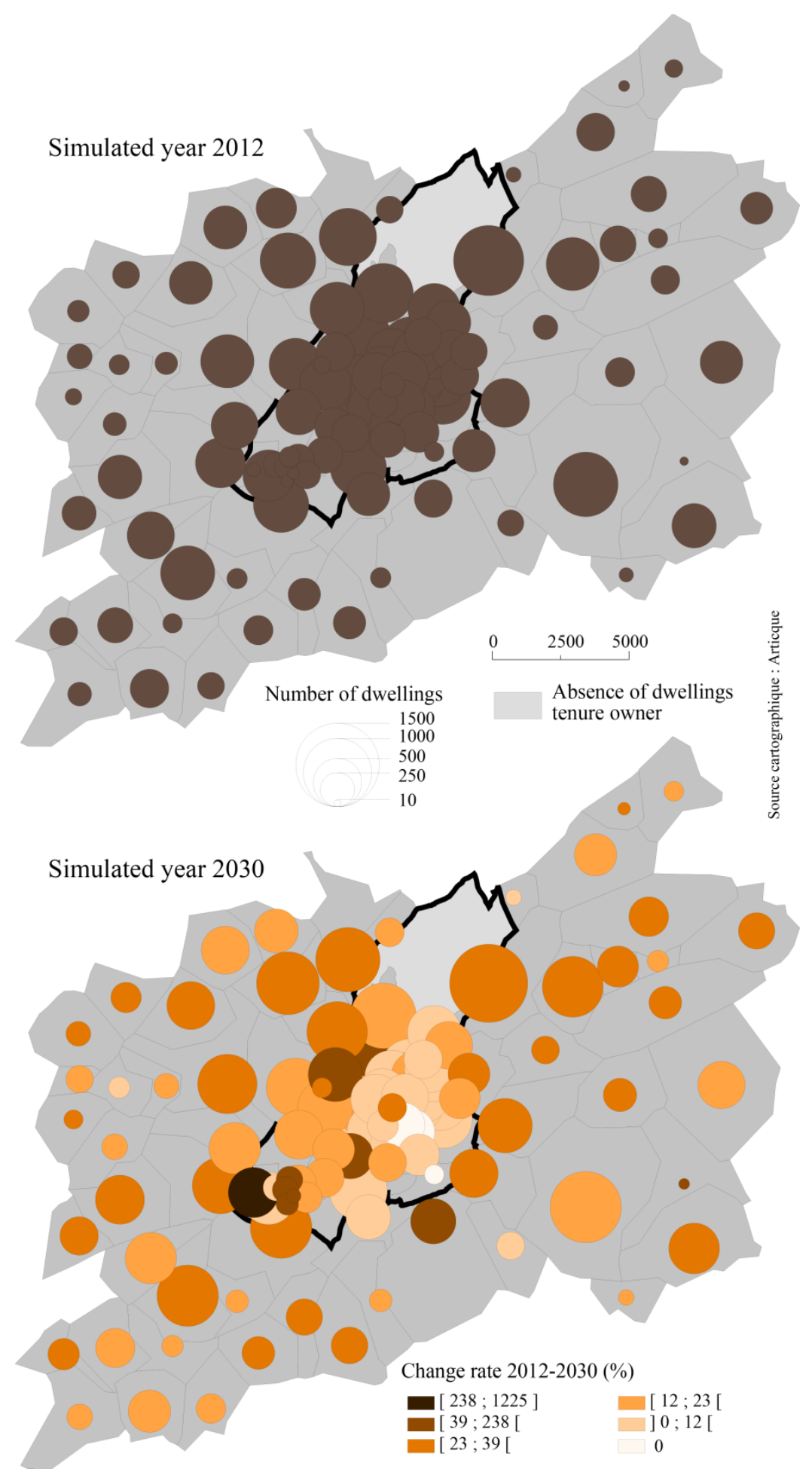

Figure 22. Scenario 'Business as usual': location of owner-occupied dwellings. Thick black line: limit of the city of Besançon.

All these results suggest that the model reproduces quite well the differences between Besançon and the surrounding periurban areas taking into account local specificities: in particular the concentration of population and rented dwellings within Besançon. The evolution of two variables crucial in residential dynamics (moving rates of households and vacancy rates of dwellings) seems to be realistic, except for the first years of the simulations. Such instability at the beginning of the simulation period is common when modelling complex systems: it often takes some time for the simulated dynamics to become stable. 


\subsection{Focus on middle- and high-income households with children}
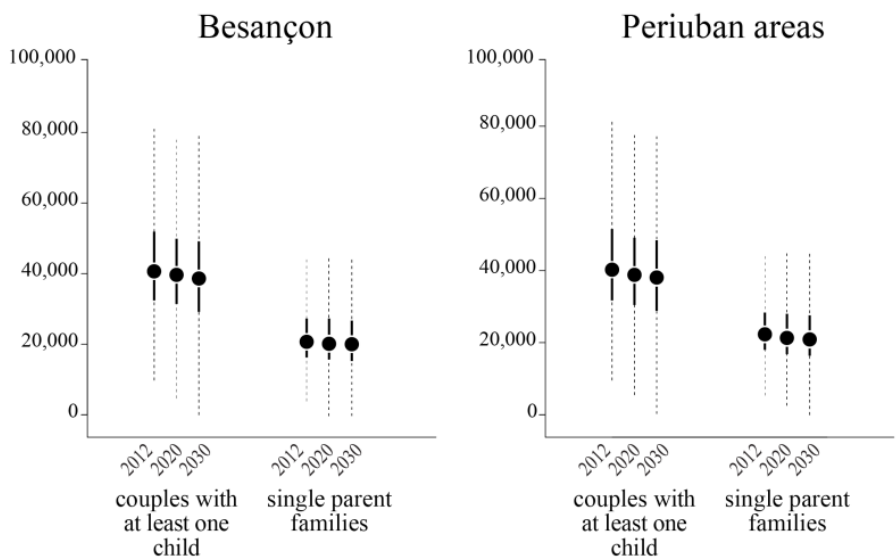

Figure 23. Scenario 'Business as usual': distribution of incomes of target households (in euros).

The income of couples with children is in general much higher than the income of single parent families (Figure 23). As a result, these two types of household (referred to here as target households) are the focus of the analysis which follows. The income distributions of one-parent families and couples with children are the same in Besançon as in periurban areas, whereas this is not the case for all households. The income of couples with children declines slightly over the years of the simulation while the income of one-parent families remains more or less constant over time.
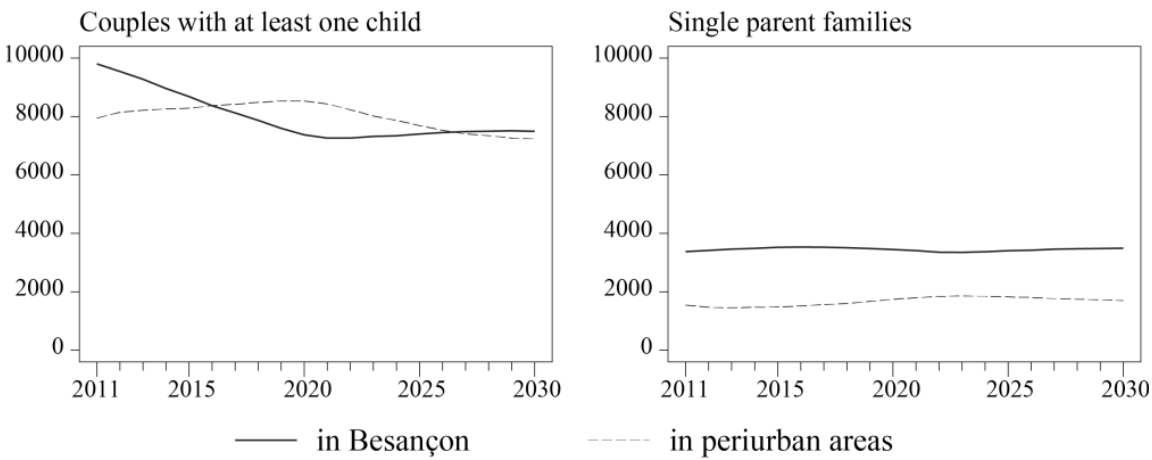

Figure 24. Scenario 'Business as usual': evolution of the number of target households

Overall, the number of couples with children diminishes in the study area (Figure 24). This decline affects Besançon first, during the first ten years of the simulation, then the periurban areas from 2020 onwards. In 2030, at the end of the simulation period there are almost as many couples with children in periurban areas as there are in Besançon, when the numbers were higher in Besançon at the beginning of the simulation. In the middle of the simulation period, the number of couples with children is even higher in the periurban area than in Besançon. The trend is quite different for one-parent families, significantly more numerous in Besançon than in periurban areas. Over time, one-parent household numbers remain broadly stable in Besançon, and rise slightly in periurban areas.

Figure 25 shows that the number of couples with children increases between 2012 and 2030 in around twenty periurban communities compared to only five neighbourhoods in Besançon. In Figure 26, however, the rises and falls in one-parent family numbers are fairly evenly distributed across the whole of the study area. 


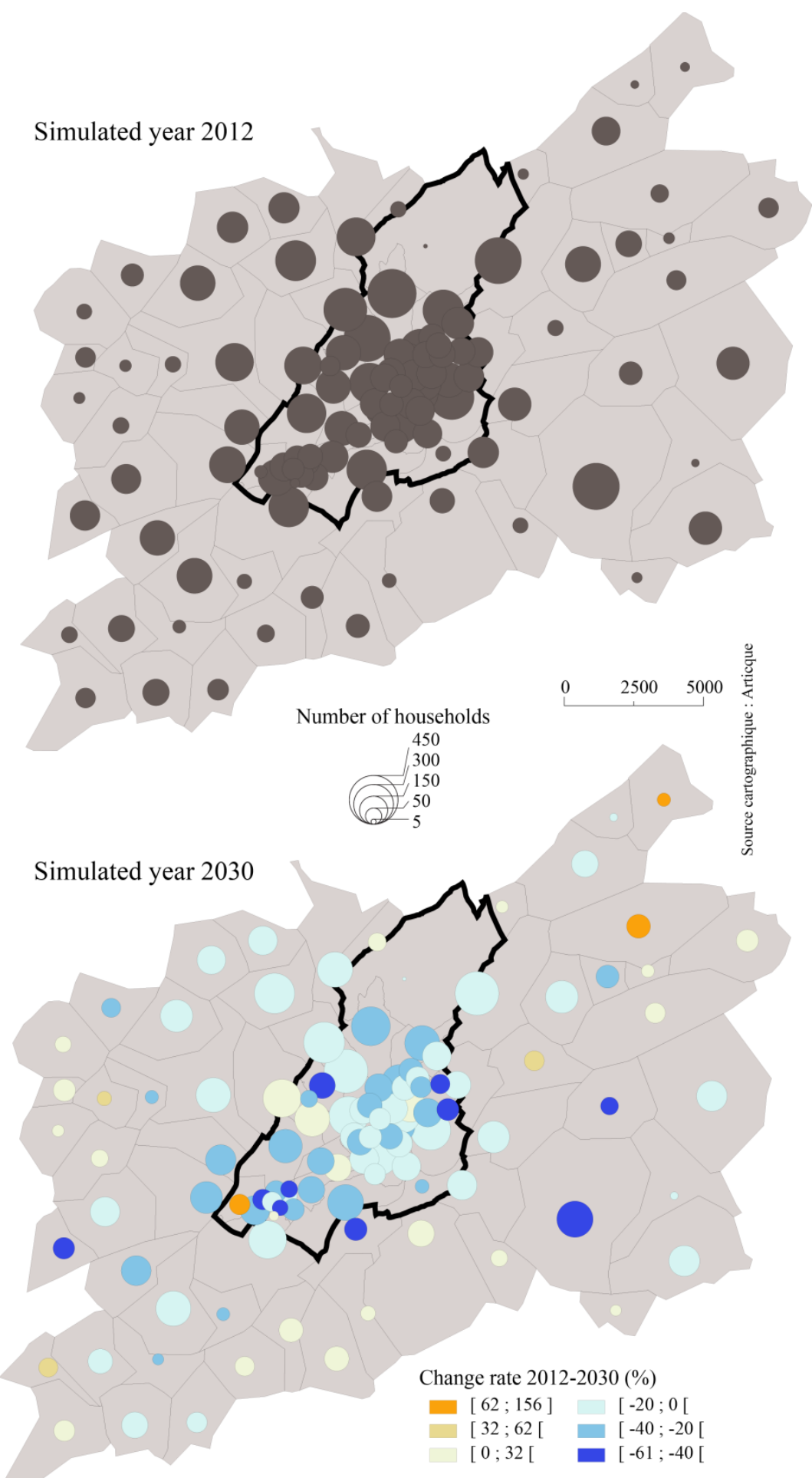

Figure 25. Scenario 'Business as usual': location of couples having at least one child and middle- and highincome. Thick black line: limit of the city of Besançon. 


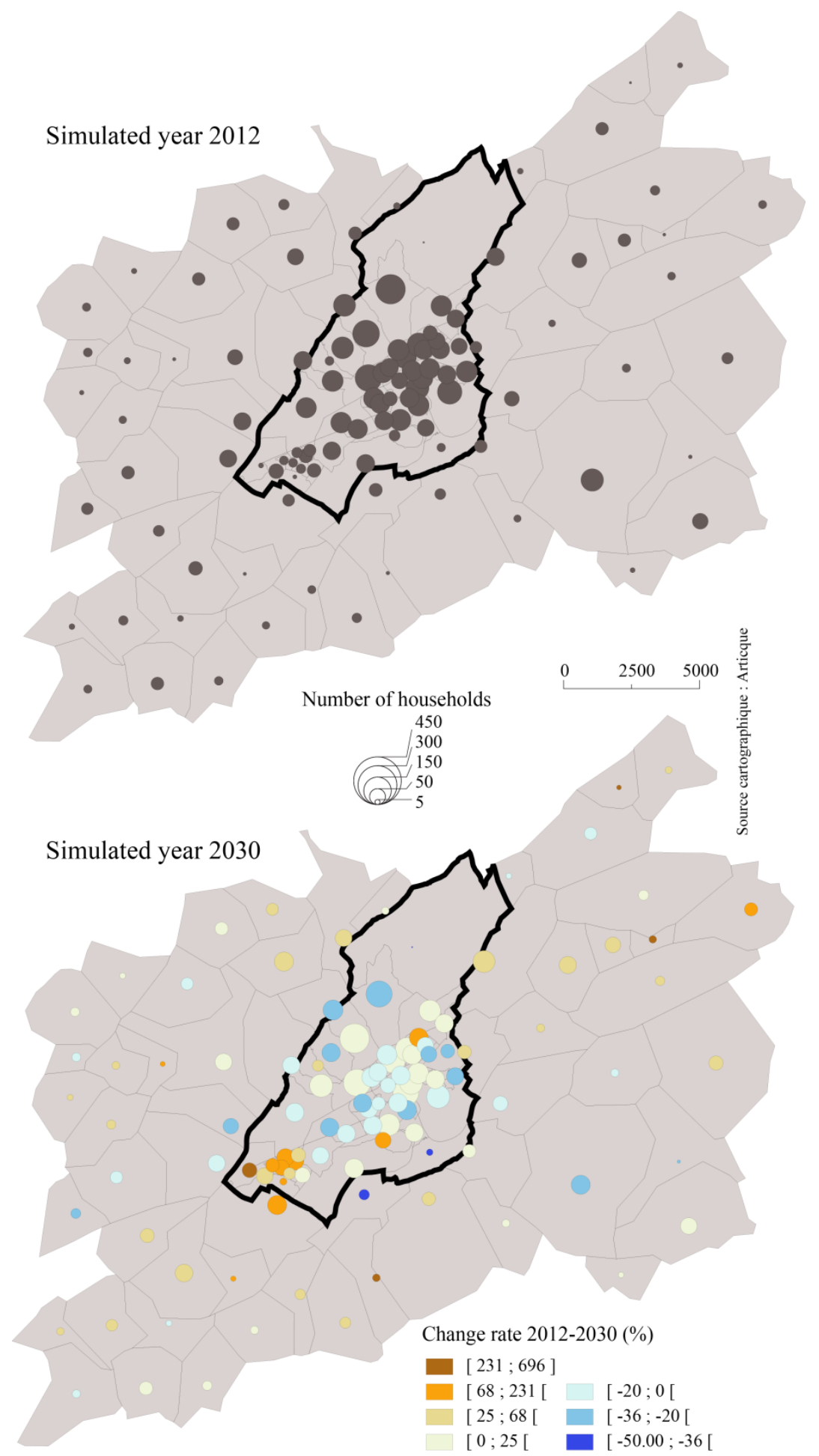

Figure 26. Scenario ‘Business as usual’: location of single parent families having middle- and high-income. Thick black line: limit of the city of Besançon. 

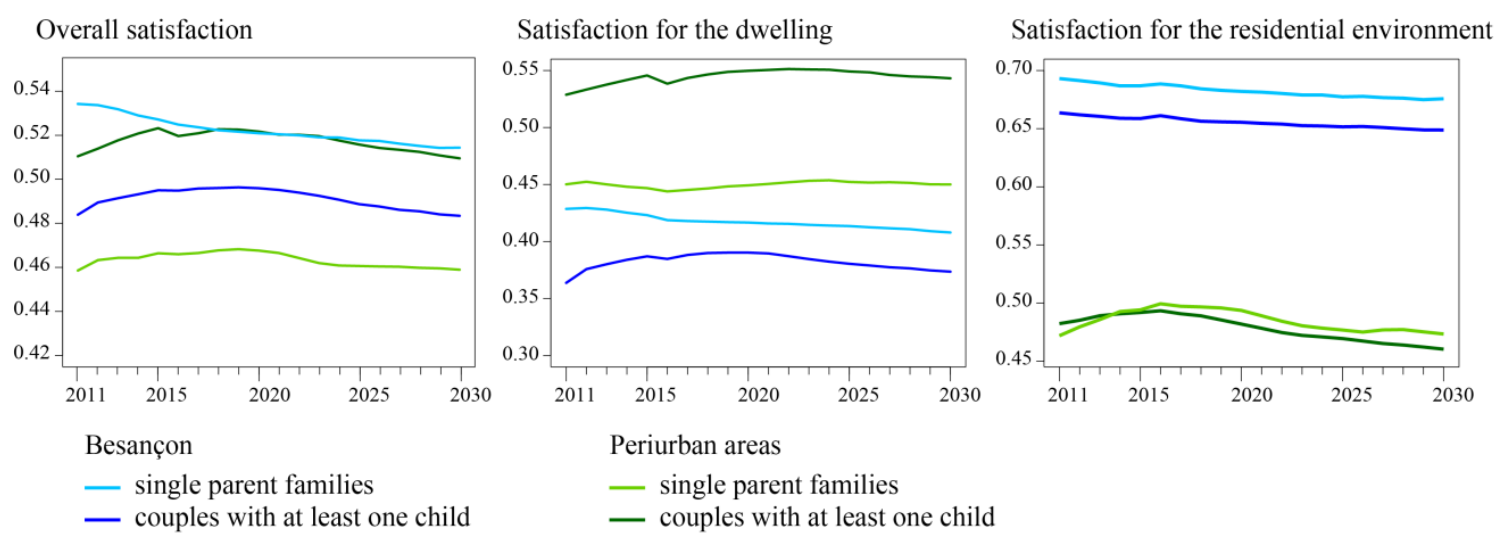

Figure 27. Scenario 'Business as usual': average satisfaction of target households. NB: the scales of Y-axes are different for the three graphs.

Overall residential satisfaction is on average slightly lower for the target households (Figure 27) than for the whole population (Figure 18). The most satisfied households are single parent families living in Besançon and couples with children living in periurban areas. The first are especially satisfied by their residential environment and less satisfied by their dwelling. The second are especially satisfied by their dwelling and less satisfied by their residential environment. All four groups' satisfaction for their residential environment tends to decrease over time. Thus, it is dissatisfaction with their dwelling, more than dissatisfaction with their residential environment that pushes target households to move outside Besançon.

The dwelling satisfaction of target households varies noticeably according to the size of the dwelling occupied (Figure 28). As expected, households with children are not satisfied when they live in dwellings of one or two rooms, but very few households are in this situation: in 2012, 770 couples with children and 250 single parent families, 1020 households in total, were in this category. However, their number increases over simulation time to reach 1320 couples with children in 2030 and 420 single parent families, in other words 1740 households in total (still less than $10 \%$ of the total number of target households). This is a consequence of the decrease of household size. Indeed, only the smallest target households (i.e. single parent families having one or two children) are more numerous in 2030 than in 2012 (about 400 households more). Conversely, the number of large households decreases: 2800 less couples with one or two children in 2030, 800 less couples with three children or more, 100 less single-parent households with three or more children.

The satisfaction of couples with children living in dwellings of three or four rooms is higher but varies considerably. This situation concerns many households in 2012 (about 5560) but many fewer in 2030 (about 3610). Single parent families are more often satisfied in dwellings of three or four rooms but they are fewer in number and decrease clearly over time (2170 in 2012 compared to 1370 in 2030). Nevertheless, the target households are not systematically more satisfied when they live in larger dwellings (five rooms or more) with the exception of couples with children living in houses, which exhibit a high median satisfaction for their dwelling (0.6). 9867 households are in this situation in 2020; 8291 in 2030. Even so the satisfaction of couples living in houses is low for numerous households (the first quartile of the distribution of satisfaction values is comprised between 0.3 and 0.4 in 2030). The satisfaction of single parent families living in a house reaches 0.6 or more for a few households (less than 200 in 2012; about 400 in 2030). In most cases, however, the satisfaction of single parent families living in a house is low. 
Small dwellings

(one or two rooms)

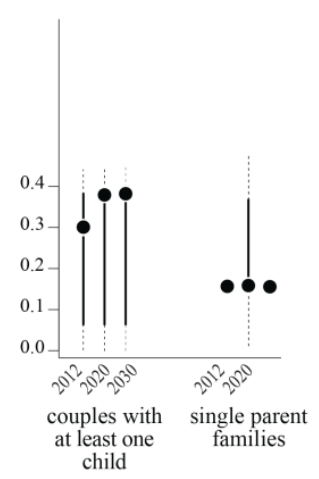

Low cost dwellings

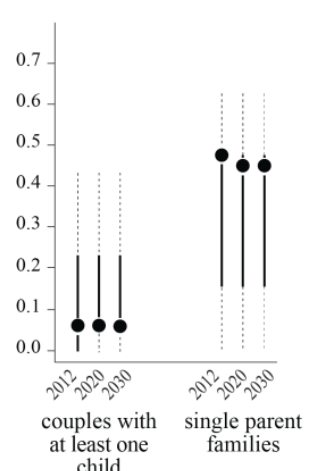

Rented dwellings

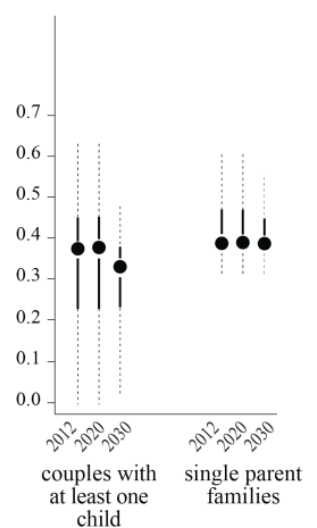

Medium-size dwellings (three or four rooms)

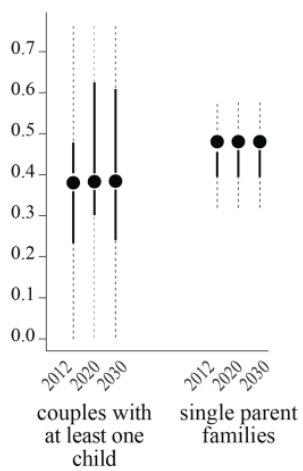

Medium cost dwellings

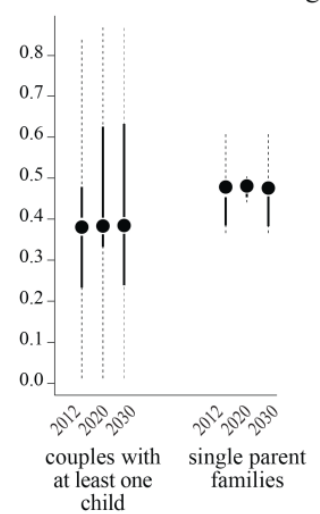

High cost dwellings

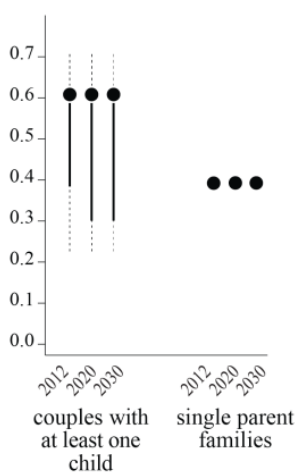

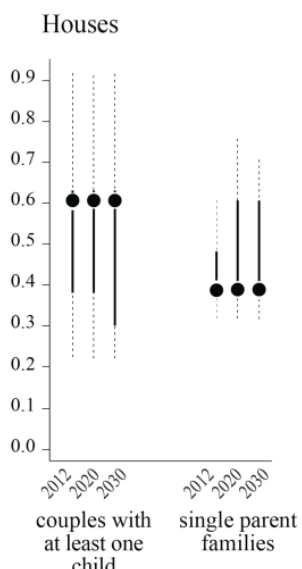

Figure 28. Scenario 'Business as usual': distribution of values of satisfaction for the dwelling according to the characteristics of the occupied dwelling

Couples with children, who generally have higher incomes than single-parent families, are happy to live in expensive dwellings. They can also be satisfied when they live in a medium cost dwelling, but this is not always the case. Single parent families, for their part, are more satisfied when the cost of their dwelling is moderate or low. They are noticeably less satisfied with their dwelling when it is expensive.

Finally, as for as dwelling occupancy status is concerned, owner-occupier couples with children are more satisfied than renting couples with children. The dwelling satisfaction of single parent households, on the other hand, does not vary with occupancy status. 
This lets us sketch a typical profile of dwelling satisfaction for a target household in the urban area considered. A couple with children is satisfied with a dwelling that is purchased at a high price, while a single-parent household is satisfied by a low or moderately priced dwelling of medium size.

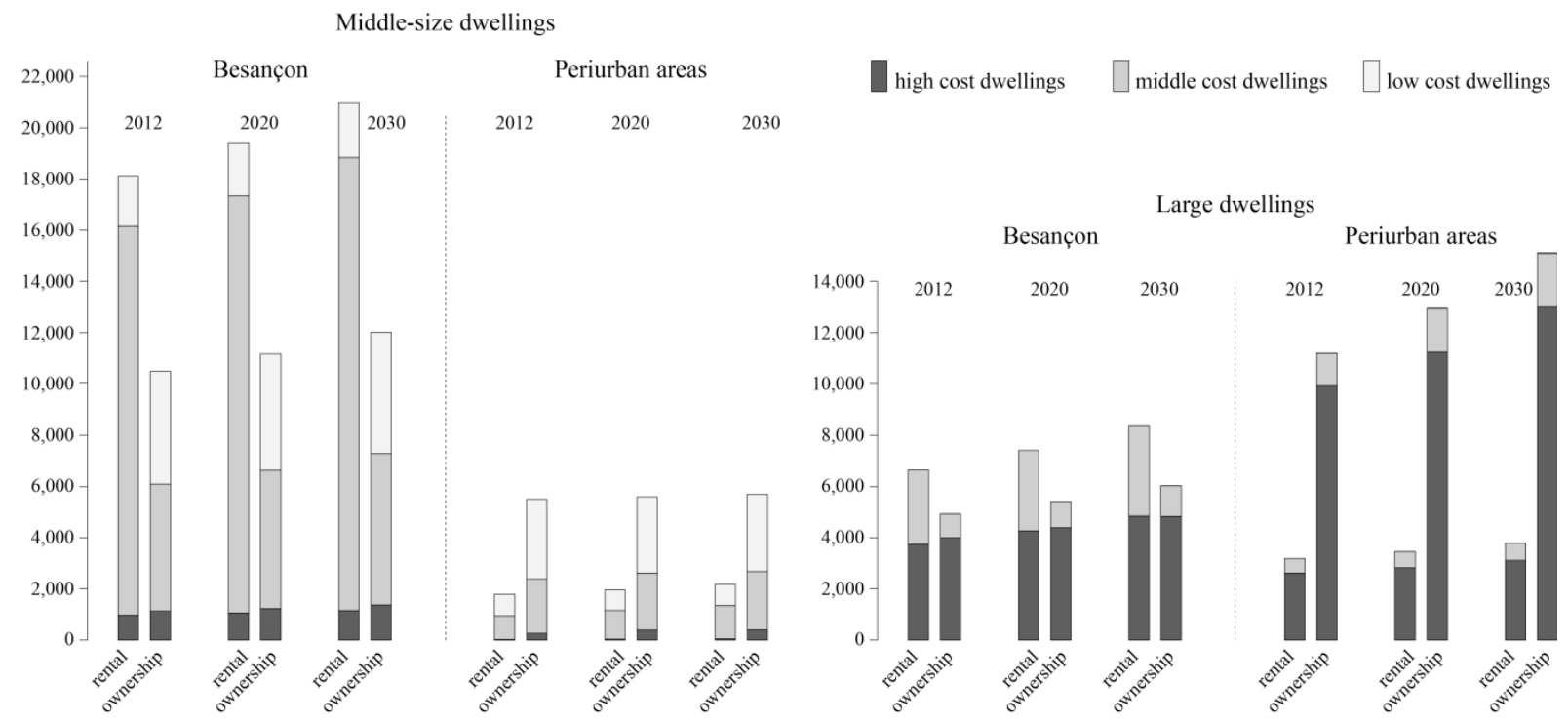

Figure 29. Number of large and middle-sized dwellings in Besançon and in periurban areas, in relation to their cost and their occupancy status.

The majority of middle-sized dwellings are to be found in Besançon (Figure 29). They are mostly medium-cost, less often high-cost and infrequently low-cost. Two thirds are for rent and around one third for purchase. Over the years of the simulation, quite a sizeable number of middle-cost dwellings for rent are built in Besançon. These are likely to satisfy singleparent households and not couples with children. In periurban areas, a certain number of middle-sized dwellings for sale can satisfy single parent households.

Large dwellings, for their part, are more numerous in periurban areas than in Besançon and their number grows noticeably over the period: in 2012, there are 11,580 large dwellings in Besançon and 14,390 large dwellings in periurban areas; in 2030, there are 14,380 large dwellings in Besançon and 18,910 large dwellings in periurban areas. The majority of large dwellings are high-cost (and therefore do not satisfy the majority of single-parent households). A few are medium-cost, above all rental properties in Besançon. Logically, there are almost no low-cost large dwellings, to the point that they do not appear on the figure.

The large dwellings are mainly detached houses in periurban areas; and flats (mostly rented) in Besançon although there are also houses (half for rent, and half for purchase) (Figure 30). The number of large flats in Besançon rises between 2012 and 2030, but much more slowly than the number of large houses in periurban areas. Very few houses are built in Besançon and very few flats are built in periurban areas. 


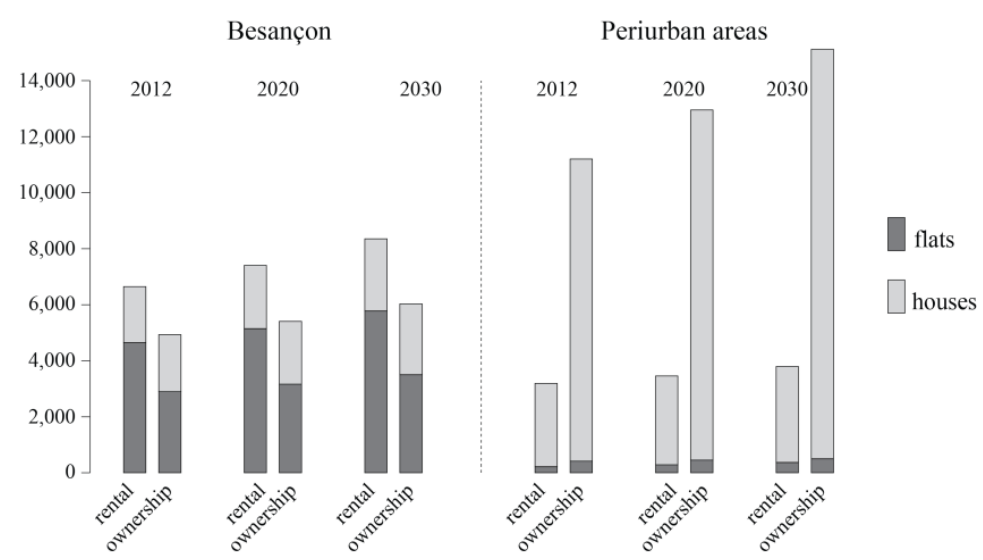

Figure 30. Number of large dwellings in Besançon and in periurban areas, in relation to their type and their occupancy status

The maps in Figures 31 and 32 summarise the results and offer a more detailed spatial perspective of the results presented above. The two maps show that the number of vacant dwellings in the city of Besançon decreases dramatically from 2012 to 2030 whereas it decreases much less in periurban communities. The attractiveness of vacant dwellings decreases also in a number of neighbourhoods in Besançon. This decrease is especially marked for couples with children. The attractiveness of vacant dwellings in periurban communities is often higher for single parent households in 2030 than in 2012 whereas it is often lower for couples with children. 


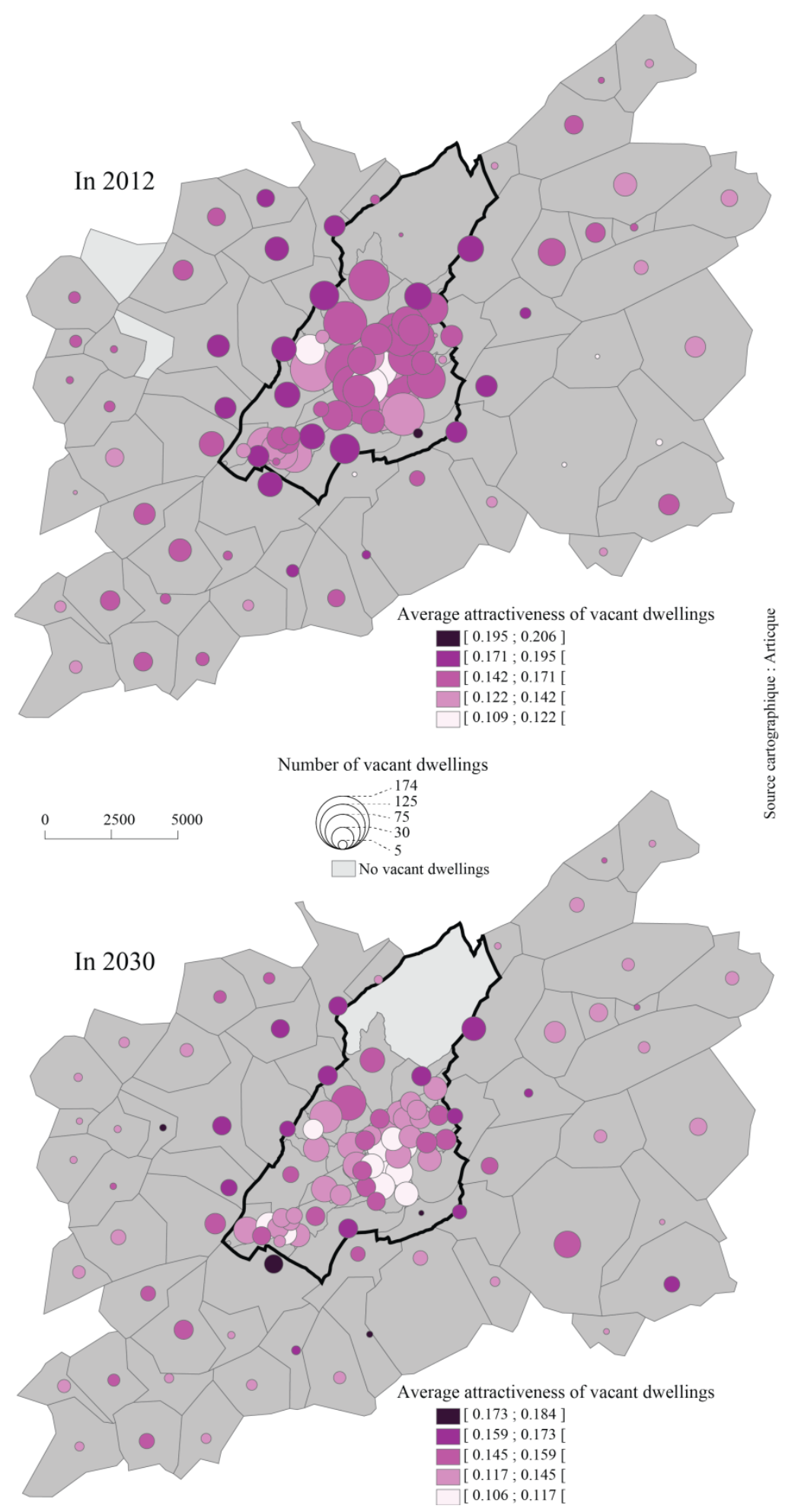

Figure 31. Scenario 'Business as usual': maps 2012-2030 by commune/census district of number and average attractiveness of vacant dwellings for couples with children. Thick black line: limit of the city of Besançon. 


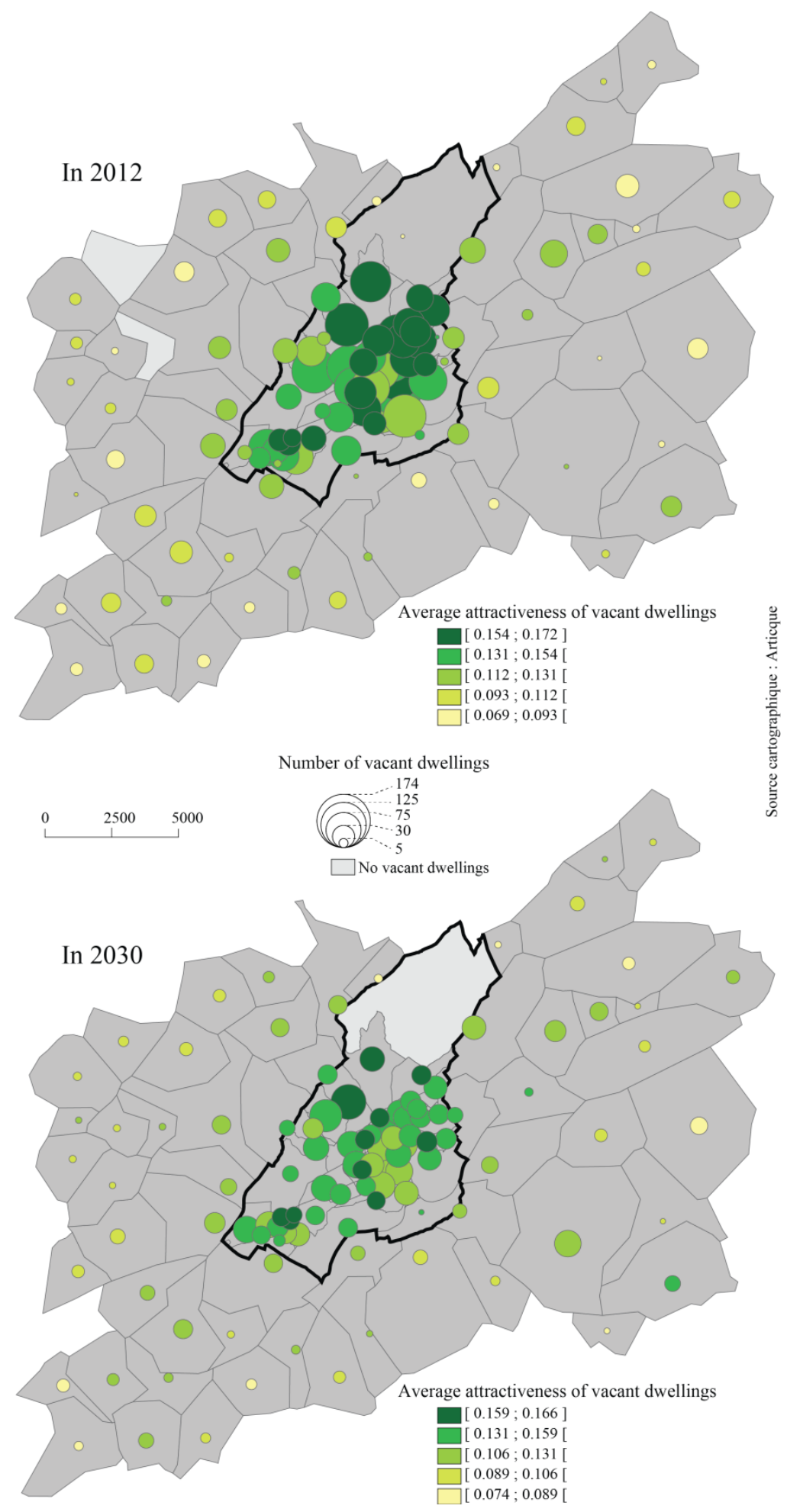

Figure 32. Maps 2012-2030 by commune/census district of number and average attractiveness of vacant dwellings for single-parent households. Thick black line: limit of the city of Besançon.

\subsection{Conclusion of these analyses}

Target household migration flows do not change fundamentally between 2012 and 2030, despite the introduction in the simulation of the achievement of the objectives of strategic land use and housing plans (the SCoT and the PLH respectively), rising fuel prices and the 
introduction of a tram system: the outward migration flows (from Besançon to periurban areas) remain dominant in the future.

There are fewer attractive dwellings for couples with children in Besançon than in periurban areas. Because of a lack of large dwellings for purchase, becoming an owner-occupier in the city of Besançon is currently not possible for lots of households. Yet becoming an owner occupier is a common desire in France, which is reinforced by the fact that the costs of renting are relatively high compared to costs of buying a real-estate property. In addition, large dwellings for purchase in Besançon are mostly flats and rarely detached houses, which is less satisfying for couples with children.

On the other hand, housing supply in Besançon seems to be attractive for single parent families. In particular, the number of middle-sized affordable owner-occupied dwellings is high. However, local actors' knowledge of the real situation on the ground nuances the results of the model. In reality, many middle-size affordable dwellings for purchase are to be in rundown joint-ownership properties and are uncomfortable (poor sound and thermal insulation, small rooms). They are thus of little interest to the target households. Moreover, as the model shows, the supply in Besançon is less attractive than the supply in periurban areas which is smaller in number but a non-negligible contribution to dwellings available for purchase (Figure 29). So medium-income households can either rent a flat in the centre city or buy a house at an affordable price in a periurban area to achieve a reasonable dwelling satisfaction.

The forecast increase of fuel price will increase the travel costs by car in future. However, this has almost no impact on the number of periurban location choices simulated by the model. The researchers and the planning actors involved in the experimentation decided to deepen this aspect. They supervised a master project (Lallement, Moyne, 2013) in which the students calculated the housing and travel costs for a couple having two children, working in Besançon, and living respectively in a flat in Besançon (near to the town centre), in a house in a periurban community close to Besançon, and in a house in a periurban community far away from Besançon. The cost estimation for housing and transportation was undertaken from 2015 (the children were respectively one and four years old; the parents were supposed to have bought their dwelling at this date) to 2030. It took into account monthly mortgage repayments, local property and residential taxes, the cost of daily travel for the four members of the household (work, school, shopping, leisure) allowing for term-times, school holidays when both parents work and periods of family holidays, and also the increase in fuel prices. The household is car-less when living in Besançon while owns two cars when living in a periurban area. Taking into account all costs (transport and housing), the cost of living is higher in the periurban community close to Besançon than for a household living in the city itself. However, by making a modest extra financial effort, the household can buy a $100 \mathrm{~m}^{2}$ house with a garden in a periurban community far away from Besançon, while in Besançon it lives in an $85 \mathrm{~m}^{2}$ flat. Since the periurban community is situated close to a major road, the two workers in the household can be at work in around 20 minutes. This study shows, ultimately, that the difference in expenses for housing, lower in the periurban area, and for travel, lower in Besançon, does not systematically favour the choice of a residential location within the municipality of Besançon. One way to tip the balance in favour of Besançon would be to reduce the cost of housing purchase in the city or reduce housing-related taxes. 


\section{Simulation of a second scenario: application of a pro-active housing construction policy by the city of Besançon}

Simulation results for the 'Business as Usual' scenario provided a basis for a joint reflection by the planning actors and the researchers with a view to identifying possible planning policies that could be used to keep middle- and high-income households with children within the city.

The first possibility is to build more houses for sale in Besançon in the parts of the city best served by public transport (particularly close to tram stops) and with a high landscape quality. One of the hillsides in Besançon (Rosemont) fits these criteria perfectly. This could be achieved by changing the local plan to allow for the construction of houses (rather than flats) at the foot of the hillside, while at the same time imposing high standards for architectural and landscape quality in the neighbourhood. This would require a relatively small investment by the municipality and would certainly attract better-off households with children. This possibility would, however, go against the political choices of the city council: for the last 30 years the development of hillsides has been outlawed and residential development has been restricted almost entirely to building apartment blocks.

Another possibility would be to implement unified property and residence taxes for the whole agglomeration, which would increase taxes in periurban areas and reduce them in Besançon. This would be justified by the fact that the population of Besançon have to bear the costs (economic and environmental) of numerous services and facilities used by periurban residents. The communities surrounding Besançon, however, object strongly to such a fiscal policy. The implementation of future joint local plans (PLUi) imposed by the French state will move urban agglomerations progressively in this direction (cf. the so-called Alur Law published in March 2014). Nevertheless, the Besançon's planning actors did not wish to integrate such a possibility into the experiment presented here.

A third possibility is to increase the number of large high-cost dwellings for purchase other than detached houses (flats with a terrace or a small garden, offering shared children's play areas, safe pedestrian and cycle access) and to increase the number of large low-cost dwellings for purchase in Besançon city, on the basis that the difference in cost will encourage households to choose a flat in the city rather than a house in the countryside.

After considering the options, the city council has finally defined an ambitious building construction project over fifteen years. The objective is to control residential development by reducing the share of new dwellings bought by real-estate investors, which leads private developers to build mainly small dwellings. Controlled housing operations take the form of a negotiation between the city council and private developers with the aim of imposing (mainly through signing agreements) minimum sizes for dwellings (four or five rooms) and a minimum share (15\%) of dwellings sold at a maximum price (i.e. affordable dwellings). This adds up to a pro-active housing policy that represents a significant cost for the city and implies a certain degree of risk. Will this project change the pattern of residential migration flows in the urban area of Besançon? Will the housing built be occupied and, if it is, by what types of households?

With MobiSim, it is possible to simulate the housing developments programmed by Besançon city council and to study their impact on residential migration up to 2030, under the 
conditions represented in the model. This involves varying only the developments over which the city council exercises control, while holding all other aspects of the model constant.

It should be noted that the development of the final pro-active housing construction policy, used for the second simulation scenario, was a non-trivial exercise. The planners and researchers explored seventeen different versions before finalising the choice of development locations. This was one of the most significant ways in which the exchange of knowledge between researchers and planners took place.

\subsection{Variable settings}

Setting of the scenario results from a collective reflection on the modifications to some of the variables and parameters of the 'Business as usual' scenario in order to simulate a pro-active policy of housing construction in the medium term.

1120 dwellings are built each year in the whole urban region, compared to 850 for the 'Business as usual' scenario. This is not just a notional figure denoting a pro-active housing construction policy, but is a reflection of real sites and realistic development potential within the urban region and the city of Besançon. Within the administrative boundaries of the city of Besançon, 720 dwellings are built each year compared to 500 for the 'Business as usual' scenario. Whereas the simulated residential development in the 'Business as usual' scenario corresponds simply to spontaneous development (self-organised residential development), the 'Pro-active' scenario integrates both spontaneous development (450 dwellings a year in Besançon) and city council controlled projects (around 320 dwellings per year built in Besançon from 2010 to 2022; around 150 dwellings per year from 2023 to 2029).

The dwellings built in the context of city controlled housing projects are 4 or 5 rooms or more in size and $8.8 \%$ of dwellings and $41 \%$ of buildings constructed are houses. Blocks of flats are relatively small (a building footprint of 200 to $2500 \mathrm{~m}^{2}$; 3 or 4 storeys). For example, for a building of $1000 \mathrm{~m}^{2}$ this corresponds to two 5 room dwellings, three 4 room dwellings and two 3 room dwellings per floor, that is to say 28 dwellings and 112 rooms in total. As the building footprints of buildings constructed by simulation are small $\left(400 \mathrm{~m}^{2}\right)$, it is assumed that each building contains around 30 rooms. Houses are all 5 or more rooms in size.

The planning actors of the city council provided a map detailing the locations of the entire city controlled housing projects, including the number of dwellings planned for each zone for each year from 2011 to 2029, as well as their breakdown by type (flats or houses). 


\subsection{Simulation results}

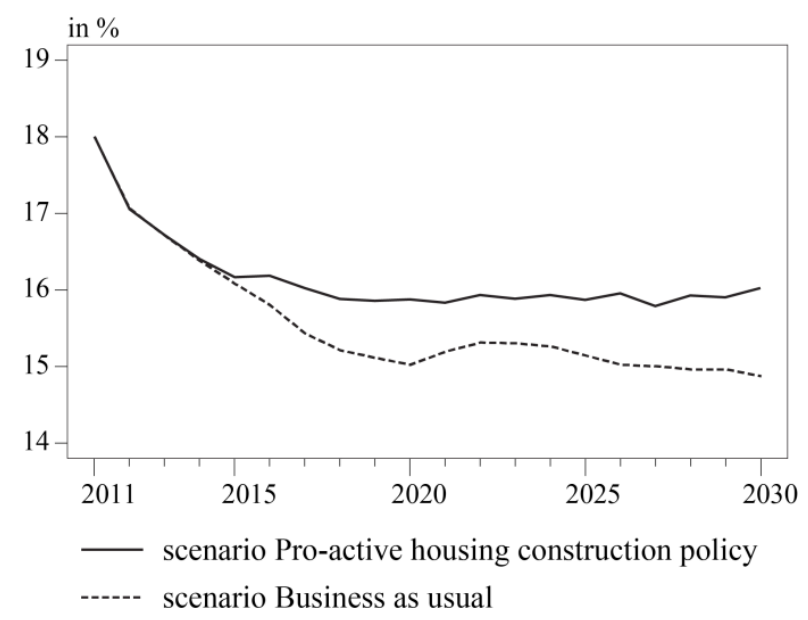

Figure 33. Two scenarios: annual rate of households moving within the urban region

With the 'Pro-active housing construction' scenario in the city of Besançon, the annual migration rate of households within the urban region is higher than for the 'Business as usual' scenario (Figure 33). The higher number of newly constructed buildings explains this result.

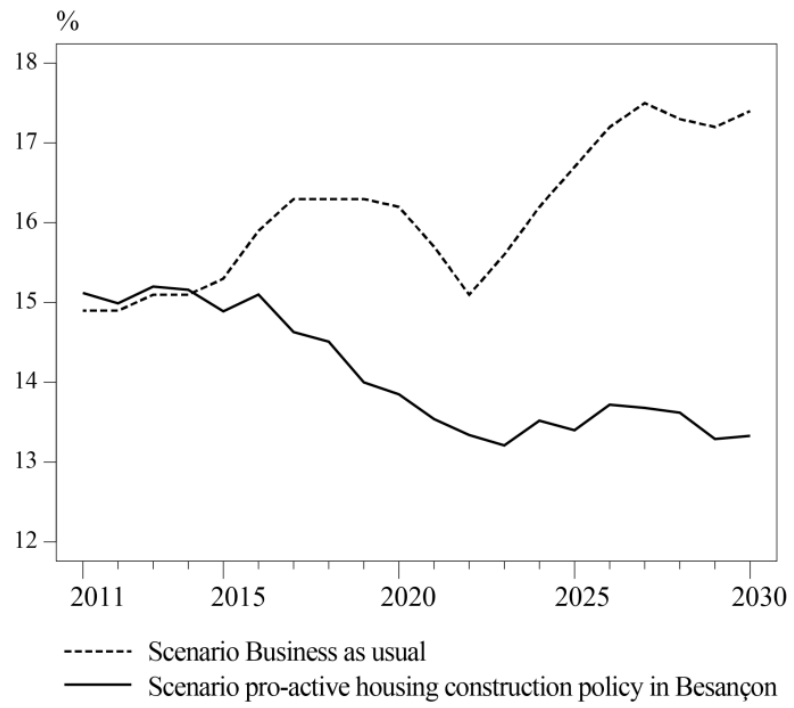

Figure 34. Two scenarios: share of households moving from Besançon to periurban areas among the total of households moving within the urban region

The share of households moving from Besançon to periurban areas as a share of the total number of households moving within the urban region is clearly lower with the 'Pro-active housing construction' scenario within the city of Besançon (Figure 34). The simulated housing policy has a positive effect in the desired direction. 
Scenario Business as usual

- in Besançon in periurban areas

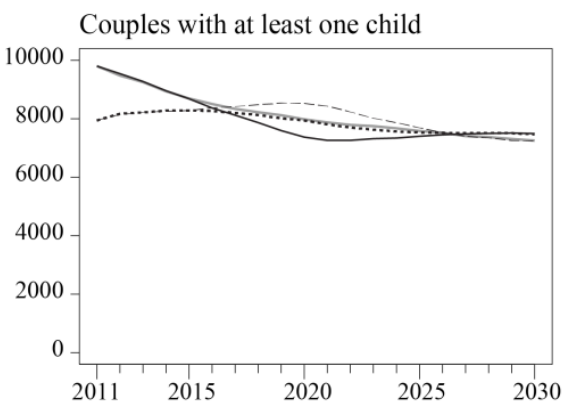

Scenario Pro-active housing construction policy

in Besançon

in periurban areas

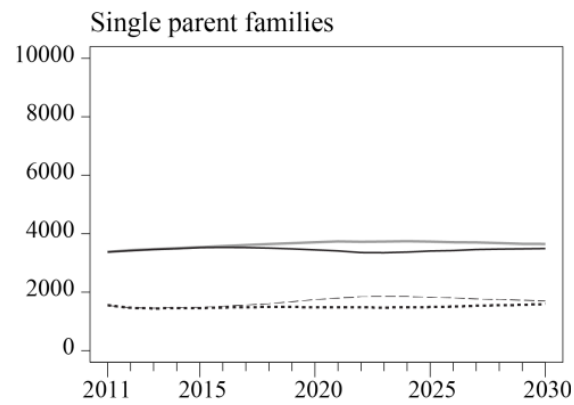

Figure 35. Two scenarios: evolution of the number of target households.

As far as the target households are concerned (i.e. middle- and high-income households with children - Figure 35), numbers of couples with children increase in the middle of the simulation period for the 'Pro-active' scenario. However, the effect has disappeared by the end of the simulation. This may be explained by the choice to make the pro-active housing construction policy less active from 2022 onwards. Single-parent families are more numerous with the 'Pro-active' scenario than the 'Business as usual' one throughout the simulation period. In any case the difference between the two scenarios is sharper in Figure 34, which considers all households in the urban region, than in Figure 35, which considers exclusively the target households. This suggests that the dwellings built in Besançon as a result of the proactive housing policy are frequently occupied by households without children.
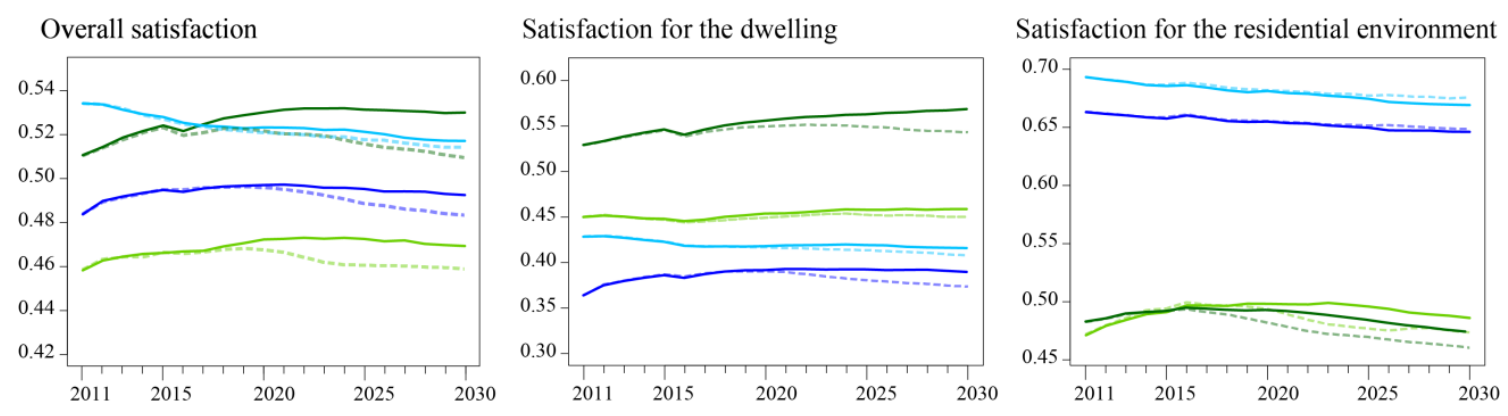

Scenario Business as usual

Scenario Pro-active housing construction policy

Besançon
---. single parent families
--. couples with at least one child
Periurban areas
--- single parent families
--- couples with at least one child

Besançon

— single parent families

— couples with at least one child

Periurban areas

— single parent families

- couples with at least one child

Figure 36. Two scenarios: average satisfaction of target households. NB: the scale of Y-axes is different for the three graphs.

Residential satisfaction of target households is in any case higher for the 'Pro-active housing construction' scenario in Besançon than for the 'Business as usual' scenario (Figure 36). The first scenario gives interesting results in this respect. The higher residential satisfaction concerns not only households living in Besançon but also periurban households, which raises the question why. A possible explanation is that other types of households living in periurban areas, especially retired households without children, choose to leave these places to settle in the new dwellings built in the context of the Besançon city council's development policy. 
Couples with children may then occupy the periurban dwellings released by the migrating retired households. This possible explanatory hypothesis, however, remains to be verified.

The number of couples with children in 2030 is higher in some periurban communities and neighbourhoods of Besançon with the Pro-active housing construction scenario in Besançon, but it is lower in other communities or neighbourhoods (Figure 37). The respective positive, and negative differences between the Pro-active and 'Business as usual' scenarios are spatially distributed across the whole urban region. The situation is different for the single parent families: in most cases, they are more numerous in 2030 in Besançon and less numerous in periurban communities with the Pro-active housing construction scenario in Besançon (Figure 38). 


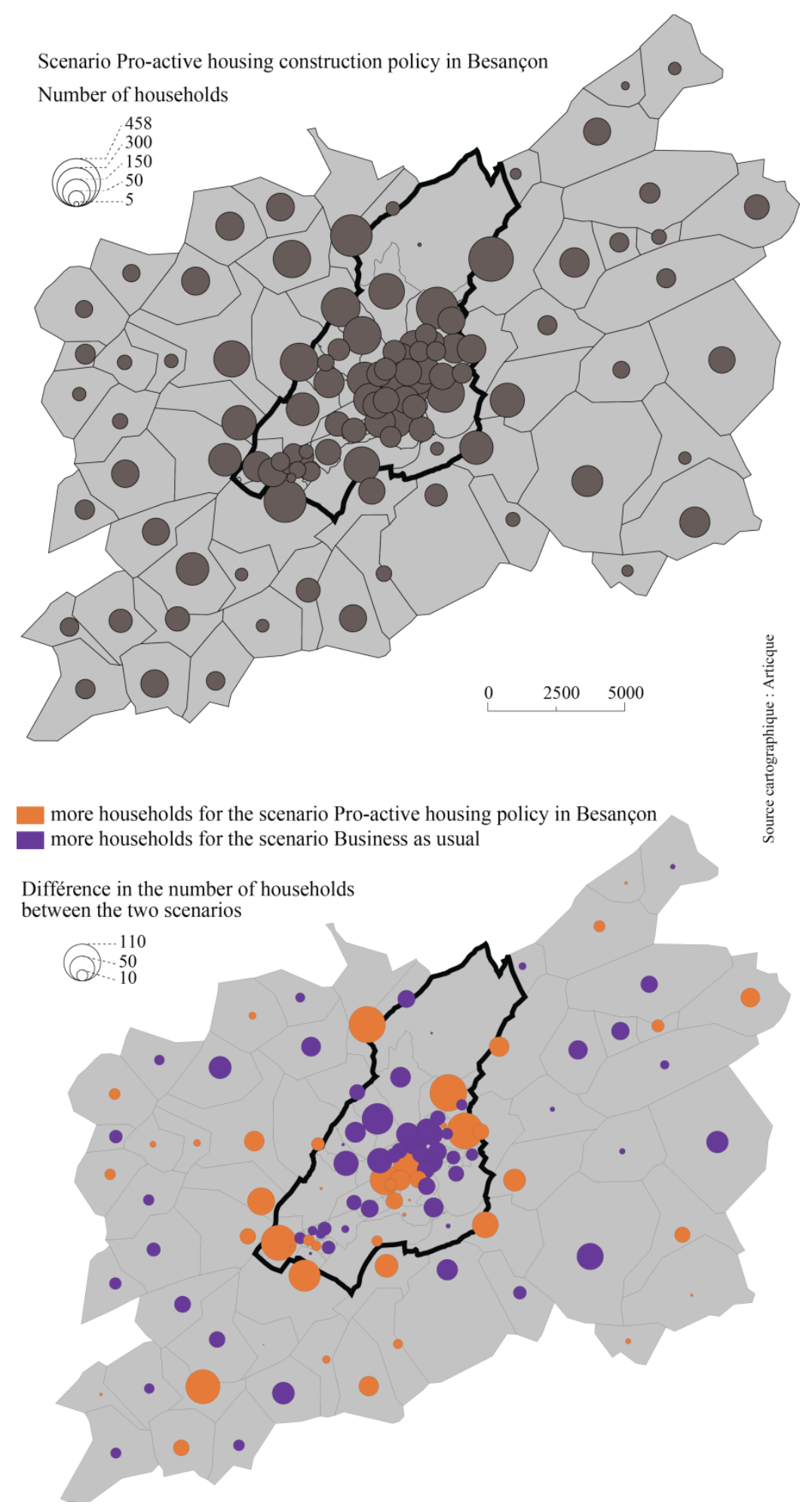

Figure 37. Location of couples having at least one child and middle- and high-income - simulated year 2030. Thick black line: limit of the city of Besançon.

The number of couples with children in 2030 is higher in some periurban communities and neighbourhoods of Besançon with the 'Pro-active housing construction' scenario in Besançon, but it is lower in other communities or neighbourhoods (Figure 37). The respective positive, and negative differences between the 'Pro-active' and 'Business as usual' scenarios are spatially distributed across the whole urban region. The situation is different for the single parent families: in most cases, they are more numerous in 2030 in Besançon and less 
numerous in periurban communities with the 'Pro-active housing construction' scenario in Besançon (Figure 38).

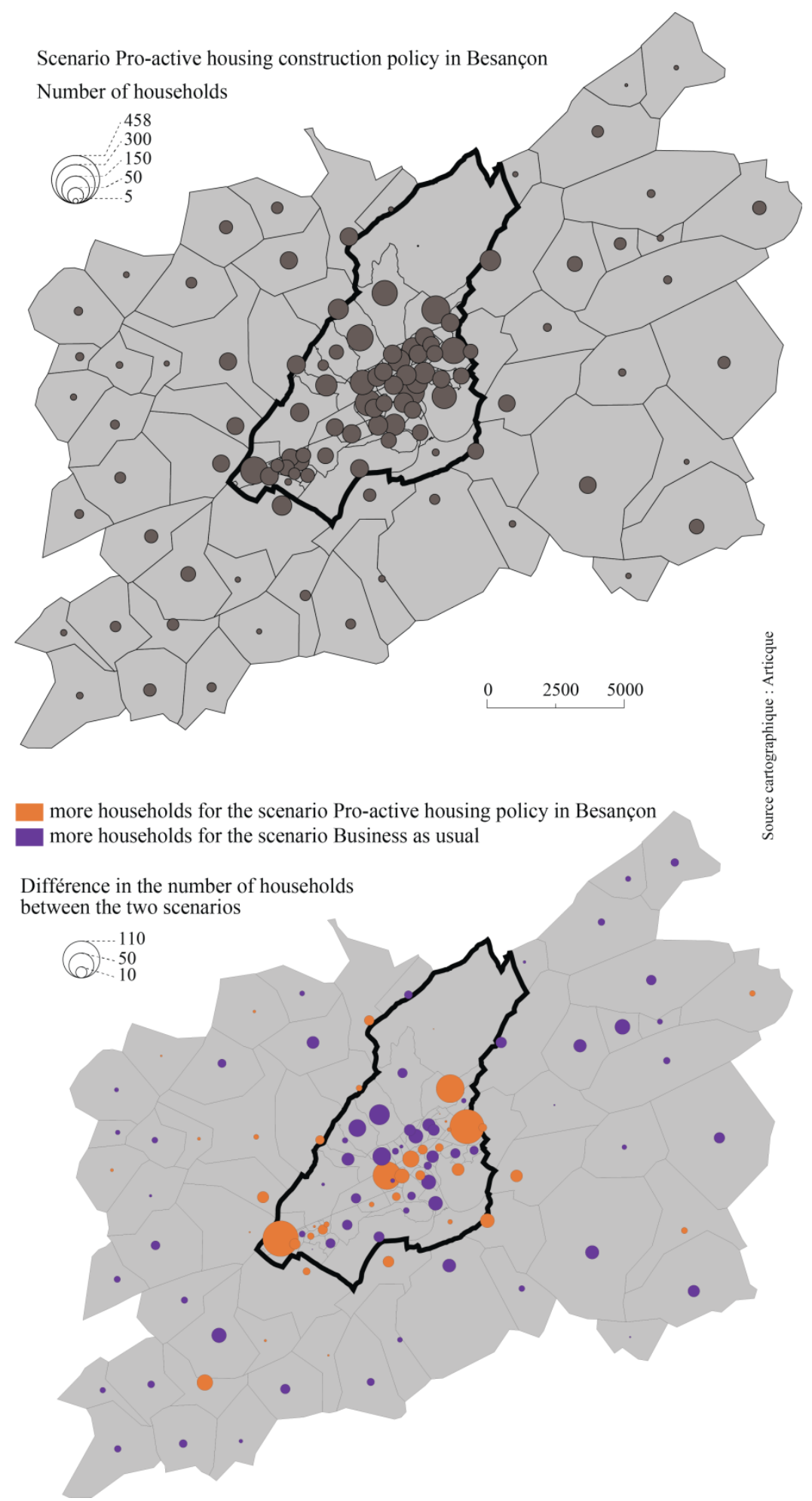

Figure 38. Location of single parent families having middle- and high-income - simulated year 2030. Thick black line: limit of the city of Besançon. 


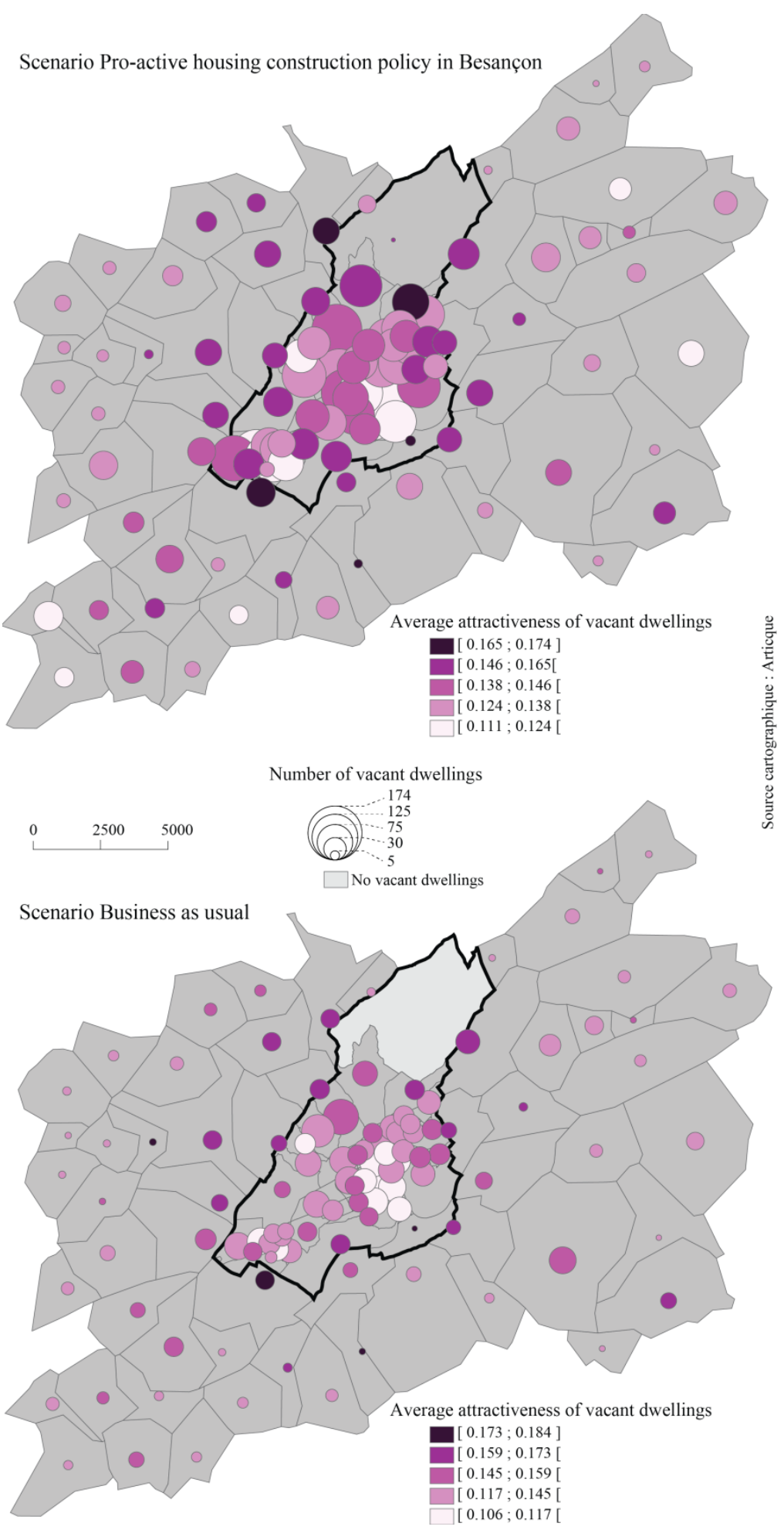

Figure 39. Two scenarios: maps 2030 by commune/census district of number and average attractiveness of vacant dwellings for couples with children. Thick black line: limit of the city of Besançon.

Figures 39 and 40 show that the number of vacant dwellings at the end of the simulation time is clearly higher for the scenario of Pro-active housing construction policy in Besançon than for the 'Business as usual' scenario, especially in the city of Besançon. Vacant dwelling are in general less attractive with the first scenario than with the second one for single parent households, especially in periurban communities. However, the differential of average attractiveness values between all neighbourhoods and communities is clearly more in favour 
of Besançon. The situation is different for couples with children: the average attractiveness values of vacant dwellings are in general higher with the pro-active housing construction policy both in the neighbourhoods of Besançon and in periurban communities. However, the differential of average attractiveness values between all neighbourhoods and communities is not particularly favourable to Besançon.

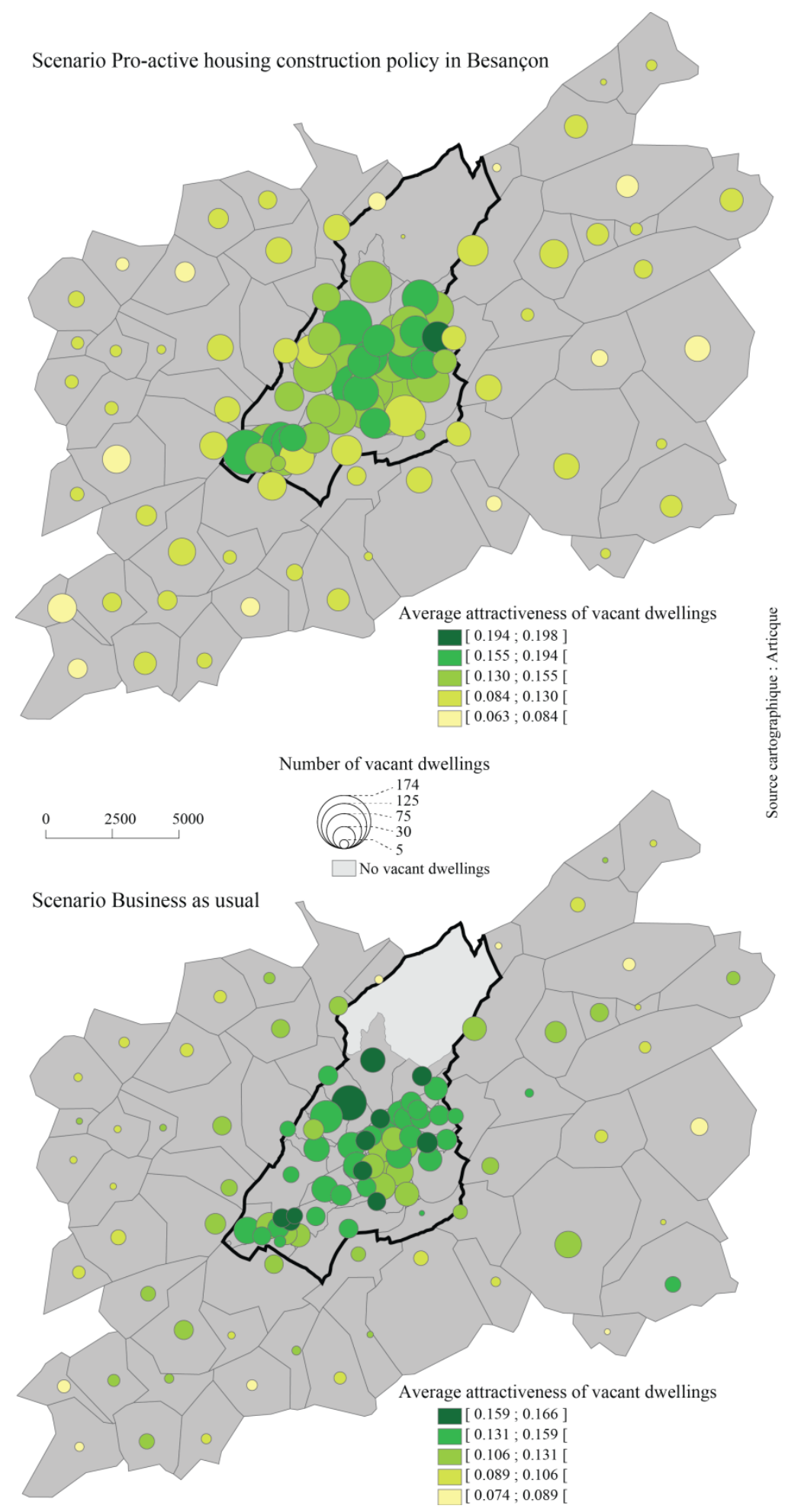

Figure 40. Two scenarios: maps 2030 by commune/census district of number and average attractiveness of vacant dwellings for single-parent households. Thick black line: limit of the city of Besançon. 


\subsection{Conclusion of these analyses}

Under the conditions represented in the model, the 'Pro-active housing construction' scenario in Besançon allows an overall reduction of migration flows from Besançon to the surrounding periurban areas. More single parent families choose to reside in Besançon during the whole simulation time (2011-2030). Couples with children, however, choose preferentially to reside in Besançon until 2022 only. At this date, the city council controlled housing developments become less numerous. By 2030, the number of couples with children is slightly higher in periurban areas compared to Besançon, which is the opposite result to that observed in the 'Business as usual' scenario. Thus, as a result of the complex mechanisms shaping the simulated residential location process, in particular the phenomena of inertia and compensation which occur over time, the simulation results for couples with children at the end of the simulation period are less satisfying for planning actors for the 'Pro-active housing construction' scenario in Besançon than for the 'Business as usual' scenario, although the former does give better results in the middle of the simulation period.

Finally, the application of the policies to control residential development planned by the local authorities do not allow the pattern of residential migrations to be changed in one desired direction because of chain effects in household re-locations (dwellings vacated and then reoccupied). In French cities, new dwellings represent at most $15 \%$ of the dwelling offer. This partly explains why those urban systems are characterized by a strong path dependency and why it seems impossible to define general planning solutions, which could be applied successfully in any location (Couch et al. 2011).

In this paper, we have presented an experimental trial involving the use of a complex spatial simulation platform (MobiSim) to support a planning decision process in the city of Besançon (France). The simulation platform was used to explore the possible outcomes of spatial planning policies, set by both the Greater Besançon authority (Besançon and the surrounding periurban communities) and the city of Besançon, on residential location dynamics. The paper illustrates the usefulness of the simulation model in two respects. Firstly, its usefulness for exploring specific land use development strategies through considering both residential choice and satisfaction, and secondly its usefulness as a medium for knowledge sharing between researchers and planners and providing a structured environment for these exchanges. As underlined by Peltzer et al. (2015), assessing the usefulness of a planning support system depends on whether its application leads to an improvement (i.e. an added value) in comparison to a situation without it. We will discuss these dimensions in the conclusion below as well as trying to assess the limitations and constraints of the trial, and speculate on possible ways to extend the research.

\subsection{Usefulness of MobiSim as a medium for knowledge sharing between researchers and planners}

This experimental trial gave the researchers and the planning actors involved in it the occasion to compare their scientific knowledge and their empirical knowledge through a specific medium: a simulation platform. Because the modelling process requires the implicit to be made explicit, it favoured such exchanges. The trial was useful for both planning actors and researchers. 
The planning actors expanded their knowledge about residential choices and residential dynamics through the exchanges with researchers. At the very beginning of the trial, some questions of the planning actors were about the decision criteria for households wishing to buy their own property: are size and cost most important, or is housing type (flat or detached house) or even the quality of the residential environment (landscape, services, public transport) equally significant? One important answer obtained though the trial is that it is the dissatisfaction with their dwelling more than the dissatisfaction with their residential environment that pushes target households to move outside Besançon. The most satisfied households are single parent families living in Besançon and couples with children living in periurban areas. The first are especially satisfied by their residential environment and less satisfied by their dwelling. The second are especially satisfied by their dwelling and less satisfied by their residential environment.

As a consequence of the trial, the interest of the planning actors regarding the researchers' knowledge of residential choices has become stronger. The planning actors, joined by several other colleagues of their planning department, have thus proposed to the researchers to work with them on the project of residential development of one neighbourhood of Besançon (Les Planches-Relançon), which is located close to a large forest at the edge of the city. This development project is governed by Besançon city council, which allows the local authority to impose planning and design rules on private developers. For defining these rules, we use MobiSim to estimate the attractiveness of the neighbourhood Les Planches-Relançon for households with children living in Greater Besançon. On this basis, we identify which attributes of the neighbourhood have to be improved in order to make it more attractive with respect to other residential places in Greater Besançon.

For the researchers, one advantage of the experimental trial was to force them to distance themselves from the theory by coming face to face with the situation on the ground and its constraints, including those of a political nature. They experienced the fact that the conception of a model, designed for a practical application, requires an interaction with the actors for whom the model is designed. Even though the focus of the model is household residential choice, the model also has to incorporate the variables representing possible planning levers. On this point, it is the planning actors themselves who are best equipped to provide the data and information that the model must take into account in its choice of variables. Last but not least, working on a scenario representing real social and community issues, and not simply the ideas of a limited number of academics, was a source of motivation for the researchers.

\subsection{Usefulness of MobiSim for exploring specific land use development strategies}

The simulation of the 'Business as usual' scenario was, as it were, a means to thoroughly explore current dynamics within Besançon and its urban region (current residential choice behaviours, current demographic trends). The trial then led the group to discuss possible planning actions designed to reduce migration flows of households with children out of Besançon into periurban areas. MobiSim does not provide planning solutions but it does allow users to test the likely effects of planning solutions postulated by the actors. Because the researchers were somewhat naïve in terms of planning and local politics, but sincerely interested in deepening their thinking, the discussion about the respective advantages and disadvantages of each planning action was open and fruitful. Following this, the planning action selected for simulation (Pro-active housing construction policy by the city of Besançon) had to be defined precisely: number of dwellings, types of dwellings, location, etc. 
For this, the planning actors thought about different alternatives and discussed them within the Department of Planning, Projects and Forward Planning and with the elected members concerned. In the end, nothing less than seventeen versions were explored successively.

Both the planning actors and the researchers are now looking into new simulations with MobiSim for responding to new planning questions. The current context in Besançon is particularly favourable: following municipal elections in March 2014, the new elected member responsible for housing wants to review the policy envisaged by the previous administration.

\subsection{Conditions under which a complex simulation platform such as MobiSim can be useful for planning}

The approach adopted for conceiving and using MobiSim responds to some conditions for further improvement of Planning Support Systems put forward by Te Brömmelstroet et al. (2014):

"1) Embrace ignorance: Most urban systems are inherently complex and open. At best, PSS can capture but a tiny part of their-often exponential and unexpected-reciprocal relations. We should always leave room to problematise model assumptions and outcomes (...)."

MobiSim takes into account many variables, and models many interactions among the variables. Therefore, the complexity of the system modelled is not hidden. Moreover, unknown and non-modelled phenomena are clearly set out.

"2) Transparency: As much as possible we need to make assumptions and all relations between input and output of our PSS transparent and understandable (...). Only then can a user verify and use the model to learn. "

MobiSim is an anti-black box platform: in principle every participant in the experimental trial knew what was inside the model; every participant could understand its variables and its functionning. The platform does not contain any technical or mathematical refinements that would not be understandable by planning practitioners or by elected members of local communities.

"3) Secure soft values: PSS traditionally work with quantitative information, but in most planning processes key qualitative aspects need to be considered. The performativity of models can be countered by focusing more on these qualitative values. "

MobiSim is based on a "soft" quantification: the use of fuzzy categories allows the introduction of many qualitative aspects in the modelling.

"4) A structured dialogue: A classic mistake in the development of urban models and PSS is to exclude the end user from important choices early in the development process.

(...) Developing PSS that allow for contextualisation seems an important way forward in combatting the planners' often antagonistic attitude. This confrontation with practical knowledge and the emerging mutual learning process will also improve the models. "

The conception of MobiSim results both from the work of the researchers in their laboratory but also from their exchanges with planning actors involved in the trial. The introduction into the model of local housing taxes and the possibility to simulate controlled residential development arose, in particular, from those exchanges. Planning actors also insisted upon the necessity of taking into account the PLH and SCoT in the simulated scenarios. 
In spite of all the encouraging results obtained, the trial also shows some limitations. First, the time period between the beginning of the trial and getting acceptable and interesting results was long: about two years. Numerous intermediary simulation results were unsatisfactory because the model was unfinalised. Given the time associated with drawing up revised landuse plans, the extended time required for such a simulation process remains compatible with plan making time-scales. Nevertheless, the conception of the 'Pro-active housing construction' scenario in Besançon took significant time, both for the planning actors and the researchers. The second limitation concerns technical and computing aspects. Running a simulation with MobiSim and making use of the results requires a high level of technical knowledge: not only does the user need to understand the model well, but he or she must also be capable of running simulations using command lines on a supercomputer (HPC) and of interpreting results represented by several gigabytes of data (the simulated data are at the scale of the household, the dwelling and the building and the output of results requires an average of ten replications of the same simulation to be calculated). These two limitations bring into question the possibility of reproducing the trial. They also highlight that this kind of PSS makes the planning actors heavily dependent on the expertise of the researchers for every stage of the process.

\subsection{Positing the experimental trial in a decision-making environment}

Malczewski (2004, page 9) has identified three stages in GIS development: the stage of "Invitation", where the perspectives for planning were essential scientific; the stage of "Integration", where perspectives for planning were political; and the current stage of "Proliferation", where perspectives for planning are participatory and collective design.

The use of the individual-based LUTI simulation model MobiSim at the stage of "Invitation" The trial involved only two planning actors belonging to the same planning department in Besançon city council, which was the single local authority involved. At this "invitation" stage, the decision-making environment was very simple: limited number of participants, a single common shared objective, no financial investment by the local authority, a limited time investment by the local authority, and no direct contact between the researchers and elected members.

A new research project that could allow MobiSim to enter the stage of "Integration" The Greater Besançon authority has become aware of the existence of the simulation platform MobiSim. One researcher and one planning actor of Besançon city council were invited in November 2014 to present the experimental trial they led with MobiSim. Between December 2014 and January 2015, a face-to-face meeting and several exchanges by email and telephone took place. Following this, the Greater Besançon authority agreed to the use of MobiSim. Elected members will participate in two workshops: one, to present the 'Business as usual' scenario for Greater Besançon and to debate alternatives; the second to discuss the simulation results produced by MobiSim for the chosen alternative scenario. One theme that will be discussed is the creation of a unified housing tax policy for the Greater Besançon area: an aspect that was not a feature of the Besançon trial. Such a policy could reduce the residential attractiveness of peri-urban parts of Greater Besançon to the benefit of surrounding rural local authorities with lower property taxes. At the same time, such a change could also increase the attractiveness of Besançon in relation to its surrounding peri-urban areas. 
As in the case of the trial in Besançon, the local authority will not fund the project, but a new aspect will be the observation by the researchers of the process of political debate and decision-making by elected members.

The decision-making situation of this new project is more complex than in the Besançon trial: it involves all the local authorities in the Greater Besançon area and not just Besançon City Council. Those local authorities have conflicting objectives, not least because the different mayors belong to different political parties. This should offer the opportunity to observe the effect of the simulation model on a larger group of actors, both planners and elected members, and see how the use of the simulation model develops in a different environment. This should help to draw some conclusions about the extent to which the usefulness of MobiSim in Besançon City Council was contingent on unique factors such as the receptiveness of the two planners or the relative simplicity of the political environment (a single local authority structure at a moment of relative openness to ideas about a new strategic direction for development).

When it is used, simulation is an input to the very early stage of the policy making process and the impact on the decision making of the elected members is unknown and unexplored as yet. The objective of this new project is thus to study the extent to which the use of MobiSim does or does not modify the planning decision processes in which it is involved as well as the representations of researchers, planners and elected members. The research design will involve an explicit protocol for assessing these effects, and posit three hypotheses:

- It is possible to change the way actors (planning practioners and politicians) perceive and understand the area they are planning for, by means of a process of knowledge exchange via a complex simulation tool like MobiSim.

- The actors (planning practioners and politicians) use their knowledge of an area stategically, and removing uncertainties may change the balance of power between them. The use of MobiSim can enable the planners to present decision makers with the likely or possible outcomes of their decisions. Consequently it would be possible for them to use MobiSim to shape the planning agenda by simulating and discussing some scenarios but not others.

- Knowledge sharing between actors and researchers leads to changes in the models and the tools developed by the latter.

Insights on the stage of "Proliferation"

Following this trial, the group has developed a capacity to conceive and test scenarios in MobiSim (data preparation, variable quantification) and analyse the simulation results. But the researchers involved in the project are not in a position to maintain an open-ended commitment to facilitating the use of MobiSim for planning scenarios in Besançon or any other city. In addition, because of the technical complexity of simulation with MobiSim, the planning department of the City of Besançon is not able to use the platform without assistance. One solution could be to create a consultancy firm, or that the TheMA research centre enters into a partnership with an existing consultancy within which the personnel would be trained in simulation using MobiSim. This would allow the platform to be used more widely as support for planning decision processes.

Nevertheless, the most well-known computer-based planning support systems (e.g. UrbanSim, What If, Community Viz, Metronamica) have not yet reached this stage of "Proliferation" although they were developed by research teams having entered public-private partnerships and/or being internationally recognized in the scientific community. Based on the analysis of Brail (2006), Klosterman and Pettit (2005) posit that three factors are required for computerbased tools to be widely used in practice: a shared commitment to a well-defined 
methodology, extensive government support, and the ability of available tools to provide needed outputs for a substantial user community. For them, none of these conditions existed in 2005 for computer-based PSS anywhere in the world. Might they exist in a near future?

\section{References}

Andersson, C., Lindgren, K., Rasmussen, S., White, R., 2002. Urban growth simulation from “first principles”. Physical review E, 66, 026204, 1-9.

Andersson, C. 2008. Ontogeny and ontology in complex systems modeling. In S. Albeverio, D. Andrey, P. Giordano, A. Vancheri, The Dynamics of Complex Urban Systems: An Interdisciplinary Approach, PhysicaVerlag Heidelberg, New York, 43-58.

Antoni, J.-P., 2006. Calibrer un modèle d'évolution de l'occupation du sol urbain. L'exemple de Belfort, Cybergéo : revue européenne de géographie, 347. http://cybergeo.revues.org/index.html

Antoni, J.-P., Tannier C., Vuidel G., Hirtzel J. 2011. MobiSim. Rapport final PREDIT, Groupe Opérationnel nº6, Recherche 09MTCV34.

Apparicio, P., Seguin, A., 2006. Measuring the accessibility of services and facilities for residents of public housing in Montréal. Urban studies, 43(1), 187-211.

Arentze, T., Borgers, A., Timmermans, H., 2006. A heuristic method for land-use plan generation in planning support systems, Progress in Design \& Decision Support Systems in Architecture and Urban Planning, van Leeuwen J., Timmermans H. (Eds.), Eindhoven University of Technology, NL, 135-151.

Batty, M., Vargas, C., Smith, D., Serras, J., Reades, J., Johansson, A., 2013. SIMULACRA: fast land-usetransportation models for the rapid assessment of urban futures. Environment and Planning B: Planning and Design, 40, 987-1002.

Baumont, C. 2009. Spatial Effects of urban public policies on housing values. Papers in Regional Science, 88, 301-326.

Becu, N., Neef, A., Schreinemachers, P., Sangkapitux, C. 2008. Participatory computer simulation to support collective decision-making: Potential and limits of stakeholder involvement. Land Use Policy 25(4): 498-509.

Benabou, R. 1993. Workings of a city: location, education and production. The Quarterly Journal of Economics, 108, 619-652.

Ben-Akiva, M., de Palma, A., 1986. Analysis of a dynamic residential location choice model with transaction costs. Journal of Regional Science, 26(2), 321-341.

Benenson, I., 1998. Multi-agent simulations of residential dynamics in the city. Computers, Environment and Urban Systems, 22(1), 25-42.

Benenson, I., Omer, I., Hatna, E., 2002. Entity-based modeling of urban residential dynamics: the case of Yaffo, Tel Aviv. Environment and Planning B: Planning and Design, 29, 491-512.

Benenson, I., 2004. Agent-based modeling: From individual residential choice to urban residential dynamics. Spatially integrated social science: Examples in best practice, 42(6-7), 67-95.

Bonaiuto, M., Fornara, F., Bonnes, M., 2003. Indexes of perceived residential environment quality and neighbourhood attachment in urban environments: a confirmation study on the city of Rome. Landscape and Urban Planning, 65, 41-52.

Bonnet, C., Burricand, C., Colin, C., Flipo, A., Mahieu, R., Ralle, P., Sédillot, B., 1999. Le modèle de microsimulation dynamique DESTINIE. Série des documents de travail de la Direction des Etudes et Synthèses Economiques - G9913", INSEE.

http://www.insee.fr/fr/themes/document.asp?reg id=0\&ref id=G9913

Booth, H., 2006. Demographic forecasting: 1980 to 2005 in review. International Journal of Forecasting, 22(3), 547-581.

Bousquet, F., Barreteau, O., D'Aquino, P., Etienne, M., Boissau, S., Aubert, S., Le Page, C., Babin, D. Castella, J.-C. 2002. Multi-agent systems and role games: collective learning processes for ecosystem management. In: M. Janssen (Ed). Complexity and ecosystem management: The theory and practice of multi-agent approaches. Edward Elgar Publishers, 248-285. 
Bramley, G., Power, S., 2009. Urban form and social sustainability: the role of density and housing type. Environment and Planning B: Planning and Design, 36, 30-48.

Brown, D.G., Robinson, D.T., 2006. Effects of heterogeneity in residential preferences on an agent-based model of urban sprawl. Ecology and society, 11(1), 46. http://www.ecologyandsociety.org/vol11/iss1/art46/

Brueckner, J., Thisse, J., Zenou, Y., 1999. Why is central Paris rich and downtown Detroit poor? An amenitybased theory. European Economic Review, 43, 91-107.

Cao, X., Mokhtarian, P., Handy, S., 2009. The relationship between the built environment and nonwork travel: a case study of northern California. Transportation Research Part A, 43, 548-559.

Carpentier, S., Gerber, P., 2009. De la mobilité quotidienne à la recomposition des espaces de vie quotidienne. Recherche, Transports, Sécurité, 102, 61-72.

Castella, J. C., Tran Ngoc Trung, Boissau, S. 2005. Participatory simulation of land-use changes in the northern mountains of Vietnam: the combined use of an agent-based model, a role-playing game, and a geographic information system. Ecology and Society 10(1, 27. http://www.ecologyandsociety.org/vol10/iss1/art27/

Cavailhès, J., Brossard, T., Foltête, J., Hilal, M., Joly, D., Tourneux, F., Tritz, C., Wavresky, P., 2009. GIS-based hedonic pricing of landscape. Environmental and Resource Economics, 44(4), 571-590.

Charlot, S., Hilal, M., Schmitt, B. 2009. La périurbanisation renforce-t-elle la ségrégation résidentielle urbaine en France ? Espace populations sociétés, 2009/1 http://eps.revues.org/index3556.html

Chingcuanco, F., Miller, E.J., 2013. A Demographic Microsimulation Model for the Integrated Land Use, Transportation, 2 Environment (ILUTE) Model System. TRB 2013 Annual Meeting, 16p.

Cho, S., Poudyal, N.C., Roberts, R.K., 2008. Spatial analysis of the amenity value of green open space. Ecological Economics, 66, 403-416.

Cornelis, E., Barthelemy, J., Pauly, X., Walle, F., 2012. Modélisation de la mobilité résidentielle en vue d'une micro-simulation des évolutions de population. Les cahiers scientifiques du transport, 62, 65-84.

Couch, C., Sykes, O., Börstinghaus, W., 2011. Thirty years of urban regeneration in Britain, Germany and France: The importance of context and path dependency. Progress in Planning, 75, 1-52.

Décamps, A., Gaschet, F. 2013. La contribution des effets de voisinage à la formation des prix du logement : une évaluation sur l'agglomération bordelaise, Revue Économique, 64(5), 883-910.

Devisch, O., Timmermans, H., Arentze, T., Borgers, A., 2009. An agent-based model of residential choice dynamics in nonstationary housing markets. Environment and Planning A, 41, 1997-2013.

Dieleman, F.M., Mulder, C.H., 2002. The geography of residential choice. In Aragonés, J., Franscecato, G., Gärling, T. (Eds.), Residential environments: choice, satisfaction, and behaviour, Bergin \& Garvey, Westport (Conn.), 35-54.

Ellis, C.D., Lee, S.-W., Kweon, B.-S., 2006. Retail land use, neighborhood satisfaction and the urban forest: an investigation into the moderating and mediating effects of trees and shrubs. Landscape and Urban Planning, 74, 70-78.

Ettema, D., Jong, K., Timmermans, H. J. P., Bakema, A., 2007. PUMA: multi-agent modelling of urban systems. In E. Koomen, J. Stillwell, Aldrik Bakema, \& H. J. Scholten, (Eds.) Modelling Land-Use Change, 90, Dordrecht: Springer, 237-258.

Ettema, D., Arentze, T., Timmermans, H.J.P., 2011. Social influences on household location, mobility and activity choice in integrated micro-simulated models. Transportation Research Part A: Policy and Practice, 45, 283-295.

Failing, L., Gregory, R., Harstone, M., 2007. Integrating science and local knowledge in environmental risk management: A decision-focused approach. Ecological enconomics, 64, 47-60.

Fernandez, L.E., Brown, D.G., Marans, R.W., Nassauer, J.I., 2005. Characterizing location preferences in an exurban population: implications for agent-based modeling. Environment and Planning B, 32(6), 799-820.

Filatova, T., Parker, D., van der Veen, A., 2009. Agent-based urban land markets: agent's pricing behavior, land prices and urban land use change. Journal of Artificial Societies and Social Simulation, 12(13), Access: http://jasss.soc.surrey.ac.uk/12/1/3.html

Föbker, S., Grotz, R., 2006. Everyday mobility of elderly people in different urban settings: the example of the city of Bonn, Germany. Urban studies, 43(1), 98-118. 
Forsyth, A., Hearts, M., Oakes, J., Schmitz, K., 2008. Design and destinations: factors influencing walking and total physical activity. Urban studies, 45(9), 1973-1996.

Franscescato, G., 2002. Residential satisfaction research: the case for and against, In Aragonés, J., Francescato, G., Gärling, T. (Eds.), Residential environments. Choice, satisfaction, and behavior. Bergin \& Garvey, 15-34.

Gärling, T., Friman, M., 2002. A psychological conceptualization of residential choice and satisfaction, In Aragonés, J., Francescato, G., Gärling, T. (Eds.), Residential environments. Choice, satisfaction, and behavior. Bergin \& Garvey, 55-80.

Ge, J., Hokao, K., 2006. Research on residential lifestyles in Japanese cities from the viewpoints of residential preference, residential choice and residential satisfaction. Landscape and urban planning, 78, 165-178.

Handy, S., Cao, X., Mokhtarian, P., 2005. Correlation or causality between the built environment and travel behavior? Evidence from northern California. Transportation Research Part D, 10, 427-444.

Hirtzel, J. 2015. Exploring the residential mobility in an urban region using an agent-based modelling (MobiSim) [In French]. PhD thesis, University of Franche-Comté, Besançon, France.

Holm, E., Holme, K., Mäkilä, K., Mattsson-Kauppi, M., Mörtvik, G., 2006. The SVERIGE spatial microsimulation model. In 8th Nordic Seminar on Microsimulation Models, Oslo. 8-9.

Hoshino, T., 2011. Estimation and analysis of preference heterogeneity in residential choice behaviour. Urban studies, 48(2), 363-382.

Hur, M., Nasar, J.L., Chun, B., 2010. Neighborhood satisfaction, physical and perceived naturalness and openness. Journal of Environmental Psychology, 30, 52-59.

Ioannides, Y.M., 1987. Residential mobility and housing tenure choice. Regional Science and Urban Economics, 17, 265-287.

Jago, R., Baranowski, T., Zakeri, I., Harris, M., 2005. Observed environmental features and the physical activity of adolescent males: gis coding differences. American Journal of Preventive Medicine, 29(2), 98-104.

Janssen R, van Herwijnen M, Stewart T, Aerts J, 2008. Multiobjective decision support for land-use planning, Environment and Planning B: Planning and Design, 35, 740-756.

Jordan, R., Birkin, M., Evans, A., 2011. Agent-based simulation modelling of housing choice and urban regeneration policy. Multi-Agent-Based Simulation XI, 152-166.

Kamps, S., 2013. Dual-agent simulation model of the residential development process: an institutional approach to explaining the spatial patterns of residential developments in France, England and the Netherlands. PhD thesis, University of Franche-Comté (Besançon, France).

Kaplan, R., Kaplan, S., 1989. The experience of nature: A psychological perspective. Cambridge University Press, New York, 341p.

Kestens, Y., Thériault, M., Des Rosiers, F., 2004. The impact of surrounding land use and vegetation on singlefamily house prices. Environment and Planning B: Planning and Design, 31(4), 539-567.

Kim, J.H., Pagliara, F., Preston, J., 2005. The intention to move and residential location choice behaviour. Urban Studies, 42(9), 1621-1636.

Kweon, B., Ellis, C., Leiva, P., Rogers, G., 2010. Landscape components, land use, and neighborhood satisfaction. Environment and Planning B: Planning and Design, 37, 500-517.

Lallement, A., Moyne, P. (2013). Analyse entre coûts de transport et de logement pour le choix d'un lieu de résidence. Comparaison de scénarios pour un ménage solvable avec enfants travaillant à Besançon. Mémoire de master, sous la direction de C. Tannier et O. Govignaux, Université de Franche-Comté.

Lévy, J.-P., 2009. Mobilités urbaines : des pratiques sociales aux évolutions territoriales. In Dureau, F., Hily, M. (Eds.), Les mondes de la mobilité. Presses universitaires de Rennes, Rennes (France), 107-136.

Li, X, Liu, X, 2008. Embedding sustainable development strategies in agent-based models for use as a planning tool, International Journal of Geographical Information Science, 22(1) 21-45.

Ligmann-Zielinska, A., Church, R L., Jankowski, P., 2008. Spatial optimization as a generative technique for sustainable multiobjective land-use allocation. International Journal of Geographical Information Science, 22(6), 601-622.

Ma, L., Arentze, T., Borgers, A., Timmermans, H., 2006. A multi-agent model for generating local land-use plans in the context of an urban planning support system. In van Leeuwen J.P., Timmermans H. (Eds.), Progress in 
Design \& Decision Support Systems in Architecture and Urban Planning, Eindhoven University of Technology, 153-168.

Malczewski, J., 2004. GIS-based land-use suitability analysis: a critical overview. Progress in Planning, 62, 365.

Moles, A., Rohmer, E., 1977. Théorie des actes. Vers une écologie des actions. Paris, Casterman.

Morand, E., Toulemon, L., Pennec, S., Baggio, R., Billari, F., 2010. Demographic modelling: the state of the art. Working Paper 2.1a. FP7-24455, Project SustainCity, INED, Paris. http://www.sustaincity.org/publications/WP 2.1a Demographic Models.pdf

Murphy, M., 2003. Bringing behavior back into micro-simulation: feedback mechanisms in demographic models. In Billari F.C., Prskawetz A. (Eds), Agent-Based Computational Demography, Physica-Verlag, Heidelberg, 159-174.

Nguyen-Luong, D., Boucq, E., 2011. Evaluation de l'impact du t3 sur les prix de l'immobilier résidentiel. Etude de l'IAU Ile-de-France pour le PREDIT (Groupe opérationnel nº). http://www.iau-idf.fr/detail/etude/evaluation-de-limpact-du-t3-sur-les-prix-de-limmobilier-residentiel.html

Nicolas, J.-P., Bonnel, P., Cabrera, J., Godinot, C., Homocianu, M., Routhier, J.-L., Toilier, F., Zucarello, P., 2009. SImuler les MoBilités pour une Agglomération Durable - Rapport final du projet Simbad, Laboratoire d’Économie des Transports, Lyon. http://simbad.let.fr/documents/Rapports/Simbad R9 Final.pdf

Pellegrini, P., Fotheringham, A., 2002. Modelling spatial choice: a review and synthesis in a migration context. Progress in Human Geography, 26(4), 487-510.

Onaka, J., Clark, W. 1983. A disaggregate model of residential mobility and housing choice. Geographical Analysis, 15(4), 287-304.

Orcutt, G., Caldwell, S., Wertheimer II, R., 1976. Policy Exploration through Microanalytic Simulation. The Urban Institute, Washington DC.

Prashker, J., Shiftan, Y., Hershkovitch-Sarusi, P., 2008. Residential choice location, gender and the commute trip to work in Tel Aviv. Journal of Transport Geography, 16(5), 332-341.

Quigley, J. M. 1985. Consumer choice of dwelling, neighborhood and public services. Regional Science and Urban Economics, 15(1), 41-63.

Raju, K., Sikdar, P.K., Dhingra, S.L., 1998. Micro-simulation of residential location choice and its variation. Computers, Environment and Urban Systems, 22(3), 203-218.

Ratiu, E., 2003. L'évaluation de l'environnement. In Moser G., Weiss K. (dir.), Espaces de vie. Aspects de la relation homme-environnement, Armand Colin, Paris, 85-112.

Ravulaparthy, S., Goulias, K., 2011. Forecasting with dynamic microsimulation: design, implementation, and demonstration. Final report "Earlier Faculty Research", University of California Transportation Center, Santa Barbara.

Roberts, S.A., Hall, G.B., Calamai, P.H., 2011. Evolutionary Multi-objective Optimization for landscape system design, Journal of geographical systems, 13(3), 299-326.

Saarloos, D., Arentze, T., Borgers, A., Timmermans, T., 2005. A multiagent model for alternative plan generation. Environment and Planning B: Planning and Design, 32, 505-522.

Saaty, T.L. 1977. A scaling method for priorities in hierarchical structures. Journal of mathematical psychology, $15,234-281$.

Saaty, T.L., 1990 The analytic hierarchy process in conflict management, International Journal of Conflict Management, 1(1), 47-68.

Srour, I., Kockelman, K., Dunn, T., 2002. Accessibility Indices: Connection to Residential Land Prices and Location Choices. Transportation Research Record: Journal of the Transportation Research Board, 1805(-1), 25-34.

Tannier, C., Frankhauser, P., 2001. From the observations to the construction of an urban dynamics simulation model: an inductive approach. Cybergeo: European Journal of Geography, 191.

http://cybergeo.revues.org/index.html

Tannier, C., Frankhauser, P., Houot, H., Vuidel, G., 2011. Probabilistic modelling for simulating intra-urban residential migration. Application to the question of traffic noise annoyance, In: Alexandre, V. (Ed.), Penser et agir. Contextes philosophique, praxéologique et langagier - Tome 2. Le manuscript, Paris, 131-175. 
Tannier, C., Thomas, I., Vuidel, G., Frankhauser, P., 2011. A fractal approach to identifying urban boundaries. Geographical Analysis, 43(2), 211-227.

Te Brömmelstroet M., 2009. Commentary. The relevance of research in planning support systems: a response to Janssen et al. Environment and Planning B: Planning and Design, 36, 4-7.

Te Brömmelstroet, M., Pelzer, P., Geertman, S. (2014). Commentaries: Forty years after Lee’s Requiem: are we beyond the seven sins? Environment and Planning B: Planning and Design, 41, 381-386.

Timmermans, H., Borgers, A., Van Dijk, J., Oppewal, H., 1992. Residential choice behaviour of dual earner households: a decompositional joint choice model. Environment and Planning A, 24, 517-533.

Thomas, I. (2002). Transportation networks and the optimal location of human activities: a numerical geography approach, Edward Elgar Publishers.

Tufte, E.R. (2001) [1983], The Visual Display of Quantitative Information, Second Edition, Graphics Press, Cheshire, Connecticut, p.125

Tyrväinen, L., Miettinen, A., 2000. Property Prices and Urban Forest Amenities. Journal of Environmental Economics and Management, 39, 205-223.

Van Imhoff, E., Post, W., 1997. Méthodes de micro-simulation pour des projections de population. Population (French Edition), 52(4), p.889.

van Ommeren, J.N., Rietveld, P., Nijkamp, P., 1999. Job moving, residential moving, and commuting: a search perspective. Journal of Urban Economics, 46(2), 230-253.

Vega, A., Reynolds-Feighan, A., 2009. A methodological framework for the study of residential location and travel-to-work mode choice under central and suburban employment destination patterns. Transportation Research Part A: Policy and Practice, 43(4), 401-419.

Watson, V., 2009. 'The planned city sweeps the poor away...’: Urban planning and 21st century urbanisation. Progress in Planning, 72, 151-193.

Wegener, M., 1985. The Dortmund housing market model A Monte Carlo simulation of a regional housing market. Microeconomic Models of Housing Markets, 239, 144-191.

Wegener, M., 2004. Overview of land-use transport models. In Hensher D.A., Button K., Handbook in transport, 9, Transport geography and spatial systems, Pergamon-Elsevier, 127-146.

Weidlich, W., Haag, G., 1987. A dynamic phase transition model for spatial agglomeration processes. Journal of Regional Science, 27(4), 529-569.

Weidlich W. 2000-2006. Sociodynamics: a systematic approach to mathematical modelling in the social sciences. Reprinted by Dover Publications, Series: Dover Books on Mathematics.

Weisbrod, G. E., Lerman, S. R., Ben-Akiva, M., 1980. Tradeoffs in residential location decisions: transportation versus other factors. Transport Policy and Decision Making, 1(1), 13-26.

White, R, Engelen, G, Uljee, I, 1997, The use of constrained cellular automata for high-resolution modelling of urban land use dynamics. Environment and Planning B, 24, 235-246.

Wilson, A. 2010. The general urban model: Retrospect and prospect. Papers in Regional Science, 89(1), 27-42.

Yager, R., 1977. Multiple objective decision-making using fuzzy sets. International journal of man-machine studies, 9, 375-382.

Youssoufi, S, Foltête, J.-C., 2013. Determining appropriate neighborhood shapes and sizes for modeling landscape satisfaction. Landscape and Urban Planning, 110, 12-24.

Zaidi, A., Rake, K., 2001. Dynamic microsimulation models : a review and some lessons for SAGE. Simulating Social Policy in an Ageing Society (SAGE), Discussion paper (2), ESRC Grant number M565-28-1001, London.

\section{Appendix 1}

\begin{tabular}{|l|l|l|l|}
\hline \multicolumn{1}{|c|}{ Name } & \multicolumn{1}{|c|}{ Competences } & \multicolumn{1}{c|}{$\begin{array}{c}\text { Role in the development of the } \\
\text { MobiSim application }\end{array}$} & $\begin{array}{c}\text { Participation in } \\
\text { the experiment }\end{array}$ \\
\hline $\begin{array}{l}\text { Armelle } \\
\text { Couillet }\end{array}$ & $\begin{array}{l}\text { Cartographer, University of } \\
\text { Franche-Comté (Besançon) }\end{array}$ & $\begin{array}{l}\text { Mapping and geovisualization of } \\
\text { simulation results }\end{array}$ & NO \\
\hline
\end{tabular}




\begin{tabular}{|l|l|l|l|}
\hline $\begin{array}{l}\text { Olivier } \\
\text { Govignaux }\end{array}$ & $\begin{array}{l}\text { Research Officer in the } \\
\text { Department of Planning, } \\
\text { Projects and Forward Planning, } \\
\text { Besançon City council }\end{array}$ & $\begin{array}{l}\text { Discussion about hypotheses of the } \\
\text { model; definition of the two simulated } \\
\text { scenarios }\end{array}$ & YES \\
\hline $\begin{array}{l}\text { Joanne } \\
\text { Hirtzel }\end{array}$ & $\begin{array}{l}\text { PhD student in geography, } \\
\text { University of Franche-Comté } \\
\text { (Besançon) }\end{array}$ & $\begin{array}{l}\text { Setting of the residential mobility } \\
\text { simulation model; conception and setting } \\
\text { of the model for simulating demographic } \\
\text { evolutions }\end{array}$ & YES \\
\hline $\begin{array}{l}\text { Pascal } \\
\text { Millard }\end{array}$ & $\begin{array}{l}\text { Head of the Department of } \\
\text { Planning, Projects and Forward } \\
\text { Planning, Besançon City } \\
\text { council }\end{array}$ & $\begin{array}{l}\text { Discussion about hypotheses of the } \\
\text { model; definition of the two simulated } \\
\text { scenarios }\end{array}$ & YES \\
\hline $\begin{array}{l}\text { Richard } \\
\text { Stephenson } \\
\text { Lecturer in English and British } \\
\text { Franche-Comté (Besançon) }\end{array}$ & $\begin{array}{l}\text { Analysis and discussion of simulation } \\
\text { results }\end{array}$ & NO \\
\hline $\begin{array}{l}\text { Cécile } \\
\text { Tannier }\end{array}$ & $\begin{array}{l}\text { Research associate in } \\
\text { geography and planning, French } \\
\text { National Centre for Scientific } \\
\text { Research }\end{array}$ & $\begin{array}{l}\text { Conception and setting of the models for } \\
\text { simulating residential mobility and } \\
\text { residential development }\end{array}$ & YES \\
\hline $\begin{array}{l}\text { Gilles } \\
\text { Vuidel }\end{array}$ & $\begin{array}{l}\text { Computer scientist, French } \\
\text { National Centre for Scientific } \\
\text { Research }\end{array}$ & $\begin{array}{l}\text { Conception and computer programming } \\
\text { of the MobiSim platform }\end{array}$ & NO \\
\hline $\begin{array}{l}\text { Samy } \\
\text { Youssoufi }\end{array}$ & $\begin{array}{l}\text { Lecturer in geography and } \\
\text { planning, University of } \\
\text { Franche-Comté (Besançon) }\end{array}$ & $\begin{array}{l}\text { Setting of the residential mobility } \\
\text { simulation model }\end{array}$ & NO \\
\hline
\end{tabular}




\section{Appendix 2}

Importance of attributes of current residential environment [E]I]

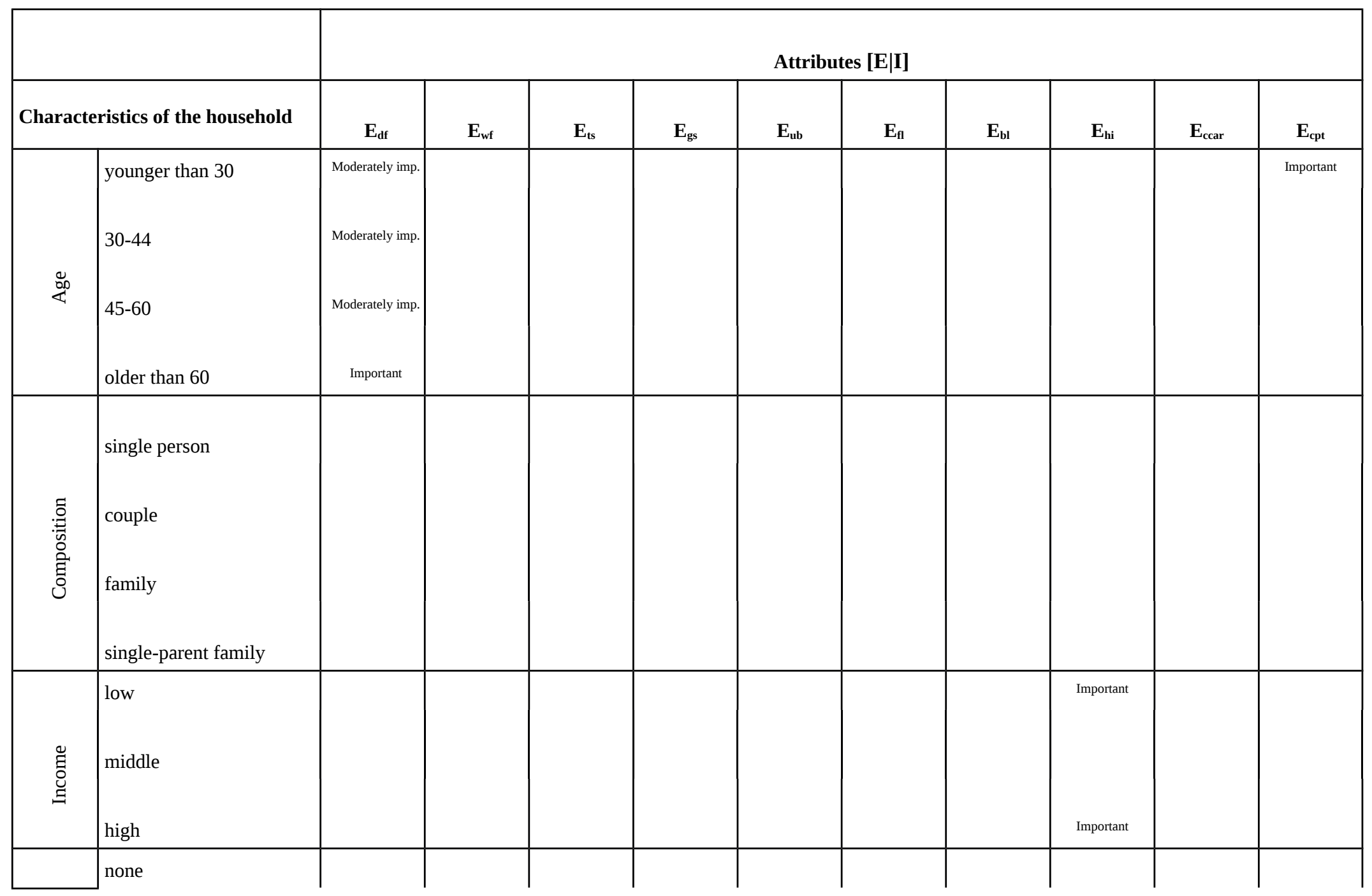




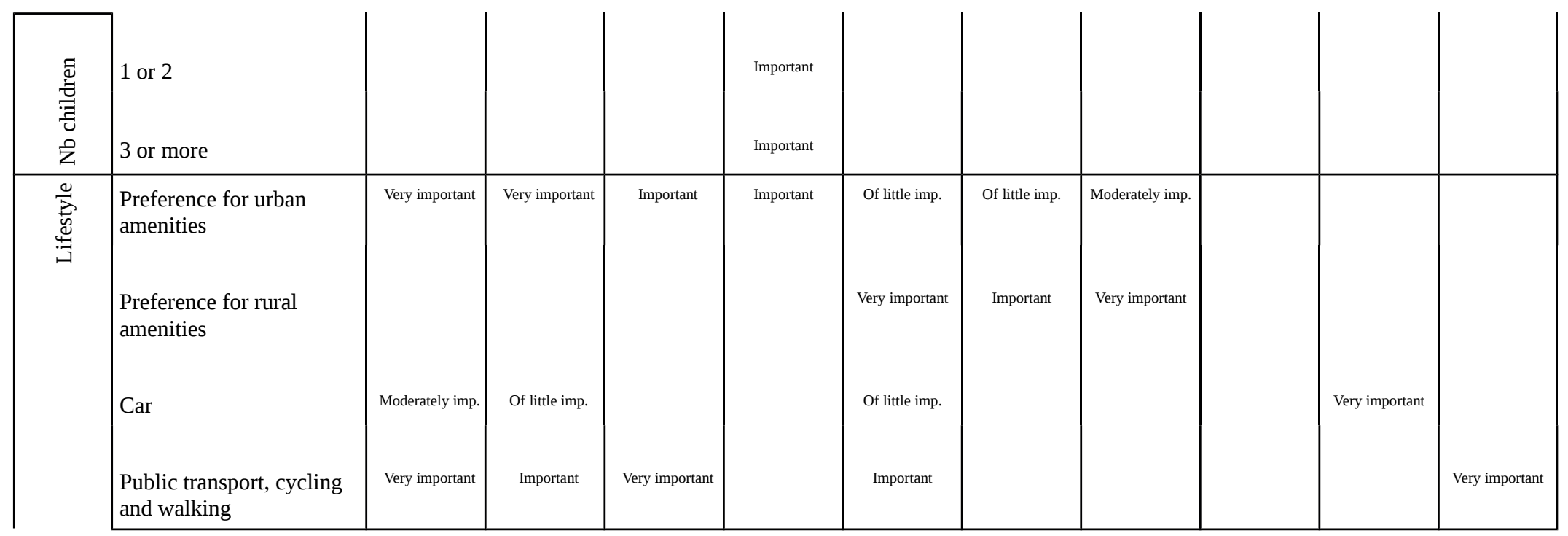


Importance of attributes of possible future residential environment [E|J]

\begin{tabular}{|c|c|c|c|c|c|c|c|c|c|c|c|c|c|}
\hline & & \multicolumn{12}{|c|}{ Attributes $[\mathbf{E} \mid \mathbf{J}]$} \\
\hline \multicolumn{2}{|c|}{ Characteristics of the household } & $\mathbf{E}_{\mathrm{df}}$ & $\mathbf{E}_{\mathrm{wf}}$ & $E_{t s}$ & $E_{g s}$ & $E_{u b}$ & $E_{\mathrm{fl}}$ & $E_{b 1}$ & $E_{h i}$ & $\mathbf{E}_{\mathrm{c} c \mathrm{a}}$ & $E_{c c t}$ & $\mathbf{E}_{\text {wcar }}$ & $\mathbf{E}_{\text {wpt }}$ \\
\hline$\stackrel{\text { on }}{4}$ & $\begin{array}{l}\text { younger than } 30 \\
30-44 \\
45-60 \\
\text { older than } 60\end{array}$ & & & & & & & & & & Important & & \\
\hline 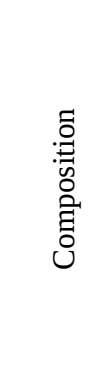 & $\begin{array}{l}\text { single person } \\
\text { couple } \\
\text { family } \\
\text { single-parent family }\end{array}$ & & & & & & & & & & & & \\
\hline 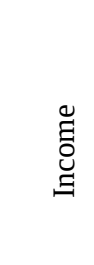 & $\begin{array}{l}\text { low } \\
\text { middle } \\
\text { high }\end{array}$ & & & & & & $\begin{array}{c}\text { Moderately imp. } \\
\text { Important }\end{array}$ & $\begin{array}{c}\text { Moderately imp. } \\
\text { Important }\end{array}$ & $\begin{array}{l}\text { Important } \\
\text { Very important }\end{array}$ & Important & & & Important \\
\hline & $\begin{array}{l}\text { none } \\
1 \text { or } 2\end{array}$ & & & & & & & & & & & & \\
\hline
\end{tabular}




\begin{tabular}{|c|c|c|c|c|c|c|c|c|c|c|c|c|}
\hline & 3 or more & & & & & & & & & & & \\
\hline \multirow{4}{*}{ 意 } & $\begin{array}{l}\text { Preference for urban } \\
\text { amenities }\end{array}$ & Important & Important & Important & Moderately imp. & & & & & \multirow[b]{4}{*}{ Important } & \multirow{4}{*}{ Important } & \\
\hline & $\begin{array}{l}\text { Preference for rural } \\
\text { amenities }\end{array}$ & & Moderately imp. & & & Very important & Important & Very important & & & & \\
\hline & Car & & & & & & & & Very important & & & \\
\hline & $\begin{array}{l}\text { Public transport, cycling } \\
\text { and walking }\end{array}$ & Important & Important & Very important & & & & & & & & Important \\
\hline
\end{tabular}

